\author{
UNIVERSIDADE DE SÃO PAULO \\ FACULDADE DE ZOOTECNIA E ENGENHARIA DE ALIMENTOS
}

MAGALY VILLAR

Avaliação da tecnologia de comunicação móvel no monitoramento de equinos de esporte 
MAGALY VILLAR

Avaliação da tecnologia de comunicação móvel no monitoramento de equinos de esporte

\author{
Versão Corrigida
}

Dissertação de Mestrado apresentada a Faculdade de Zootecnia e Engenharia de Alimentos da Universidade de São Paulo, como parte dos requisitos para obtenção do Título de Mestre em Ciências no Programa de Pós-graduação em Gestão e Inovação na Indústria Animal.

Área de concentração: Gestão e Inovação na Indústria Animal

Orientador: Prof. Dr. Ernane José Xavier Costa 

Villar, Magaly
VA945a Avaliação da tecnologia de comunicação móvel no monitoramento de equinos de esporte / Magaly Villar ; orientador Ernane José Xavier Costa. -- Pirassununga, 2019.

$86 \mathrm{f}$.

Dissertação (Mestrado - Programa de PósGraduação em Mestrado Profissional Gestão e Inovação na Indústria Animal) -- Faculdade de Zootecnia e Engenharia de Alimentos, Universidade 
MAGALY VILLAR

\section{Avaliação da tecnologia de comunicação móvel no monitoramento de equinos de esporte}

Dissertação apresentada à Faculdade de Zootecnia e Engenharia de Alimentos da Universidade de São Paulo, como parte dos requisitos para obtenção do título de mestre em Ciências no Programa de Pós-graduação em Gestão e Inovação na Indústria Animal.

Data da aprovação:

Banca Examinadora

Prof. Dr. Ernane José Xavier Costa - FZEA/USP

Profa Dra. Cristiane Gonçalves Titto - FZEA/USP

Prof. Dr. Guilherme Augusto Spiegel Gualazzi - AFA - Pirassununga/SP

Prof. Dr. Celso Eduardo Lins de Oliveira- FZEA/USP 


\section{DEDICATÓRIA}

Esta pesquisa é dedicada a minha filha Paula Cassia, e a todos os amantes de equinos que, assim como eu, dedicam suas vidas ao bem-estar desses fascinantes animais.

Minha inspiração é minha égua, New Winny do Feroleto. 


\section{AGRADECIMENTOS}

Ao Prof. Dr. Ernane José Xavier Costa pelo carinho em me orientar me ensinando muito mais que Ciência, me ensinando a pesquisar.

Aos colegas do LAFAC por tão generosa acolhida, em especial ao Prof. Dr. Adriano Rogério Bruno Tech, a Dra Luciana Vieira Piza por compartilharem seus conhecimentos técnicos e científicos, engrandecendo esta pesquisa.

A Faculdade de Zootecnia e Engenharia de Alimentos, pela oportunidade de realização do curso de mestrado. 
As tecnologias mais profundas são as que desaparecem e, por estarem tão entrelaçadas ao cotidiano das pessoas, passam despercebidas.

MARK WEISE, 1993. 


\section{RESUMO}

\section{VILLAR, M. Avaliação da tecnologia de comunicação móvel no monitoramento}

de equinos de esporte. 2019. 86f. Dissertação (Mestrado) - Faculdade de Zootecnia e Engenharia de Alimentos, Universidade de São Paulo, Pirassununga, 2019.

Com o aumento do poder da computação e o surgimento de dispositivos de comunicação móvel (smartphones), cada vez mais inteligentes, acompanhado de uma variedade de aplicativos capazes de monitorar eventos externos, observa-se um crescimento no desenvolvimento de aplicações capazes de monitorar, em tempo real, processos e sistemas, usando a tecnologia disponível nos smartphones. Dentro desse contexto, este trabalho tem como objetivo avaliar a possibilidade da aplicação dessas tecnologias também em sistemas biológicos, como nos equinos. Estes animais apresentam pré-disposição para a síndrome cólica, podendo levá-los a óbito, quando não socorridos em tempo hábil. Uma forma de socorrê-los é diagnosticá-los precocemente. Tal diagnóstico pode ser realizado por meio da observação e/ou detecção de alteração do padrão de comportamento cinético do animal. Logo, os smartphones, que possuem sensores de movimento, podem ser um dos mecanismos de auxílio ao diagnóstico da síndrome cólica. Para testar esta aplicabilidade foram utilizados três equinos que usaram, um por vez, um smartphone acoplado a caneleira. Para o monitoramento, o dispositivo móvel instalado no animal, possuia um aplicativo que armazenava os dados dos sensores e os disponibilizava em outro dispositivo digital, via e-mail. Os sensores foram calibrados em quatro tomadas, sendo uma no cavalo 1: treinando, duas no cavalo 2: na baia e no pasto e uma no cavalo 3: no pasto. Os animais foram analisados no momento que estiveram usando o equipamento de forma contínua. A análise comportamental foi alicerçada na interação animal-sensor baseado no conceito descrito por Henson e Hayward (2010), ou seja, o comportamento cinético do animal foi a entrada pertubativa para avaliar as respostas dos sensores.

Palavras-chave: Cavalos de esporte. Monitoramento. Tecnologia móvel. Síndrome cólica. Pecuária de precisão. Zootecnia. 


\section{ABSTRACT}

VILLAR, M. Evaluation of mobile communication technology in the monitoring of equine sport. 2019. 86f. M.Sc. Dissertation - Faculdade de Zootecnia e Engenharia de Alimentos, Universidade de São Paulo, Pirassununga, 2019.

With the increase in computer power, mobile communication or smartphones and the wide variety of applications developed for the devices that are able to track external events, there are a growing number of applications that involve the real-time tracking of processes and systems using the technology available in smartphones. This work aims to evaluate the possibility of applying these technologies also in biological systems, how the horses. These animals are prone for the colic syndrome that may lead them to death when not rescued in a time. In addition, one way to help them is early diagnosis. Such a diagnosis can be performed in part by the kinetic behavior pattern of the animal and the smartphones have kinetic (motion) sensors. Therefore, the smartphone can be one of the mechanisms to aid in the diagnosis of colic syndrome, thus defining the central objective of this project. To test the applicability three horses will be used, they will use one at a time, the smartphone coupled. The mobile device, installed in the animal, will have an application that will store the data of the sensors and make them available in another digital device via e-mail. The sensors were calibrated in four outlets, one on horse 1: training, two on horse 2: in coach horse and on pasture, one on horse 3: on pasture. The animals will be evaluated when they are using the equipment in continuous way. Behavioral analysis will be based on the animal-sensor interaction based on the concept described by Henson and Hayward (2010), that is, the kinetic behavior of the animal will be the pertubative input to evaluate the responses of the sensors.

Keywords: Sport horses. Monitoring. Mobile technology. Colic syndrome. Precision cattle-raising. Zootechny. 


\section{LISTA DE FIGURAS}

Figura 1 - Demonstração da disposição dos eixos de um acelerômetro num

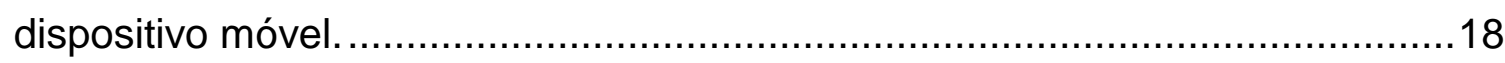

Figura 2 - Giroscópio direções de rotação ……………....................................19

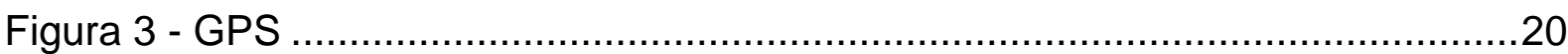

Figura 4 - Anatomia do trato gastrointestinal dos equinos ...................................27

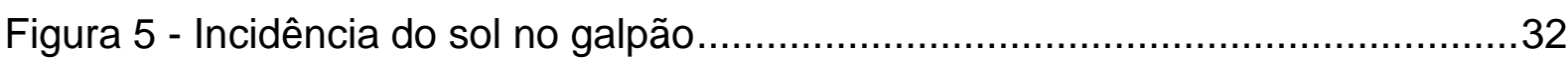

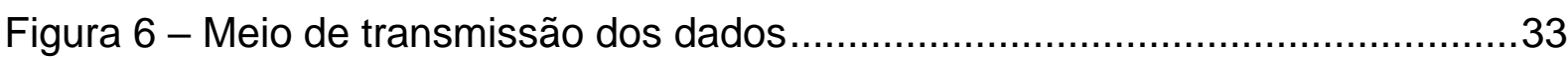

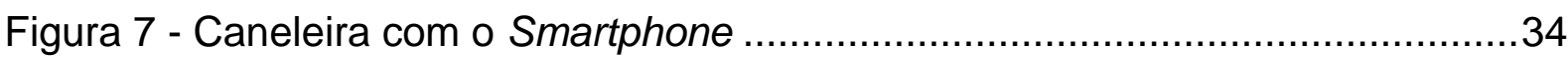

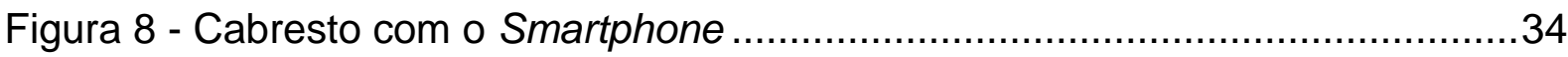

Figura 9 - Cilha com o Smartphone

Figura 10 -A) smartphone usado; B) caneleira; C) capinha de celular na tira de fechamento da caneleira; D) caneleira com a capinha de célular; E) smartphone dentro da capinha; F) conjunto caneleira com smartphone;

G) bandagem elástica; H) conjunto envolto pela bandagem elástica; I)

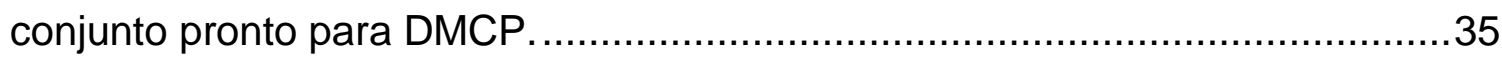

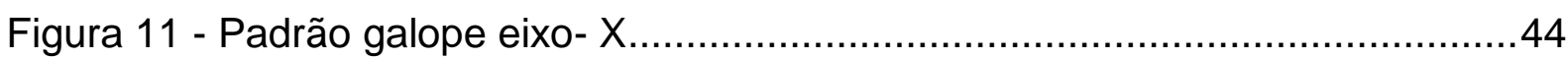

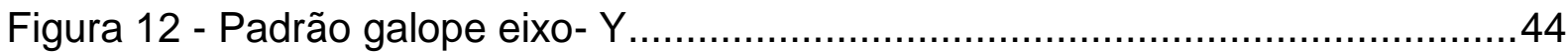

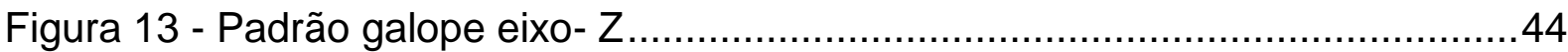

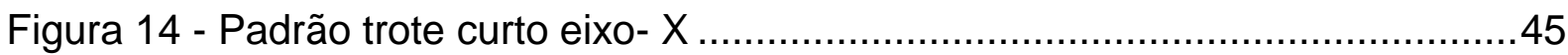

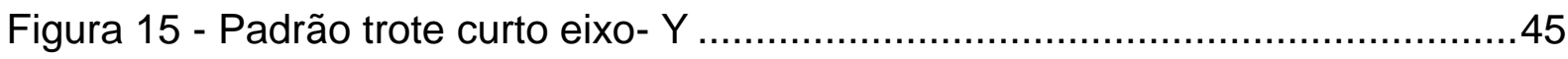

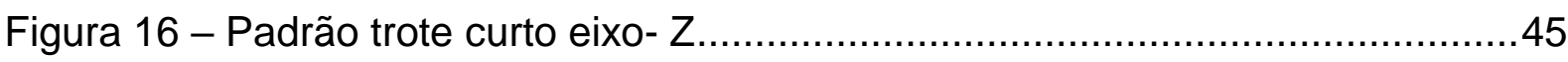

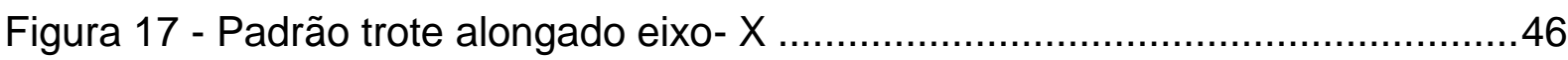

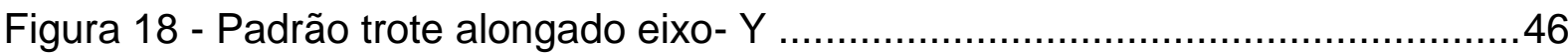

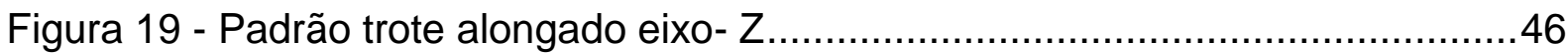

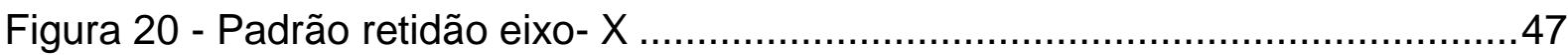

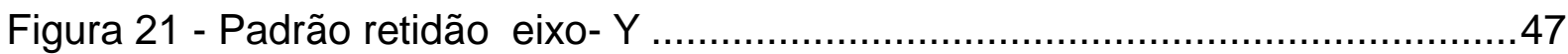

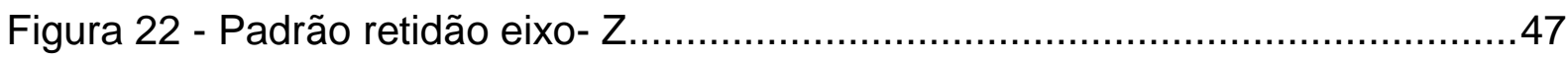

Figura 23 - Padrão passo controlado eixo- X ..................................................48

Figura 24 - Padrão passo controlado eixo- Y ...................................................... 48

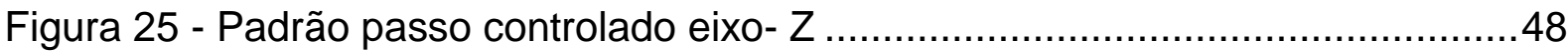

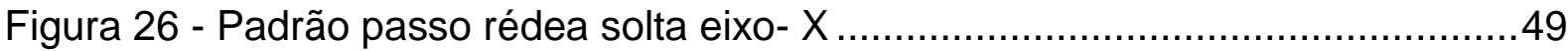

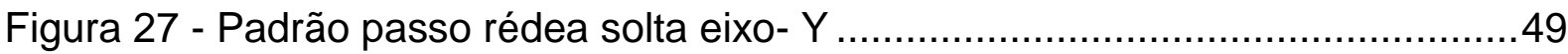

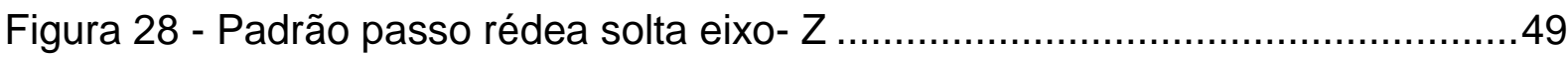




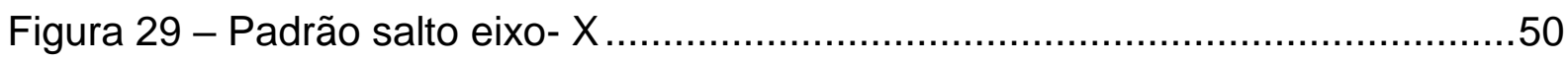

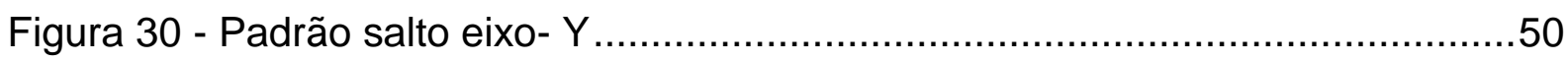

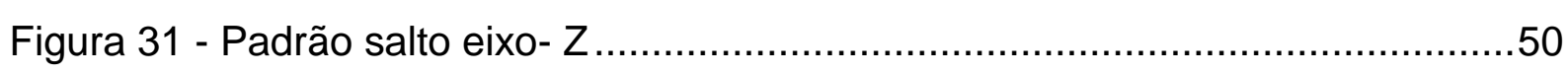

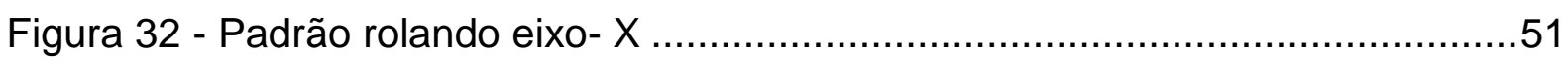

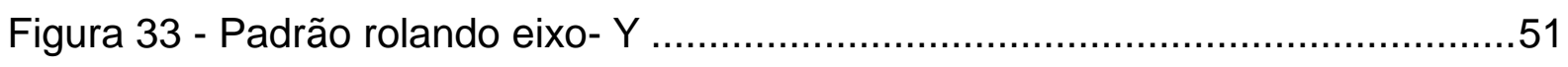

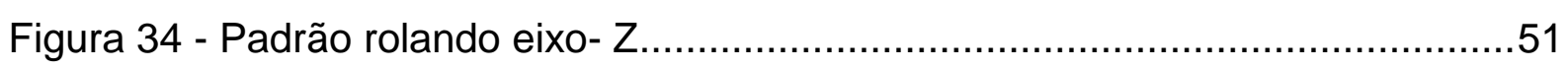

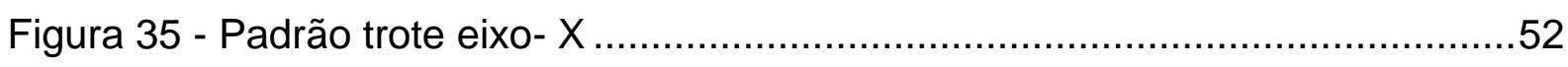

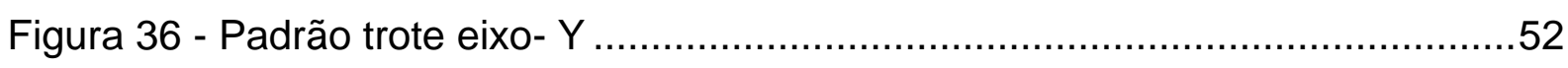

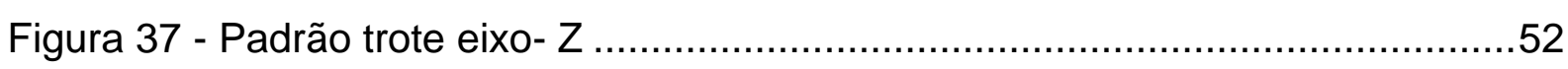

Figura 38 - Densidade espectral de potência dos sinais no eixo $X$ : A) passo

rédeas livres; $B$ ) passo controlado; C) retidão; D) trote curto; E) trote alongado; F) Galope .53

Figura 39 - Densidade espectral de potência dos sinais no eixo Y: A) passo rédeas livres; B) passo controlado; C) retidão; D) trote curto; E) trote alongado; F) Galope .54

Figura 40 - Densidade espectral de potência dos sinais no eixo $Z$ dos

movimentos do cavalo $1::$ A) passo rédeas livres; B) passo controlado;

C) retidão; D) trote curto; E) trote alongado; F) Galope .55

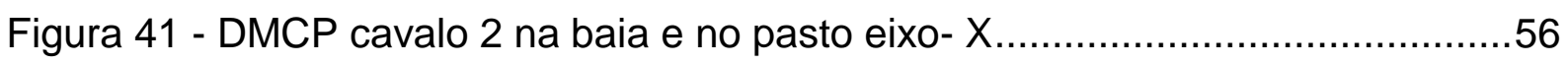

Figura 42 - DMCP cavalo 2 na baia e no pasto eixo- Y..........................................56

Figura 43 - DMCP cavalo 2 na baia e no pasto eixo- Z .......................................56

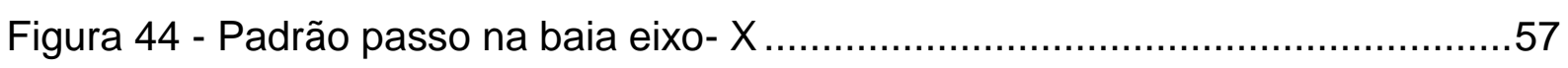

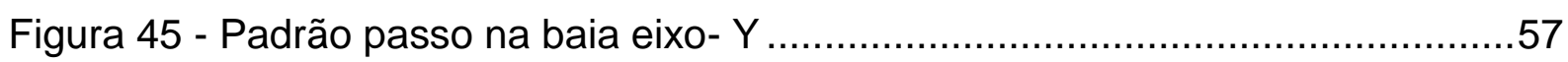

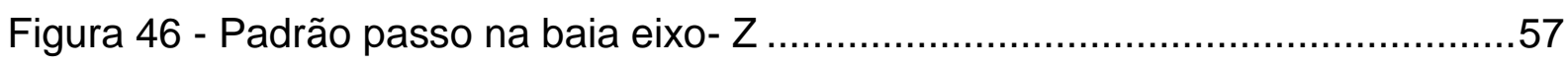

Figura 47 - Padrão bater MAD na barriga dentro da baia eixo- $X \ldots \ldots \ldots \ldots \ldots \ldots \ldots \ldots . . . .58$

Figura 48 - Padrão bater MAD na barriga dentro da baia eixo- $Y$...........................58

Figura 49 - Padrão bater MAD na barriga dentro da baia eixo- Z...........................58

Figura 50 - Comparando bater o MAD na barriga e levantar o MAD eixo- $X$............59

Figura 51 - Comparando bater o MAD na barriga e levantar o MAD eixo- $Y$............59

Figura 52 - Comparando bater o MAD na barriga e levantar o MAD eixo- Z.............59

Figura 53 - Padrão passo com cabresto indo para o pasto eixo- $X$..........................60

Figura 54 - Padrão passo no cabresto indo para o pasto eixo- Y.............................60

Figura 55 - Padrão passo no cabresto indo para o pasto eixo- Z.............................60

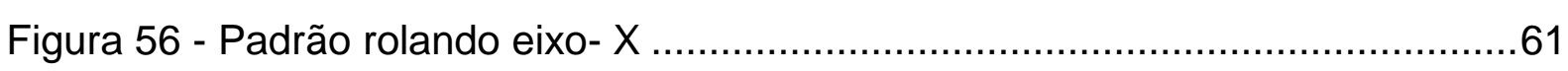

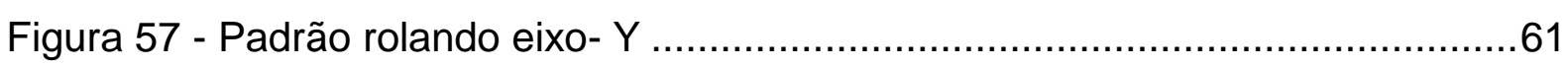




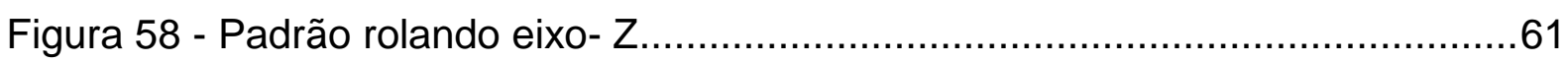

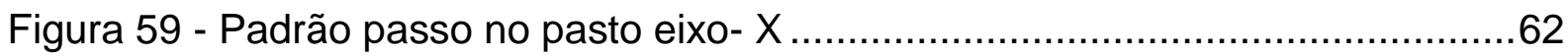

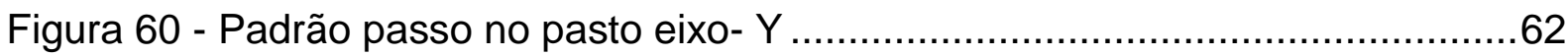

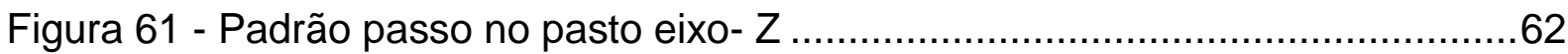

Figura 62 - Diagrama de fluxo ilustrando Modelo de Identificação de padrões

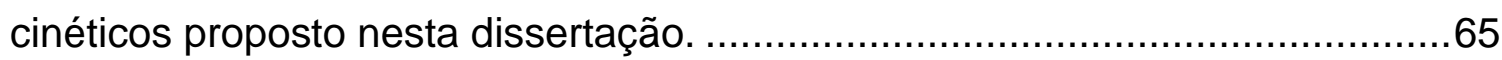

Figura 63 - Tabela de levantamento de custos de um Smartphone ........................73

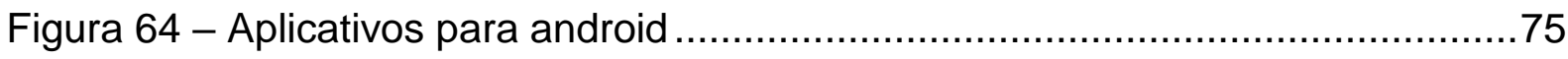

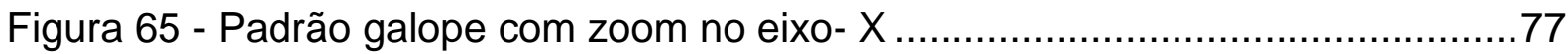

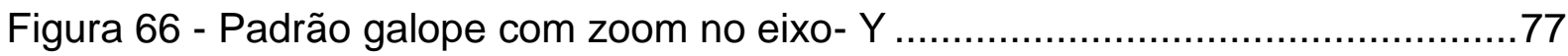

Figura 67 - Padrão galope com zoom no eixo- Z …………………………....77

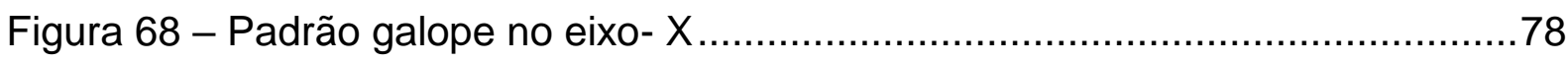

Figura 69 - Padrão galope no eixo- Y.........................................................

Figura 70 - Padrão galope no eixo- Z ....................................................... 78

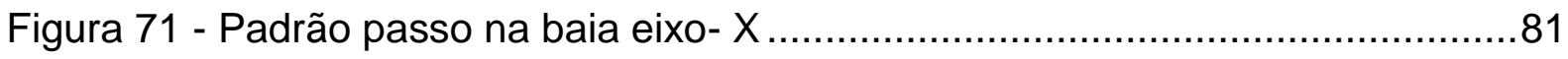

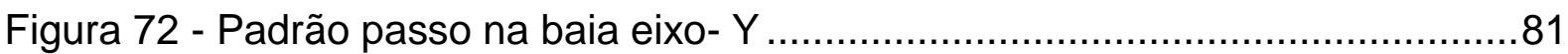

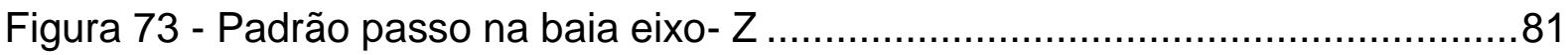

Figura 74 - Comparação entre parado e passo no pasto $C 2$ eixo- $X$......................... 82

Figura 75 - Comparação entre parado e passo no pasto $C 2$ eixo- $Y$.......................82

Figura 76 - Comparação entre parado e passo no pasto C2 eixo- Z .........................82

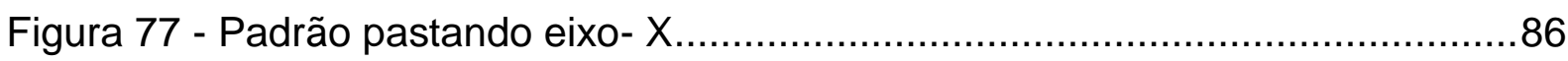

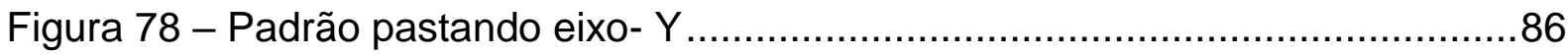

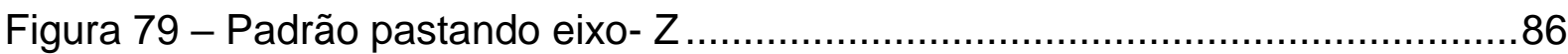




\section{LISTA DE TABELAS}

Tabela 1 - Dados do cavalo 1 e do ambiente antes do experimento.........................40

Tabela 2 - Dados do cavalo 2 antes do experimento ................................................ 41

Tabela 3 - Dados do cavalo 3 antes do experimento ..............................................4 4

Tabela 4 - Primeira medição com o cavalo 1 no treino ...........................................42

Tabela 5 - Padrão dos movimentos obtidos em uma frequência de

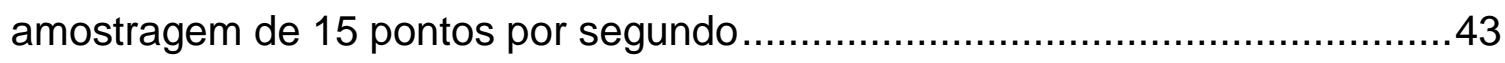

Tabela 6 - Primeira medição com o cavalo2 na baia e no pasto..............................79

Tabela 7 - Calibração 30 pontos por segundo C2, o início da filmagem

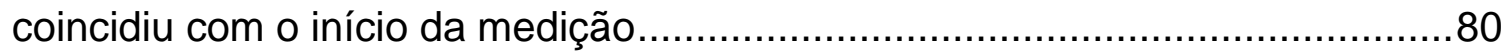

Tabela 8 - Primeira medição com o cavalo3 (C3) no pasto ...................................... 83

Tabela 9 - Calibração 30 pontos por segundo com o início do cálculo do aplicativo acrescido de 180 s do início do filme 


\section{LISTA DE ABREVIATURA E SIGLAS}

\begin{tabular}{ll} 
ACC & Acelerômetro \\
GPS & Sistema de Posicionamento Global (Global Positioning System) \\
C1 & Cavalo um \\
C2 & Cavalo dois \\
C3 & Cavalo três \\
Cel/hab & Celular por habitante \\
CSV & Valores separdos por vírgulas (Values Separated by Commas) \\
DMCP & Determinação dos movimentos cinéticos padrão \\
ECG & Eletrocardiograma \\
OMCP & Obtenção dos movimentos cinéticos padrão \\
MAD & Membro anterior direito \\
MPE & Membro posterior esquerdo \\
S & Segundos \\
Min & Minutos \\
MPM & Movimentos por minuto \\
BPM & Batimentos por minuto \\
FC & Frequência cardíaca \\
FR & Frequência respiratória \\
TR & Temperatura retal \\
PA & Pressão Atmosférica \\
TA & Temperatura ambiente \\
UR & Umidade Relativa do Ar \\
\hline
\end{tabular}




\section{SUMÁRIO}

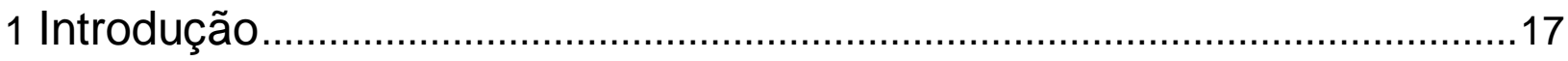

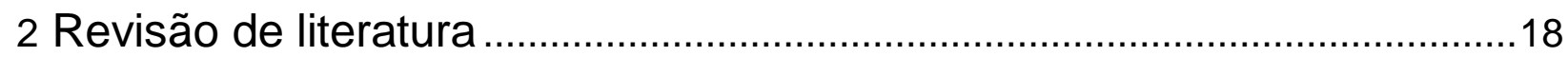

2.1 Sensores cinéticos presentes em um smartphone ...................................18

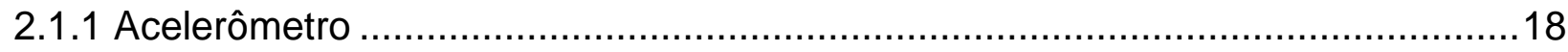

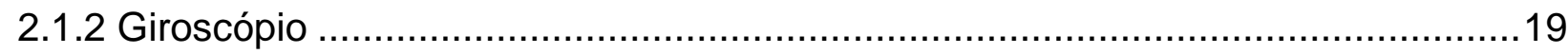

2.1.3 GPS - Sistema de posicionamento global ..................................................20

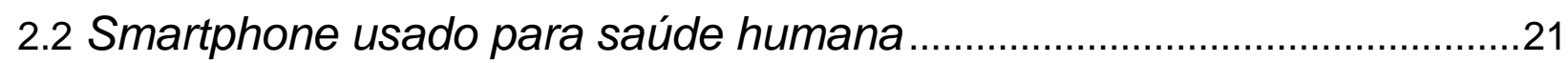

2.2.1 Smartphone na detecção de doenças cardíacas............................................21

2.2.2 Smartphone para monitoramento de pacientes com Alzheimer em ambiente

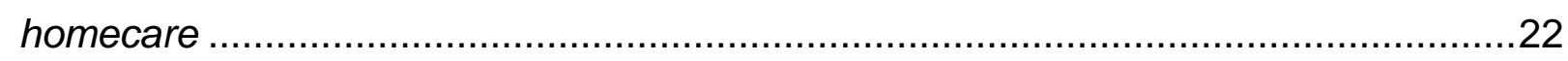

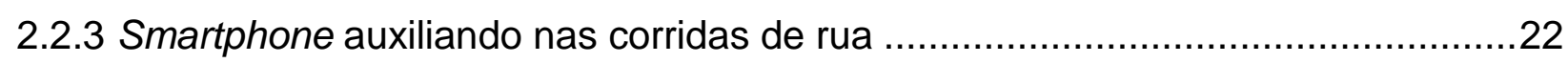

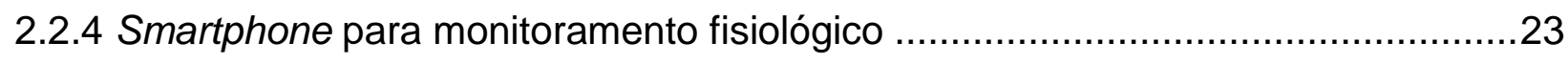

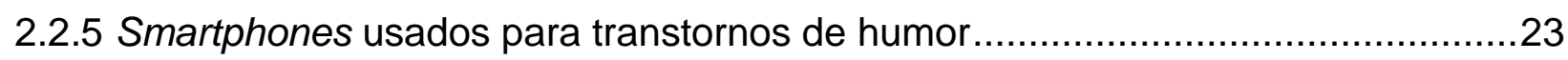

2.3 Utilização de smartphones na área de saúde animal ........................................24

2.3.1 Sistema para transmissão sem fio do eletrocardiograma (ECG) em equinos ......24

2.3.2 Monitoramento da atividade de mastigação em cavalos ....................................24

2.3.3 Uso de eletrodos têxteis para monitoramento de eletrocardiograma em cavalos 25 2.3.4 Monitoramento da ingestão de capim por bovinos .........................................25

2.3.5 Estimativa de energia digestível dos cavalos usando o aplicativo para smartphone .25

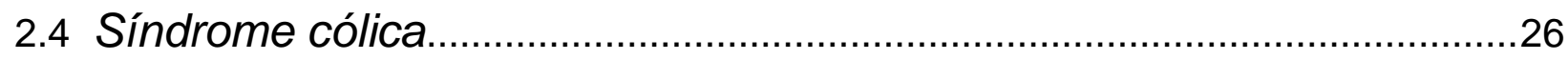

2.5 Processamento digital de sinais: Análise no domínio da frequência......28

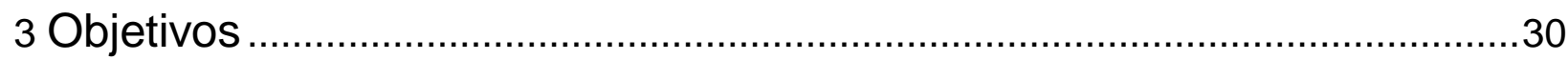

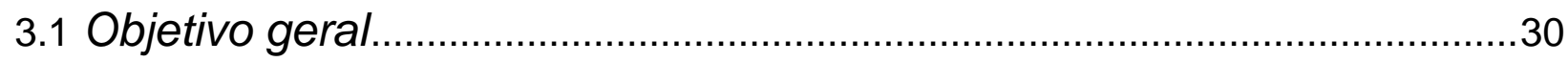

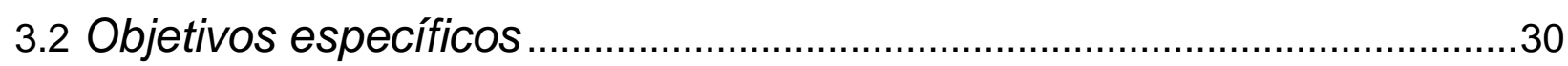

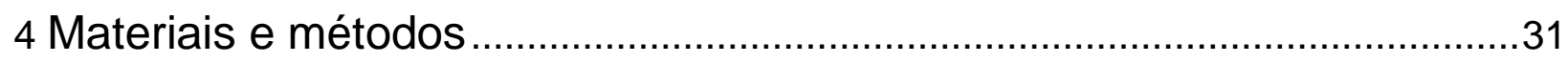

4.1 Aplicativo usado para coletar os movimentos cinéticos dos equinos.....32

4.2 Equipamento ( caneleira com o smartphone) ..............................................33

4.3 Determinação dos movimentos cinéticos padrão (DMCP) .......................35

4.3.1 Obtenção dos movimentos cinéticos padrão (OMCP) ......................................37

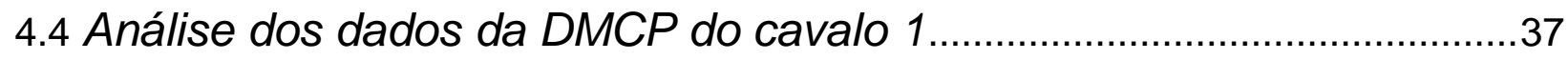




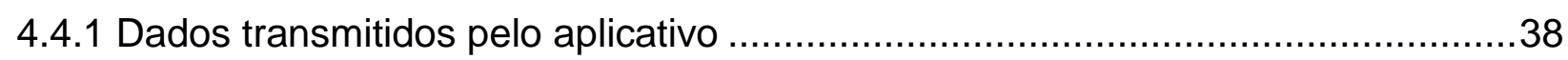

4.4.2 Métodos de análise e processamento de sinais ..............................................39

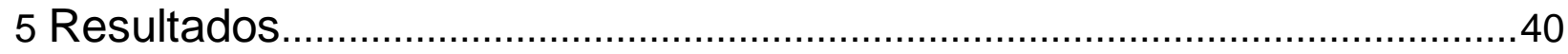

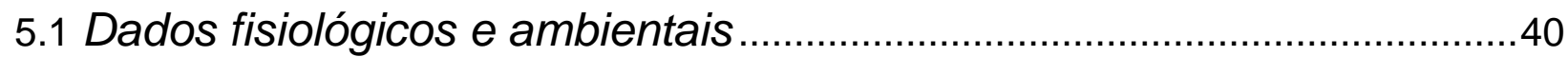

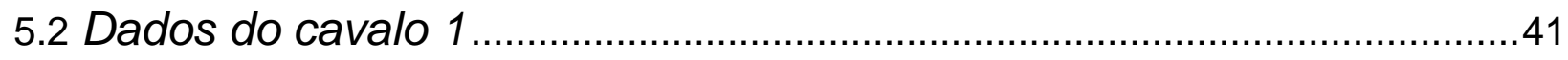

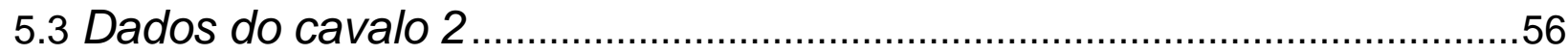

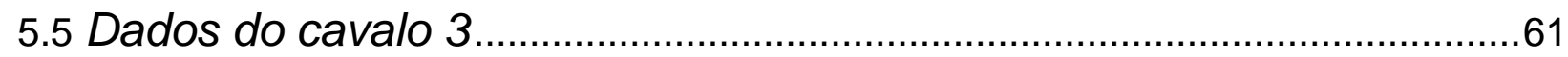

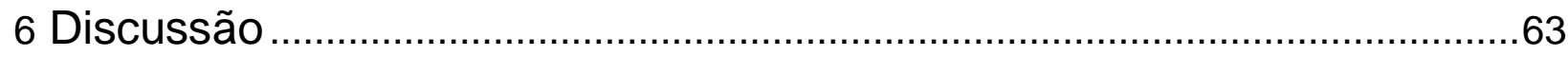

6.1 Proposição de modelo de análise do movimento cinético padrão ...........64

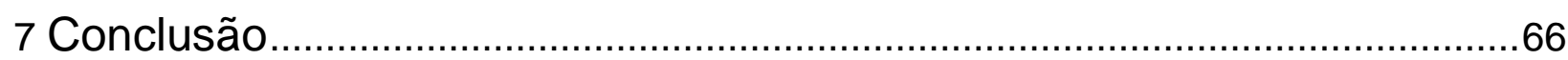

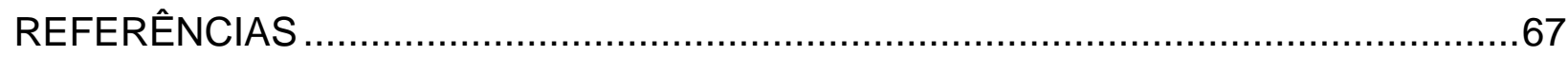

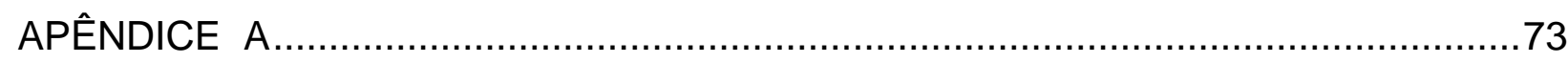

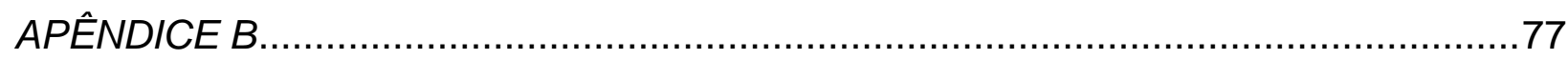




\section{Introdução}

Com o aumento da tecnologia associada aos dispositivos de comunicação móvel, bem como a variedade de aplicativos capazes de monitorar eventos externos, esses aparelhos crescentemente vêm sendo empregados para uso comercial, médico, agrícola, veterinário, entre outros, que envolvam o monitoramento, em tempo real, de processos e sistemas. Já nos anos 90, Weiser (1991), cientista chefe da XEROX PARC, usou o termo Ubíqua em uma de suas publicações, que significa "a presença constante da tecnologia na vida da população". Os sistemas inteligentes dos computadores, celulares, tablets e televisores se relacionam com as pessoas por meio da fala, visão e gestos, interagindo com o ambiente e respondendo a esses estímulos para benefício dos usuários, sendo geralmente imperceptíveis.

Com a computação ubíqua, a área da saúde, em geral, vem obtendo benefícios. Esta integração vem tornando, cada vez mais acessíveis, os diagnósticos de doenças. Em cidades onde não há recursos de equipamentos médico-hospitalares ou disponibilidade de especialistas, um exame como um eletrocardiograma pode ser realizado por meio de um smartphone em tempo real e acessado por um médico especialista para diagnóstico. Esses monitoramentos são realizados por meio de sensores embutidos em alguns smartphones como o acelerômetro, giroscópio, GPS, sensor de pressão, temperatura, microfone e câmera.

Diante deste cenário, este trabalho propôs a avaliação do uso do smartphone com sensores cinéticos para o monitoramento em tempo real do padrão dos movimentos dos equinos, visando auxiliar no diagnóstico precoce da síndrome cólica, já que o Brasil possui o quarto maior rebanho equino do mundo, com 5.496.817 cabeças, segundo dados da Organização das Nações Unidas para Alimentação e Agricultura (FAO), e movimenta 16 bilhões da economia nacional. A síndrome cólica é o que causa o maior número de perdas desses animais (FRANCELLINO, 2015). 


\section{Revisão de literatura}

O poder da computação presente nos smartphones e a qualidade dos sensores cinéticos disponíveis nesses aparelhos a um custo acessível, permite supor que tais sistemas possam ser úteis em diagnósticos precoces na síndrome cólica de equinos. O uso de um smartphone de monitoramento para rápidas tomadas de decisões pode garantir o bem-estar animal adequado, 24 horas por dia durante os sete dias da semana, reduzindo o índice de mortalidade e os custos com tratamentos e cirurgias.

\subsection{Sensores cinéticos presentes em um smartphone}

\subsubsection{Acelerômetro}

O Acelerômetro de um smartphone é capaz de medir a aceleração linear na direção de um eixo em relação a um referencial inercial. Representa a variação da velocidade no tempo. $O$ sensor mede as componentes de aceleração em três eixos perpendiculares X, Y, Z (VIEIRA; AGUIAR, 2013), como na (Figura 1). A unidade de medida no Sistema Internacional é o metro por segundo, elevado à segunda potencia $\left(\mathrm{m} / \mathrm{s}^{2}\right)$.

Figura 1 - Demonstração da disposição dos eixos de um acelerômetro num dispositivo móvel.

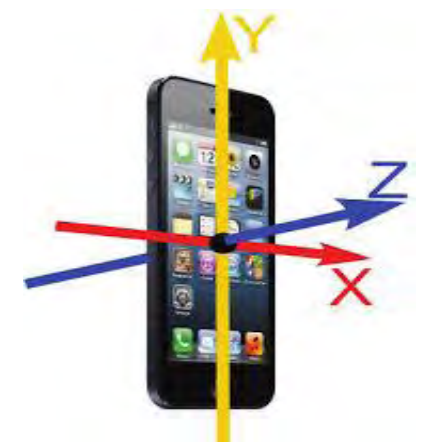

Fonte: Vieira; Aguiar, Mecânica com o acelerômetro de smartphones e tablets. Física na Escola, v. 14, n. 1, 2016. 


\subsubsection{Giroscópio}

O giroscópio mede a velocidade angular e funciona com o princípio de uma placa que vibra, mostrando a mudança de direção, como pode ser visualizado na Figura 2. A velocidade angular é uma grandeza que representa a taxa de variação da posição angular no tempo, cuja unidade de medida no Sistema Internacional é o radiano por segundo ( $\mathrm{rad} / \mathrm{s})$. Esse sensor tem a capacidade de funcionar com gravidade zero. Geralmente, o giroscópio é integrado ao acelerômetro para permitir o reconhecimento mais preciso do movimento e direção dentro de um espaço de tempo (LAHEY JR, 1992; L. P. VIEIRA, 2013; PIMENTA; WILLIMAR; SOUZA, 2017).

Figura 2 - Giroscópio direções de rotação

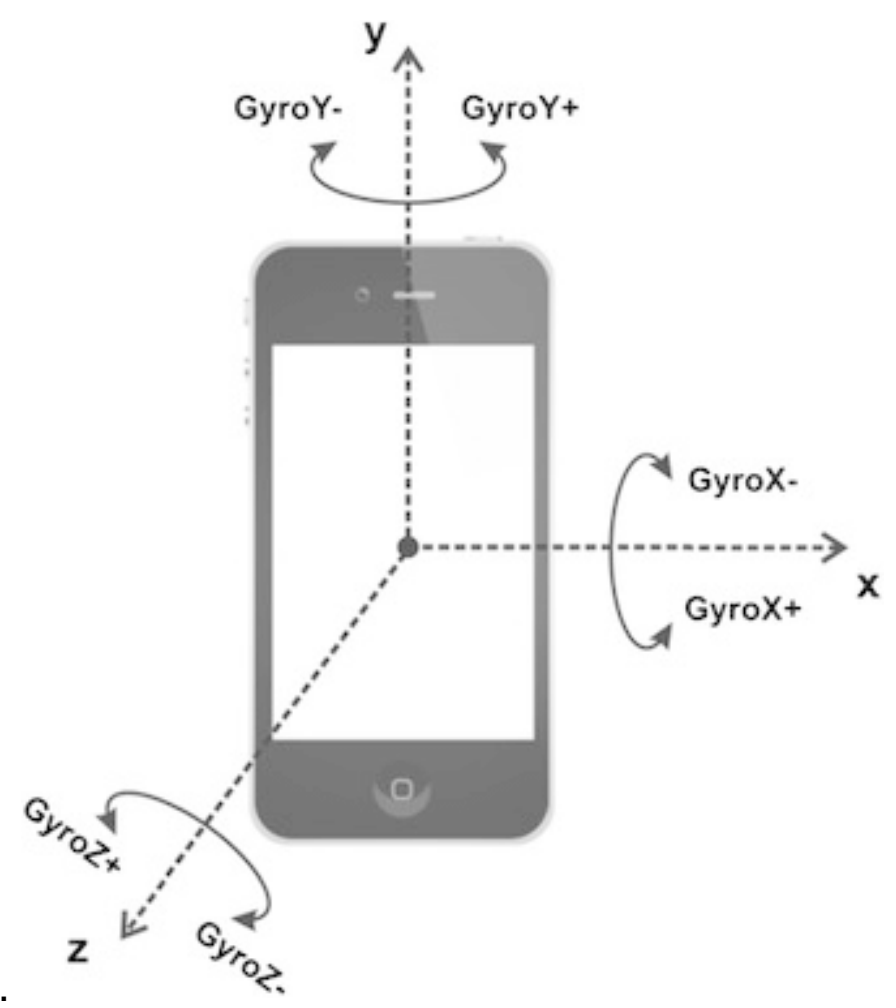

Fonte: Umek, A.; Kos, A. Validation of smartphone gyroscopes for mobile biofeedback applications. Personal and Ubiquitous Computing. 10.1007/s00779-016-0946-4, 2016. 


\subsubsection{GPS - Sistema de posicionamento global}

Segundo Martins (2009) o GPS (Global System Position) consiste em uma tecnologia de localização por satélite. Esse dispositivo funciona a partir de 24 satélites distribuídos em 6 planos, próximos a órbita da Terra. Esses satélites enviam sinais para o aparelho de GPS (receptor), que por sua vez é interpretado, sendo possível dizer exatamente a localização do dispositivo em um determinado momento.

Tanto os satélites quanto os receptores possuem relógio interno que armazenam os horários dos sinais emitidos e recebidos. Dessa forma, quando o receptor recebe um sinal do satélite, é possível calcular o tempo, com precisão de nano segundos, que esse sinal demorou a chegar. A partir daí, é possível dizer a posição exata que o dispositivo se encontra (MARTINS, 2009).

A margem de erro dos GPSs comuns é de aproximadamente 20 metros, e essa precisão se deve ao sistema de triangulação Figura 3, usado para essa localização. Nesse sistema 3 satélites enviam sinal para o receptor, que calcula quanto tempo cada um demorou a chegar. Por meio desses cálculos é possível saber a localização exata de um objeto ou pessoa (MARTINS, 2009).

Figura 3 - GPS

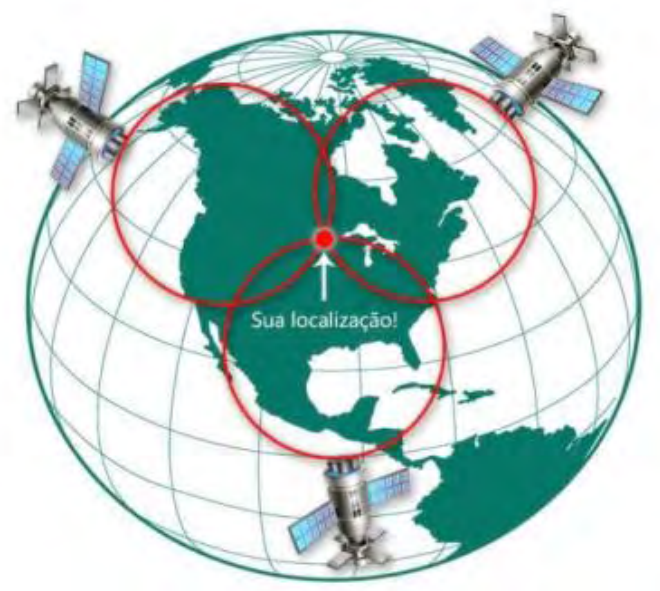

Fonte: https://www.oficinadanet.com.br/post/12406-como-funciona-o-gps 


\subsection{Smartphone usado para saúde humana}

A tecnologia móvel está se tornando comum a todas as pessoas. Dados da Agência Nacional de Telecomunicações (ANATEL, 2019) em fevereiro de 2019 o Brasil possuía 109,8 cel/hab.

Dentro desse contexto, esses dispositivos vêm sendo pesquisados há alguns anos, com sucesso, em diversos tipos de monitoramento remoto (SAHA; MUKHERJEE, 2003).

\subsubsection{Smartphone na detecção de doenças cardíacas}

O tempo é um fator importantíssimo na área médica e o diagnóstico precoce é o grande segredo para salvar vidas. Dentro desse contexto, os smartphones têm auxiliado por exemplo, em exames cardiológicos (ROSS, 2004). Para detectar uma doença cardiovascular (CVD) por smartphone, foi criado um aplicativo com acelerômetro de três eixos, que grava a atividade elétrica do coração capturada por um mini monitor de ECG, sendo os dados transmitidos via Bluetooth para o smartphone e analisados em tempo real (ORESKO et al., 2010).

Exemplo disso, foram os resultados significativos encontrados por Lau et al. (2013) no monitoramento de ECG, usando dispositivos móveis. De acordo com esses experimentos a sensibilidade na detecção de fibrilação atrial foi de 94-100\%, o que caracteriza, esse tipo de monitoramento, como seguro e eficiente.

Já estudos relacionados com frequência respiratória (FR), problema característico em pacientes cardíacos, Scully et al. (2012) utilizaram a câmera do smartphone para gravar e analisar a variação da cor de um dedo colocado em contato com o aparelho. Foi provado que as câmeras de smartphones têm potencial para medir a FR com resultados semelhantes aos produtos comerciais específicos, auxiliando também na detecção de problemas associados ao coração. 


\subsubsection{Smartphone para monitoramento de pacientes com Alzheimer em ambiente homecare}

Segundo Indicadores Sócios Demográficos e de Saúde no Brasil, publicados pelo Instituto Brasileiro de Geografia e Estatística (IBGE, 2016), o país vem apresentando uma diminuição de nascimentos e um aumento da população de idosos. Com o aumento da idade média da população, as doenças crônicodegenerativas tendem a aumentar e os cuidadores ficarão sobrecarregados, necessitando de auxílio para detectar a fragilidade e incapacidade de seus pacientes (LEMOS; GAZZOLA; RAMOS, 2006; MORAES, 2012).

Para melhorar o conforto desses idosos uma estrutura homecare seria adequada. A arquitetura utilizada para desenvolver esse tipo de sistema pervasivo é embasada em dois domínios que trocam informações entre si. Um desses domínios é a nuvem computacional que armazena e processa informações referentes ao ambiente pervasivo (homecare). O outro domínio representa o próprio ambiente homecare, no qual estão situados os sensores, como: o GPS, acelerômetro, giroscópio, câmera, microfone, sensor de temperatura e de umidade, dispositivos computacionais, o módulo de monitoramento e distribuição das informações por meio de Wi-fi ou Bluethooth (FREITAS, 2011). Nesse domínio os movimentos e dados do usuário e do ambiente são inseridos no sistema (como a temperatura do ambiente, se está quente, o sistema liga $O$ ar condicionado), processados e respondem às mudanças que ocorrem, seja por dispositivos fixos ou móveis (SAHA; MUKHERJEE, 2003).

\subsubsection{Smartphone auxiliando nas corridas de rua}

Segundo o levantamento feito pela Associação Brasileira de Academias (ACAD, 2014) o Brasil tem 7,6 milhões de clientes filiados, o que representa um aumento de $61,7 \%$ em comparação com o ano de 2010, no qual muitos desses filiados são corredores de rua (CBN, 2017).

Por meio dos smartphones com acelerômetro, tornaram-se disponíveis os acessos a aplicativos que auxiliam em um bom treinamento, auxiliando no uso das técnicas certas para evitar lesões (MILLER, 2013). Na corrida, os braços dão 
estabilidade ao corpo e não devem cruzar a linha média que, quando ultrapassada, pode causar uma lesão por demasiada pressão sobre a pélvis. Para evitar o movimento exagerado dos braços, foi desenvolvido um aplicativo que o faz o smartphone vibrar sempre que o braço não estiver paralelo ao corpo (PULEO; MILROY, 2010).

\subsubsection{Smartphone para monitoramento fisiológico}

Dentro do paradigma de diagnóstico precoce, os parâmetros fisiológicos devem ser medidos em tempo real. Para isso, o uso do conceito de WBSN (Wireless Body Sensor Network) integrado a smartphones, permite a monitorização de pacientes em tempo real, não importa se o paciente está em diferentes enfermarias, hospitais ou mesmo em outras cidades. Os pacientes usam sensores, por exemplo, oxímetro de pulso que transmitem sinais via Wi-fi ou Bluetooth para o smartphone. Nesse modelo todos os cálculos são executados em dispositivos móveis e as notificações são dadas aos médicos via Wi-fi, sempre que houver necessidade de atenção imediata (TAMBE; THOLL; THOLL, 2016).

\subsubsection{Smartphones usados para transtornos de humor}

Segundo dados do National Institute of Mental Health, (2015a) e National Institute of Mental Health, (2015b), foram analisados dentre a população adulta dos Estados Unidos da América (EUA), em doze meses, pacientes com dois transtornos de humor: o transtorno depressivo maior com uma prevalência de $6,9 \%$ e o distúrbio bipolar com uma prevalência de $2,9 \%$ (da população em geral). Desse total, somente $21 \%$ dos pacientes com depressão maior e $10 \%$ dos pacientes com transtornos bipolar recebem tratamento. Como a maioria dos doentes possuem smartphones com vários sensores, como acelerômetro, giroscópio,magnetômetro, sensor de temperatura e umidade e barómetro, esses dispositivos podem ser empregados para detecção desses transtornos e monitoramento da saúde mental, uma vez que. muitos desses sensores podem ser usados para medir a emoção, incluindo a condutividade da pele, frequência cardíaca, respiração, pressão arterial, 
eletrocardiograma (ECG), eletroencefalograma (EEG), tornando o tratamento mais abrangente e confiável (GLENN; MONTEITH, 2014).

Dessa forma, os smartphones com capacidade para executar aplicativos, podem oferecer um novo método de coleta de dados, com praticidade e viabilidade, para a saúde mental e psiquiátrica (TOROUS; FRIEDMAN; KESHVAN, 2014).

\subsection{Utilização de smartphones na área de saúde animal}

\subsubsection{Sistema para transmissão sem fio do eletrocardiograma (ECG) em equinos}

Em uma pesquisa para transmissão de dados de um eletrocardiograma em equinos por biotelemetria (ciência que trata da transmissão e da recepção de sinais modulados por algum parâmetro fisiológico de origem humana ou animal), foi usado um circuito transmissor adaptado com um amplificador acoplado à base do transistor. Os sinais elétricos do coração foram captados por antenas com distância de $21 \mathrm{~cm}$, permitindo um monitoramento eficiente do traçado cardíaco com curto alcance (ALBANO; ABATTI; DECONTO, 2014).

\subsubsection{Monitoramento da atividade de mastigação em cavalos}

Segundo pesquisas realizadas por Werner et al. (2016), em um cabeçada (arreio de couro com ou sem bridão usado para controlar a andadura do animal) foi colocado um tubo de silicone contendo um fluido com um medidor de pressão e uma fonte de energia. Esse sistema foi usado para medir a frequência de mastigação em bovinos com excelentes resultados. O mesmo sistema foi testado em equinos. Mesmo com diferenças dos movimentos labiais, no final da mastigação do concentrado, foi encontrado o resultado de $91 \%$ de acerto na detecção da frequência de mastigação dos equinos, sugerindo que esse sistema pode ser usado também em cavalos. 


\subsubsection{Uso de eletrodos têxteis para monitoramento de eletrocardiograma em cavalos}

Guidi et al. (2017) monitoraram o ECG de equinos com dois equipamentos: um modelo tradicional com eletrodos prata cloreto de prata $(\mathrm{Ag} / \mathrm{AgCl})$ e outro com eletrodos têxteis inteligentes (sistemas vestíveis) que foram desenvolvidos combinando fios condutores com elastano que é ligado ao tecido durante a fabricação. Além disso, esta tecnologia é facilmente integrada com 4 dispositivos eletrônicos miniaturizados. Esses estudos são fundamentais, pois, com equipamentos convencionais, os resultados apresentam grande variação nos sinais elétricos, provenientes de artefatos causados pelos movimentos da pele contra 0 eletrodo. Os equipamentos foram conectados via Bluetooth a um smartphone com um aplicativo desenvolvido para armazenamento e análise de dados. Pode-se observar que a porcentagem de artefatos com os eletrodos de tecidos inteligentes foi menor do que os modelos tradicionais, sugerindo que os eletrodos têxteis inteligentes sejam mais confiáveis e precisos na coleta desses dados.

\subsubsection{Monitoramento da ingestão de capim por bovinos}

Muitas pesquisas vêm sendo desenvolvidas para analisar o comportamento do gado, usando tecnologias baseadas em sensores (VOULODIMOS et al., 2010). Nesse contexto, Andriamandroso et al. (2017) utilizaram 19 vacas. Cada vaca foi equipada com um iPhone $4 S$ contendo um aplicativo baixado do próprio aparelho com acelerômetro, giroscópio e GPS, que conseguiram capturar 40 sinais. Para essa captura de sinais foram necessárias: aquisição de dados com 106 vídeos gravados de 15-30 minutos, usados para calibração, e construção de um algoritmo de detecção de comportamento e validação. As análises de sinais foram realizadas no Matlab. O resultado encontrado pode mensurar o desempenho de pastar, com acerto de 85 a $91 \%$.

2.3.5 Estimativa de energia digestível dos cavalos usando o aplicativo para smartphone 
Pagan et. al. (2017) desenvolveram um aplicativo para inserir dados de quilômetros percorridos nos treinos e alimentação dos equinos envolvidos no experimento e desta maneira monitorar a energia digestível (DE). O estudo estimou os requisitos de DE dos cavalos em 3 dias de treinamento: em caminhada, trote, galope e galope rápido. Os requisitos de DE (\% de manutenção) foram altamente correlacionados com a distância total em quilômetros. Pagan et. al. (2007) conclui que pode ser avaliado a DE para cavalos, monitorando suas atividades semanais com smartphone.

\subsection{Síndrome cólica}

O Brasil possui o quarto maior rebanho equino do mundo, com 5.496.817 cabeças (MALINOSKI, 2018), e movimenta 16 bilhões da economia nacional. A síndrome cólica é o que causa o maior número de perdas desses animais (FRANCELLINO, 2015).

A dor é definida pela Associação Internacional para o Estudo da Dor (IASP) como uma "experiência sensorial e emocional desagradável associada ao dano tecidual real ou potencial" (MERSKEY; BOGDUK, 1994).

Para diminuir a dor, a objetividade e precisão na realização do diagnóstico nos cavalos são imprescindíveis, por razões éticas e de bem-estar animal (ZIMMERMANN, 1983).

A dor por síndrome cólica nos equinos pode ocorrer por distúrbios do aparelho digestivo ou de algum órgão que não são especificamente digestórios como tumores abdominais, nefrites e metrites (inflamação do útero) (THOMASSIAN, 2005).

Os equinos apresentam uma anatomia e fisiologia do aparelho digestivo propensa a distúrbios gastrointestinais. O estômago é pequeno com capacidade entre 15 e 18 litros, já o jejuno é longo e preso a um mesentério posicionado livremente no interior da cavidade abdominal, facilitando as torções gástricas. $O$ ceco, local onde ocorre a fermentação, tem capacidade de aproximadamente 30 litros e o cólon maior, que contém 3 flexuras é onde ocorrem maiores dificuldades no fluxo de alimento. Os equinos possuem ainda um peristaltismo alto e a falta do 
centro de vômito no cérebro (REED; BAYLY; SELLON, 2004). A anatomia do trato gastrointestinal dos equinos pode ser visualizada na Figura 4.

Figura 4 - Anatomia do trato gastrointestinal dos equinos

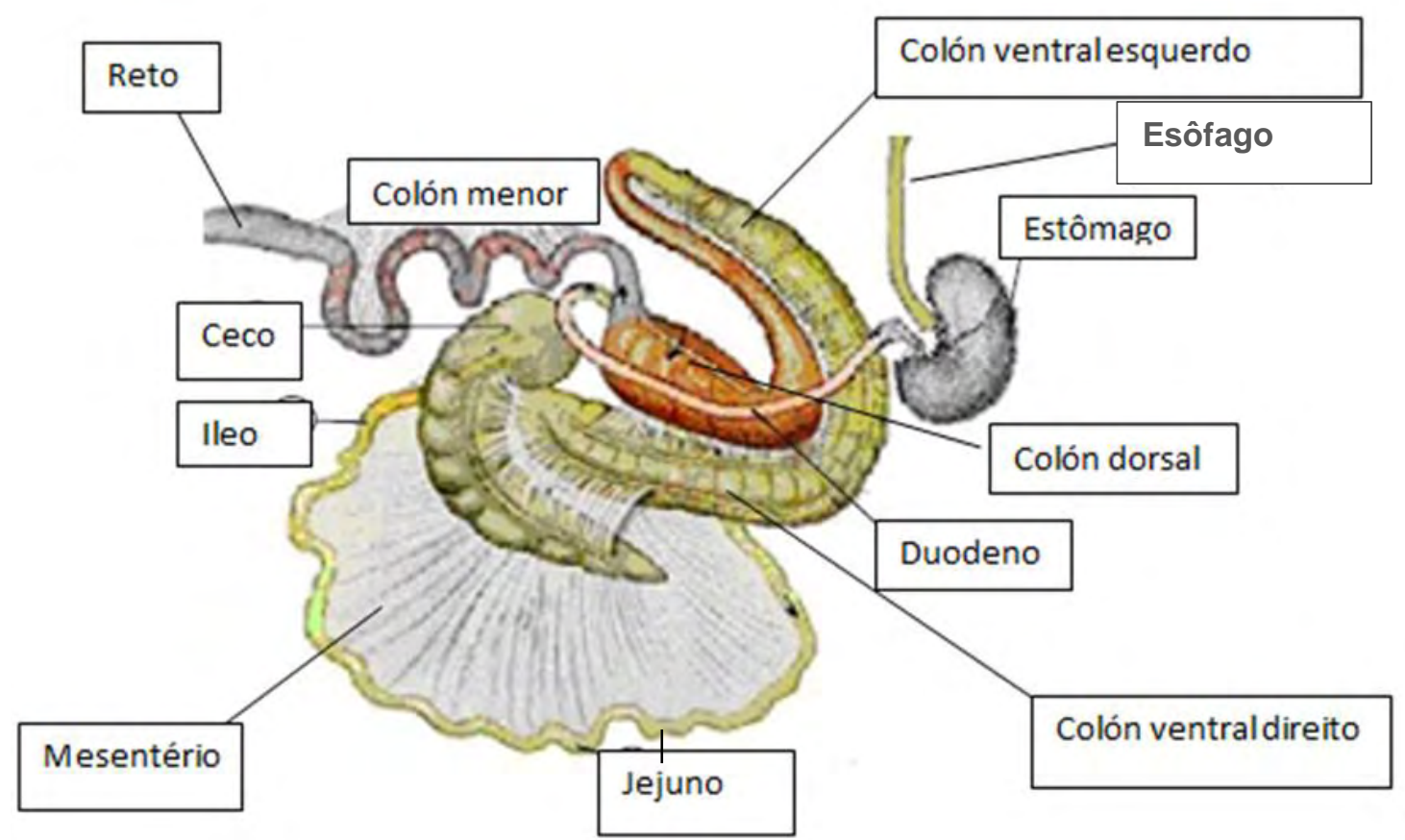

Fonte: Adaptado de POPESKO. Atlas de Anatomia Topográfica dos Animais Domésticos, 1998.

A etiologia da cólica é bastante vasta e acredita-se que problemas dentários dificultando a mastigação, alimentos de baixa qualidade, grande quantidade de concentrado, mudança brusca na alimentação, dificuldade de acesso à água e, vermes são fatores predisponentes à cólica do sistema digestivo (THOMASSIAN, 2005).

Os sinais da cólica em equinos incluem intranquilidade, deitar e levantar, patear o chão, gemidos, grunhidos, rolar, sudorese, coices no abdômen ou queda ao solo repentina em razão da dor, ou seja, a síndrome influencia no comportamento cinético do animal. A anorexia e a depressão frequentemente estão presentes. A maioria das cólicas de gravidade leve ou moderada responde favoravelmente aos analgésicos. Já a dor que não responde ao tratamento sintomático indica gravidade elevada, sendo necessária uma intervenção cirúrgica (BRADFORD, 2006). 
As doenças digestivas, como cólica, diarréia ou enterotoxemia, representam $50 \%$ dos problemas veterinários que resultam em óbito do equino adulto, sendo a cólica por compactação a causa mais comum (ABUTARBUSH; CALMART; SHOEMAKER, 2005; GONÇALVES; JULLIAND; LEBLOND, 2002; MURRAY; GUARD, 1993; THOMASSIAN, 2005).

\subsection{Processamento digital de sinais: Análise no domínio da frequência}

Após a conversão de um sinal de analógico para digital, que é o processamento digital de sinais (PDS) efetuado através da matemática, dos algoritmos e das técnicas usadas na manipulação de sinais. Sinais digitais podem ser processados tanto no domínio do tempo, quanto no domínio da frequência. $A$ análise no domínio do tempo trata o sinal a ser analisado como uma função do tempo, dessa maneira, várias informações estatísticas podem ser obtidas, tais como média, desvio padrão, histograma, variância, valor RMS e valores máximos e mínimos da amplitude do sinal (JINGXIA; WEIMIN, 2011).

A análise e processamento no domínio da frequência se mostra extremamente importante no PDS, pois o sinal adquirido do ambiente pode conter ruídos aleatórios e distorções harmônicas formando uma onda ruidosa que contém pouca informação visível ao olho humano no domínio do tempo. Uma solução para esse caso é utilizar-se de técnicas de PDS para converter o sinal de um domínio para o outro. A técnica mais empregada nesse caso é a transformada discreta de Fourier (DTF). O teorema de Fourier diz que qualquer sinal pode ser representado pela soma ponderada de senos e cossenos, portanto, qualquer sinal pode ser representado no domínio da frequência pelos componentes de amplitude e fase, podendo assim, ser conceitualmente separada as senóides que compõem o sinal (essas informações compõem o espectro da frequência do sinal) (SMITH, 2003).

Sinais obtidos de sensores podem conter componentes aleatórios, nãolineares e não-estacionários e, portanto, os métodos tradicionais como a DTF e a transformada rápida de Fourier (FFT) sofrem algumas limitações (COSTA, 2006). Consequentemente, métodos de estimação espectral de potência como de Welch e o Periodograma são adotados. Estes métodos transformam a relação entre a 
amplitude do sinal elétrico no tempo em uma relação entre potência e frequência. Dessa maneira, é possível observar mais claramente a distribuição e diferença nesses tipos de sinais (PAPPACHAN et al., 2017). Dentre esses dois métodos, o periodograma tem uma variância maior e uma menor suavização que o método de Welch (CAMPOS, 2012), no entanto, o método de Welch possui uma menor resolução, o que o torna mais adequado para sinais oriundos de sensores com acelerômetros (CONCEICÃO JUNIOR et al., 2016). 


\section{Objetivos}

\subsection{Objetivo geral}

O objetivo geral deste projeto foi avaliar a viabilidade técnica e econômica do uso de tecnologia móvel para monitorar o comportamento cinético de equinos e inferir sua importância no diagnóstico precoce dos sintomas da síndrome cólica.

\subsection{Objetivos específicos}

- Avaliar diferentes tipos de dispositivos móveis para telefonia (smartphones) para posterior uso com equinos;

- Avaliar como fixar o smartphone no animal;

- Avaliar a relação custo $X$ benefício do sistema estudado

- Avaliar aplicativos que possam ser usados para adquirir os dados dos sensores do smartphone embarcado no animal;

- Fazer os testes nos animais;

- Avaliar a relação dos dados com os movimentos dos equinos;

- Analisar os dados obtidos;

- Fazer uma proposição de modelo. 


\section{Materiais e métodos}

Inicialmente foram pesquisados aplicativos'para android existentes para equinos e analisados quanto a forma de coleta e armazenamento desses dados. Foram encontrados 27 aplicativos, destes somente 1 era adequado ao experimento.

Para o experimento foram usados três animais que estão estabulados no $13^{\circ}$ Regimento de Cavalaria Mecanizado, em Pirassununga e o smartphone utilizado para a coleta dos dados foi o Galaxy GT-19192 pesando $108 \mathrm{~g}, 12 \mathrm{~cm}$ de comprimento $\times 5,5 \mathrm{~cm}$ de largura.

Os animais foram chamados por número para facilitar o trabalho.

O cavalo 1 é da raça Brasileiro de Hipismo, com 8 anos de idade, tem um trabalho moderado por 30 minutos todos os dias da semana. O cavalo 2 é da raça Manga Larga Paulista com 9 anos de idade, pratica treinos moderados de cavalgada todos os dias por 30 minutos. E por fim, o cavalo 3 que é da raça Puro Sangue Inglês com 20 anos e com doença pulmonar obstrutiva crônica (DPOC) atualmente está sem crise, com boa qualidade fisiológica e está aposentado.

Os três cavalos recebem ração às 5 horas da manhã, ao meio dia e às 20 horas. O cavalo $1 \mathrm{e} o 2$ recebem $1 \mathrm{~kg}$ pela manhã, $1 \mathrm{~kg}$ ao meio dia e $1 \mathrm{~kg}$ à noite, $\mathrm{e}$ o cavalo 3 recebe $1,5 \mathrm{~kg}$ pela manhã $1,5 \mathrm{~kg}$ ao meio dia, $750 \mathrm{~g}$ às $17 \mathrm{~h} 30 \mathrm{e} 750 \mathrm{~g}$ às 20 horas.

Os cavalos 1,2 e 3 ficam no pasto das $7 \mathrm{~h} 30$ às $11 \mathrm{~h}$ quando são recolhidos às baias permanecendo até às $16 \mathrm{~h}$ e após esse horário os 3 cavalos retornam ao pasto até às $17 \mathrm{~h} 30$. Os animais comem além do concentrado, feno e sal mineral à vontade, probiótico e prebiótico.

As camas dos cavalos 1 e 2 são de maravalha de eucalipto e seus fenos ficam situados no chão. Já a cama do cavalo 3 é de borracha, fabricada sob medida, e o seu feno está posicionado em um suporte de ferro que fica no alto.

As baias dos animais possuem uma área de $12,25 \mathrm{~m}^{2}$ e paredes de blocos de cimento com altura de 190 centímetros.

Os cochos de água e de ração são de cimento e estão posicionados a altura de $80 \mathrm{~cm}$ e a água é de abastecimento, com cloro e flúor.

O pavilhão está situado na direção norte - sul, com telhado de telhas onduladas de fibrocimento, conforme pode ser visualizado na (Figura 5). 
Figura 5 - Incidência do sol no galpão

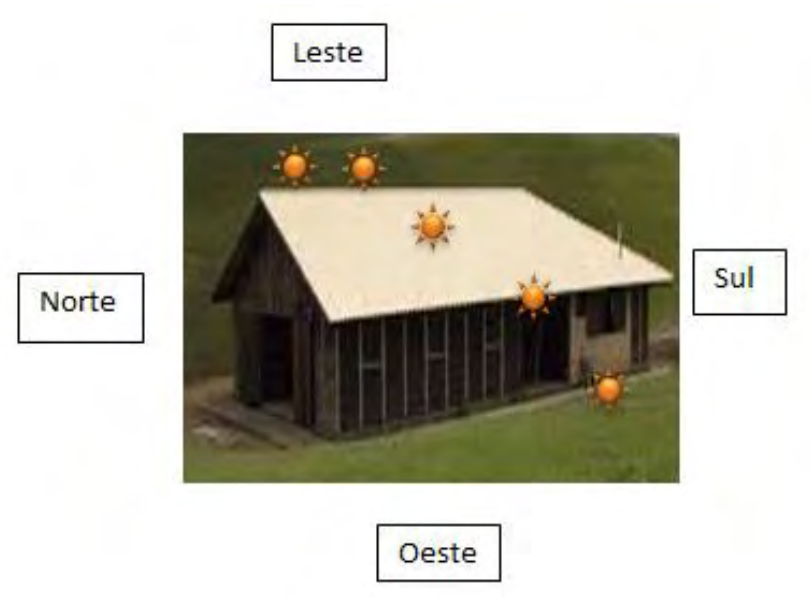

Fonte: Própria autoria

\subsection{Aplicativo usado para coletar os movimentos cinéticos dos equinos}

Foi encontrado um aplicativo para android chamado Sensor Kinetics Pro versão 3.1.2. Este aplicativo teve a função de captar os dados coletados e o smartphone armazenou e enviou através da tecnologia 3G ou 4G para a rede de telefonia móvel que os enviou por e-mail para outro dispositivo como um celular, um tablet ou um computador. Este processo de envio usou a rede de telefonia móvel já estabelecida pelas operadoras. Os dados coletados foram enviados por e-mail para o pesquisador na forma de uma planilha do excell. Esse meio de transmissão pode ser visualizada na (Figura 6). 
Figura 6 - Meio de transmissão dos dados

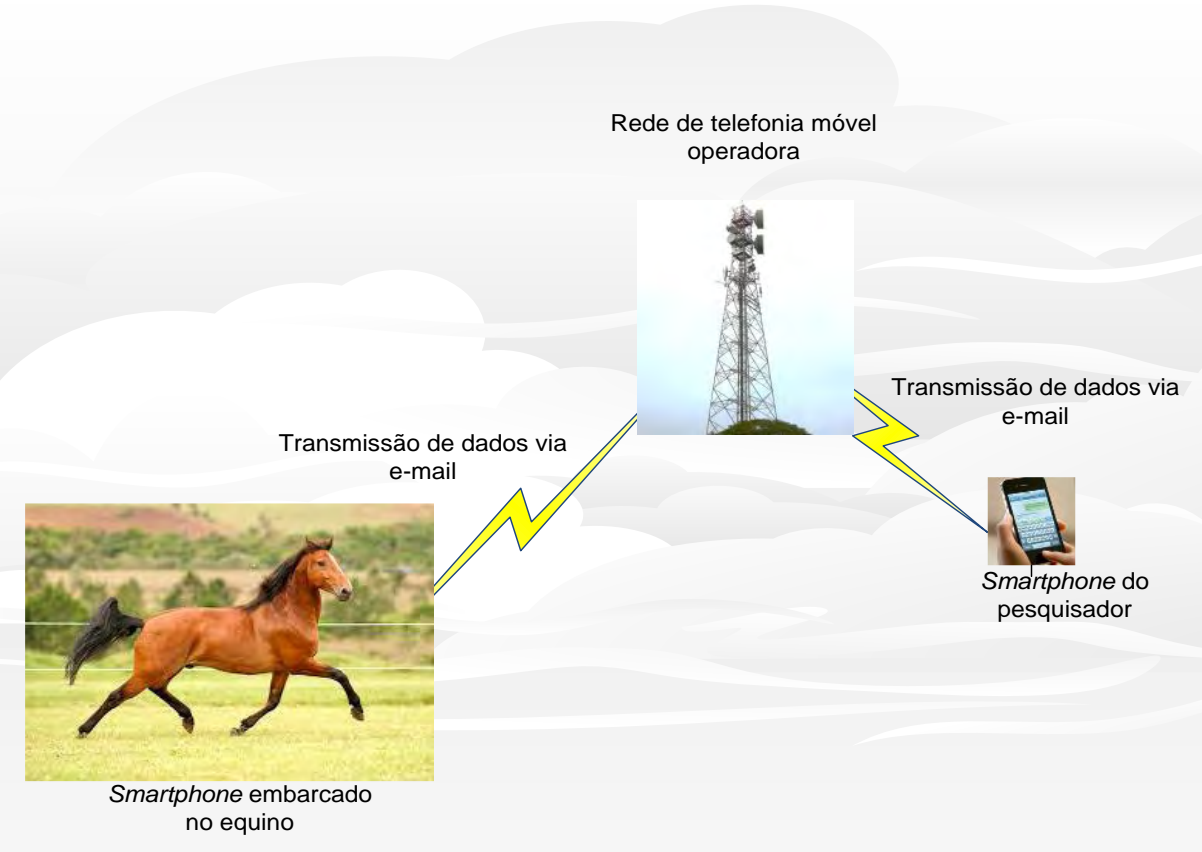

Fonte: Própria autoria

\subsection{Equipamento ( caneleira com o smartphone)}

Inicialmente o equipamento seria testado, além do MAD, no cabresto e na cilha, porém como no membro anterior direito o smartphone foi ajustado perfeitamente dispensando os outros locais de testes, como pode ser visualizado na (Figura 7). No cabresto o que demonstra a (Figura 8) e no tórax por meio de uma cilha (Figura 9). 
Figura 7 - Caneleira com o Smartphone

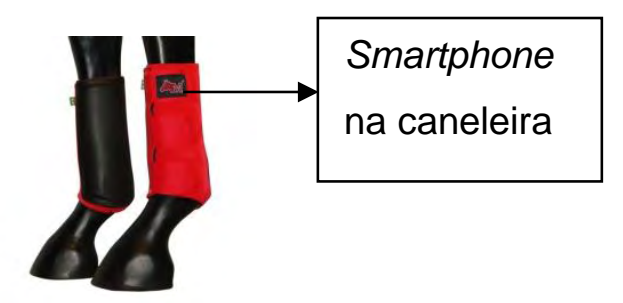

Fonte: Própria Autoria

Figura 8 - Cabresto com o Smartphone

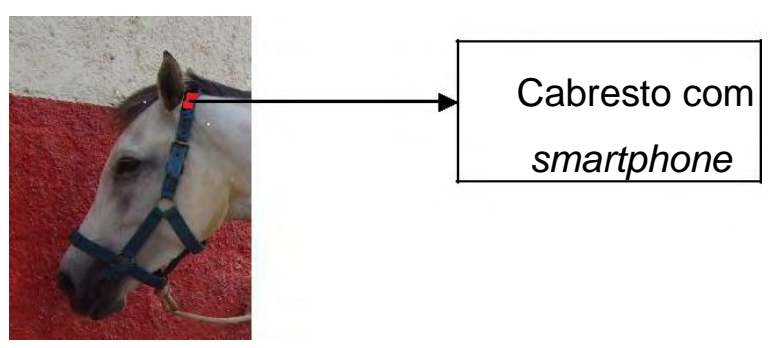

Fonte: Própria autoria

Figura 9 - Cilha com o Smartphone

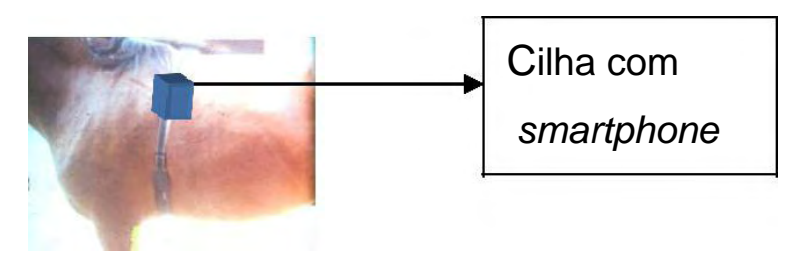

Fonte: Própria autoria

Para adequar o smartphone na caneleira fechada a pino, foi usado uma capa de celular com velcro, que pode ser visualizada a seguir e a tira superior da caneleira passou por dentro de uma alça da própria capa formando um conjunto.

Dentro desse conjunto foi colocado o smartphone com o visor voltado para o animal.

Para evitar que o velcro da capa do celular abrisse, passou-se uma bandagem elástica ao redor do conjunto, tornando o aparato seguro para teste. A seguir o cavalo embarcado com o equipamento pronto para a DMCP (Determinação 
do movimento cinético padrão). Essa montagem do equipamento pode ser visualizado nas Figuras 10.

Figura 10 -A) smartphone usado; B) caneleira; C) capinha de celular na tira de fechamento da caneleira; D) caneleira com a capinha de célular; E) smartphone dentro da capinha; F) conjunto caneleira com smartphone; G) bandagem elástica; H) conjunto envolto pela bandagem elástica; I) conjunto pronto para DMCP.
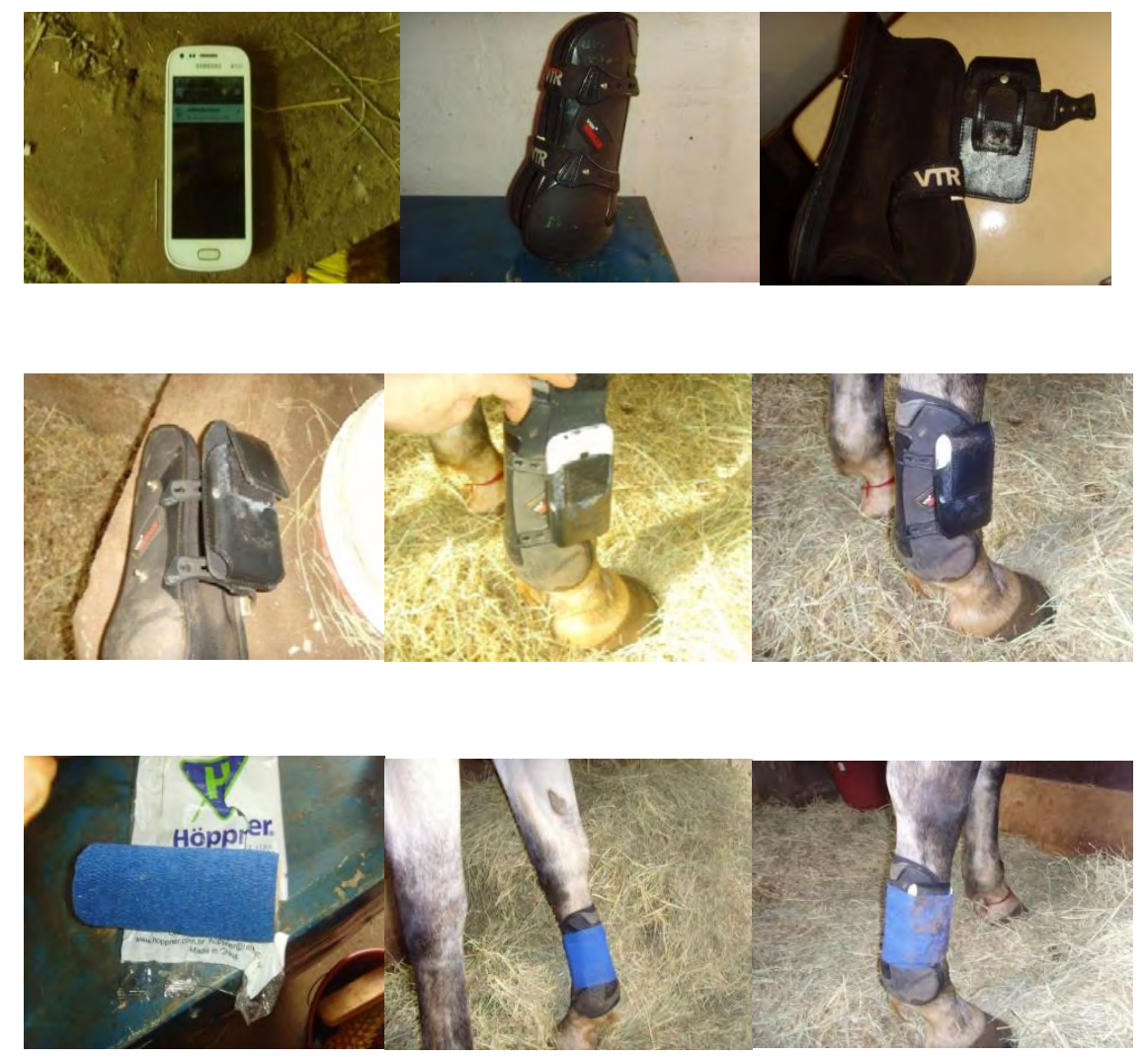

Fonte: Própria autoria

O cavalo 2 usou a caneleira sem o smartphone por um dia para que se acostumasse a andar normalmente e cessasse o estresse antes do experimento, os outros dois já estavam acostumados com o uso de caneleiras.

\subsection{Determinação dos movimentos cinéticos padrão (DMCP)}

Para a determinação dos movimentos cinéticos padrões capturados pelos sensores e determinados pelos movimentos dos cavalos, o sensor Kinetics Pro já vem pré definido com ajustes e foi escolhido uma frequência de amostragem de 15 
pontos por segundo. Os sinais cinéticos dos cavalos entraram como sinais analógicos no smartphone onde foram transformados em sinais digitais e armazenados no aplicativo.

A saída do aplicativo para o e-mail do pesquisador saiu em forma analógica, como sinais elétromagnéticos, para que pudessem ser analisados e transfornados em gráficos pelo programa Matlab ${ }^{\circledR}$.

A primeira DMCP com o sensor nos cavalos aconteceu no dia 14 de setembro de 2018, no qual o cavalo 1 usou a caneleira com o sensor já calibrado e foi montado pelo seu cavaleiro fazendo o percurso do treino em pista de areia, como descrito a seguir:

1. Ao passo com rédeas soltas, ou seja, sem interferência do cavaleiro,

2. Ao passo controlado,

3. Retidão: treinamento para tornar o cavalo e o cavaleiro equilibrados e simétricos, distribuindo o peso sobre o centro de equilíbrio de ambos, relaxando e contraindo a musculatura, alongando e tensionando nas horas corretas (TOMAZELLI, 2015),

4. Trote curto,

5. Galope,

6. Salto,

7. Passo.

A DMCP do cavalo 1 mostrou que para cada movimento existe um padrão diferente que também se diferenciam em cada eixo do acelerômetro, mostrando que todos os eixos são importantes no espaço.

Após essa primeira DMCP no cavalo 1 foi feito a DMCP no cavalo 3 para obter o movimento de rolar no chão e pastejando. O movimento de rolar é normal para todos os cavalos como uma forma de relaxamento, porém neste experimento pode-se relacionar o rolar do cavalo 3 com o rolar da síndrome cólica. No pasto o cavalo 3 bateu o MAD na barriga e levantou o MAD sem bater na barriga e notou-se que cada movimento apresenta um padrão distinto o que pode inferir que o movimento de bater o MAD na barriga mostra o movimento de escoicear a barriga na síndrome cólica. Esse cavalo também usou o sensor preso na caneleira no MAD e ajustado para obter uma frequência de amostragem de 30 pontos por segundo. Os dados foram armazenados no smartphone e transmitidos por e-mail para o pesquisador. 
No dia seguinte, o sensor foi colocado preso na caneleita no MAD do cavalo 2. Novamente o sensor foi ajustado para obter uma frequência de amostragem de 30 pontos por segundo, o cavalo 2 ficou na baia e depois foi solto no pasto. Na baia obteve-se a DMCP de bater o MAD na barriga e de um passo mostrando que os padrões se diferenciam para cada movimento.

Em todas essas DMCP foram realizadas filmagens dos movimentos e monitoramento visual para posterior correlação com os dados gravados pelo sensor. Com a DMCP pôde-se saber os movimentos padrões dos cavalos e o que estiver fora do padrão pode ser considerado como um sinal de alerta para detectar a síndrome cólica.

\subsubsection{Obtenção dos movimentos cinéticos padrão (OMCP)}

Posteriormente a DMCP dos 3 cavalos, iniciou-se a OMCP por 10 horas/dia em 3 dias para cada cavalo. $O$ sensor foi ajustado para obter 15 pontos por segundo em todos os dia.

Os experimentos foram realizados em um cavalo por vez, seguindo o mesmo padrão. Antes do ínicio da coleta dos dados foram aferidos os sinais vitais do animal como auscutar o coração e o pulmão, frequência cardíaca, frequência respiratória e temperatura retal, bem como as medidas do ambiente: como temperatura, umidade relativa do ar e pressão atmosférica, a fim de verificar se estavam em conforto ambiental.

O sensor era posicionado nos cavalos por volta das 7 h30 e retirado às $17 \mathrm{~h} 30$. Desde o momento da colocação da caneleira com o sensor, o cavalo ficava no pasto com os demais cavalos até as $11 \mathrm{~h}$. Após esse período eles retornavam para a baia contendo água e alimentação, voltando ao pasto as $16 \mathrm{~h}$ onde permaneciam até as 17h30. Tanto no cavalo 1 , como no 2 e no 3 notou-se comportamento normal e sem estresse devido ao uso da caneleira.

\subsection{Análise dos dados da DMCP do cavalo 1}

Os dados foram recebidos na forma de séries temporais (série de dados coletados em um dado período denominado de período amostral). Sendo uma série 
temporal, a informação foi avaliada de duas formas: uma baseada na evolução temporal dos dados dos sensores e a outra baseada na evolução periódica.

A primeira é uma análise no domínio do tempo e a segunda é uma análise no domínio da frequência, que mostra quanto do sinal reside em cada faixa de frequência. No domínio do tempo foram consideradas as medidas estatísticas comumente usadas como: média temporal, autocorreção e medidas de similaridades. No domínio da frequência usou-se a análise espectral. Todas estas ferramentas estão disponibilizadas no softwares de análise de séries temporais denominado Matlab ${ }^{\circledR}$.

O sinal analógico mostra valores contínuos no tempo ou no espaço, ele existe por toda a natureza, como por exemplo, o som ou as correntes elétricas. São representados por ondas contínuas e assimétricas. Esses sinais são difíceis de serem processados pois são afetados por ruídos, pela temperatura e outras variações em valores de componentes.

O sinal digital, por sua vez, tem valores discretos com números descontínuos, são mais fáceis de reconfigurar bastando alterar um algoritmo computacional. Como nesses sinais o sistema de numeração é binária ( 0 e 1), a faixa de frequência é menor, consequentemente as oscilações são menores (SILVA, 2005; VELLOS, 2014).

Neste experimento os valores foram obtidos por sinais analógicos, que foram digitalizados dentro do smartphone, no qual também ficaram armazenados, em seguida foram enviados por e-mail como sinais analógicos, em forma de sinais elétromagnéticos, para serem convertidos em gráficos pelo Matlab ${ }^{\circledR}$. Para essa transformação, o sinal analógico deve ser amostrado e depois quantizado, isto é, os valores devem ser aproximados ou por arredondamento, ou por truncamento (SILVA, 2005)

\subsubsection{Dados transmitidos pelo aplicativo}

Durante os experimentos o sensor armazenou os dados em uma planilha excel. O aplicativo sensor Kinetics pro converteu o sinal recebido em forma de texto para valores separados por vígulas (csv) para todos os cavalos. O gráfico do acelerômetro foi definido como padrão com 3 eixos, $\mathrm{X}, \mathrm{Y}$ e Z $\mathrm{Z}$ O experimento com o 
cavalo 1 foi realizado no dia 14 de setembro de 2018. A filmagem durou 2228 segundos e durante esse período foram coletados 31755 pontos por segundo.

O experimento com o cavalo 2 foi realizado no dia 06 de janeiro de 2019. A filmagem durou 497 segundos e durante esse período foram coletados 12312 pontos por segundo.

O experimento com o cavalo 3 foi realizado no dia 03 de janeiro de 2019. A filmagem durou 840 segundos e durante esse período foram coletados 20618 pontos por segundo.

\subsubsection{Métodos de análise e processamento de sinais}

Os dados digitais coletados foram armazenados em um banco de dados e processados em um computador provido da ferramenta de Software Matlab ${ }^{\circledR}$. Para o processamento e análise dos sinais no domino do tempo utilizou-se as ferramentas gráficas do Matlab ${ }^{\circledR}$. Para o processamento no domino da frequência usou-se 0 método de Welch para transformar a amplitude dos sinais elétricos no tempo em uma relação entre potência e frequência que estima a potência de um sinal em diferentes frequências, o sinal é dividido em segmentos que são sobrepostos, usouse valores de sobreposição de 50\%. Quando ocorre sobreposição precisa-se usar janelamentos para detectar o sinal de menor amplitude, neste experimento foi usado a janela de Hamming e um intervalo de confiança de 95\%. Para esse processamento também foram usadas as ferramentas gráficas do Matlab ${ }^{\circledR}$. 


\section{Resultados}

\subsection{Dados fisiológicos e ambientais}

A coleta dos dados realizados antes dos experimentos, tanto dos dados fisiológicos dos cavalos quanto dos dados meteorológicos, podem ser visualizados na Tabela 1, para o cavalo 1, Tabela 2 para o cavalo 2 e Tabela 3 para o cavalo 3.

Depois de calibrado o sensor Kinetics pro, deu-se o início do experimento com o equipamento embarcado no membro anterior direito (MAD) do cavalo 1 e na sequencia o cavalo 2 e o 3 . No decorrer do experimento todos movimentos dos cavalos foram captados pelo sensor Kinetics Pro por dez horas.

Durante a pesquisa foram auscultados o coração e o pulmão, medido a frequência cardíaca, frequência respiratória e mensurada a temperatura retal dos três animais como também os dados ambientais antes de colocarem a caneleira com o smartphone e logo que voltaram do pasto, os dados foram inseridos na (Tabela 1), (Tabela 2) e (Tabela 3).

A frequência cardíaca e respiratória foram aferidas no tempo de 60 segundos.

Tabela 1 - Dados do cavalo 1 e do ambiente antes do experimento

\begin{tabular}{ccccccccc}
\hline Dia & Hora & Treino & TA & PA & UR & FC & FR & TR \\
\hline $23 / 09 / 18$ & $07: 06$ & Pasto & $15^{\circ} \mathrm{C}$ & $1.014 \mathrm{hPa}$ & $100 \%$ & $32 \mathrm{bpm}$ & $12 \mathrm{mpm}$ & $37,8^{\circ} \mathrm{C}$ \\
$27 / 09 / 18$ & $08: 00$ & Pasto & $24^{\circ} \mathrm{C}$ & $759,025 \mathrm{hPa}$ & $77 \%$ & $31 \mathrm{bpm}$ & $15 \mathrm{mpm}$ & $37,8^{\circ} \mathrm{C}$ \\
$27 / 09 / 18$ & $17: 41$ & Baia & $28^{\circ} \mathrm{C}$ & $758,807 \mathrm{hPa}$ & $46 \%$ & $35 \mathrm{bpm}$ & $17 \mathrm{mpm}$ & $38,0^{\circ} \mathrm{C}$ \\
$28 / 09 / 18$ & $07: 18$ & Pasto & $21^{\circ} \mathrm{C}$ & $759,947 \mathrm{hPa}$ & $87 \%$ & $31 \mathrm{bpm}$ & $13 \mathrm{mpm}$ & $37,8^{\circ} \mathrm{C}$ \\
$28 / 09 / 18$ & $17: 20$ & Baia & $25^{\circ} \mathrm{C}$ & $760,090 \mathrm{hPa}$ & $66 \%$ & $36 \mathrm{bpm}$ & $14 \mathrm{mpm}$ & $38,1^{\circ} \mathrm{C}$ \\
$29 / 09 / 18$ & $7: 40$ & Pós treino & $22^{\circ} \mathrm{C}$ & $760,172 \mathrm{hPa}$ & $78 \%$ & $41 \mathrm{bpm}$ & $24 \mathrm{mpm}$ & $38,2^{\circ} \mathrm{C}$ \\
$29 / 09 / 18$ & $17: 47$ & Baia & $29^{\circ} \mathrm{C}$ & $759,955 \mathrm{hPa}$ & $46 \%$ & $35 \mathrm{bpm}$ & $19 \mathrm{mpm}$ & $37,8^{\circ} \mathrm{C}$ \\
\hline
\end{tabular}

Observação: TA (temperatura do ambiente) PA (Pressão Atmosférica) UR (Umidade Relativa do Ar) FC (frequência cardíaca) FR (frequência respiratória) TR (temperatura retal)

Fonte: própria autoria 
Tabela 2 - Dados do cavalo 2 antes do experimento

\begin{tabular}{ccccccccc}
\hline Dia & Hora & Treino & TA & PA & UR & FC & FR & TR \\
\hline 30/09/18 & $06: 55$ & Pasto & $20^{\circ} \mathrm{C}$ & $760,375 \mathrm{hPa}$ & $95 \%$ & $36 \mathrm{bpm}$ & $20 \mathrm{mpm}$ & $37,5^{\circ} \mathrm{C}$ \\
$30 / 09 / 18$ & $17: 45$ & Pasto & $23^{\circ} \mathrm{C}$ & $759,025 \mathrm{hPa}$ & $60 \%$ & $34 \mathrm{bpm}$ & $16 \mathrm{mpm}$ & $37,8^{\circ} \mathrm{C}$ \\
$01 / 10 / 18$ & $07: 40$ & Treino & $21^{\circ} \mathrm{C}$ & $760,577 \mathrm{hPa}$ & $89 \%$ & $40 \mathrm{bpm}$ & $29 \mathrm{mpm}$ & $37,6^{\circ} \mathrm{C}$ \\
$01 / 10 / 18$ & $17: 33$ & Pasto & $26^{\circ} \mathrm{C}$ & $759,872 \mathrm{hPa}$ & $59 \%$ & $40 \mathrm{bpm}$ & $25 \mathrm{mpm}$ & $38,0^{\circ} \mathrm{C}$ \\
$02 / 10 / 18$ & $08: 05$ & Treino & $23^{\circ} \mathrm{C}$ & $759,805 \mathrm{hPa}$ & $83 \%$ & $50 \mathrm{bpm}$ & $25 \mathrm{mpm}$ & $37,8^{\circ} \mathrm{C}$ \\
$02 / 10 / 18$ & $17: 39$ & Baia & $31^{\circ} \mathrm{C}$ & $759,700 \mathrm{hPa}$ & $36 \%$ & $33 \mathrm{bpm}$ & $27 \mathrm{mpm}$ & $37,8^{\circ} \mathrm{C}$ \\
\hline
\end{tabular}

Observação: TA (temperatura do ambiente) PA (Pressão Atmosférica) UR (Umidade Relativa do Ar) FC (frequência cardíaca) FR (frequência respiratória) TR (temperatura retal) Fonte: Própria autoria

Tabela 3 - Dados do cavalo 3 antes do experimento

\begin{tabular}{ccccccccc}
\hline Dia & Hora & Treino & TA & PA & UR & FC & FR & TR \\
\hline $03 / 10 / 18$ & $07: 42$ & Baia & $20^{\circ} \mathrm{C}$ & $759,452 \mathrm{hPa}$ & $77 \%$ & $41 \mathrm{bpm}$ & $23 \mathrm{mpm}$ & $37,2^{\circ} \mathrm{C}$ \\
$03 / 10 / 18$ & $17: 45$ & Pasto & $24^{\circ} \mathrm{C}$ & $759,437 \mathrm{hPa}$ & $67 \%$ & $35 \mathrm{bpm}$ & $19 \mathrm{mpm}$ & $37,8^{\circ} \mathrm{C}$ \\
$04 / 10 / 18$ & $07: 33$ & Baia & $22^{\circ} \mathrm{C}$ & $760,660 \mathrm{hPa}$ & $84 \%$ & $36 \mathrm{bpm}$ & $17 \mathrm{mpm}$ & $37,4^{\circ} \mathrm{C}$ \\
$04 / 10 / 18$ & $17: 39$ & Pasto & $28^{\circ} \mathrm{C}$ & $760,697 \mathrm{hPa}$ & $53 \%$ & $38 \mathrm{bpm}$ & $26 \mathrm{mpm}$ & $37,8^{\circ} \mathrm{C}$ \\
$05 / 10 / 18$ & $08: 05$ & Baia & $23^{\circ} \mathrm{C}$ & $759,805 \mathrm{hPa}$ & $83 \%$ & $50 \mathrm{bpm}$ & $25 \mathrm{mpm}$ & $37,8^{\circ} \mathrm{C}$ \\
$05 / 10 / 18$ & $17: 39$ & Baia & $31^{\circ} \mathrm{C}$ & $759,700 \mathrm{hPa}$ & $36 \%$ & $33 \mathrm{bpm}$ & $27 \mathrm{mpm}$ & $37,8^{\circ} \mathrm{C}$ \\
$06 / 10 / 18$ & $07: 30$ & Baia & $18^{\circ} \mathrm{C}$ & $761,508 \mathrm{hPa}$ & $77 \%$ & $32 \mathrm{bpm}$ & $17 \mathrm{mpm}$ & $37,1^{\circ} \mathrm{C}$ \\
$06 / 10 / 18$ & $17: 28$ & Pasto & $24^{\circ} \mathrm{C}$ & $761,418 \mathrm{hPa}$ & $66 \%$ & $36 \mathrm{bpm}$ & $20 \mathrm{mpm}$ & $37,1^{\circ} \mathrm{C}$ \\
$07 / 10 / 18$ & $07: 15$ & Baia & $18^{\circ} \mathrm{C}$ & $761,388 \mathrm{hPa}$ & $91 \%$ & $40 \mathrm{bpm}$ & $18 \mathrm{mpm}$ & $37,5^{\circ} \mathrm{C}$ \\
$07 / 10 / 18$ & $17: 28$ & Pasto & $24^{\circ} \mathrm{C}$ & $761,418 \mathrm{hPa}$ & $90 \%$ & $42 \mathrm{bpm}$ & $20 \mathrm{mpm}$ & $37,8^{\circ} \mathrm{C}$ \\
\hline
\end{tabular}

Observação: TA (temperatura do ambiente) PA (Pressão Atmosférica) UR (Umidade Relativa do Ar) FC (frequência cardíaca) FR (frequência respiratória) TR (temperatura retal)

Fonte: Própria autoria

\subsection{Dados do cavalo 1}

Baseado no tempo de filmagem e amostragem pré definida, foram obtidos os números de pontos de cada coleta, conforme pode ser visualizado na (Tabela 4). sensor foi calibrado para obter uma frequência de amostragem de 15 pontos por 
segundo com início do cálculo do aplicativo acrescido de 180 s que foi o início do filme, quando a filmadora foi ligada (Tabela 5). De 0 a 9,18 min foi o tempo que o cavalo 1 estava ao passo com rédea solta, esse tempo foi multiplicado por 60 para transformar em segundos e multiplicado por 15 para obtermos a frequência de amostragem a qual o sensor foi ajustado para obter 15 pontos por segundo. Em cada andadura repetiu-se esse cálculo.

Tabela 4 - Primeira medição com o cavalo 1 no treino

\begin{tabular}{|c|c|c|c|}
\hline Comportamento & $\begin{array}{c}\text { Tempo de } \\
\text { movimento(min) }\end{array}$ & Cálculo & Número de pontos \\
\hline Passo rédea solta & $0-9,18=$ & $9,18^{*} 60^{*} 15=8262$ & $1-8262$ \\
\hline Passo controlado & $9,18-11,55=$ & $2,37^{*} 60^{*} 15=2133$ & $8263+2133=10395$ \\
\hline Retidão & $11,55-13,25=$ & $1,7^{*} 60^{*} 15=1530$ & $10396+1530=11925$ \\
\hline Trote curto & $13,25-15,18=$ & $1,93^{*} 60^{*} 15=1737$ & $11926+1737=13663$ \\
\hline Trote alongado & $15,18-19,40=$ & $4,22^{*} 60^{*} 15=3798$ & $13664+3798=17462$ \\
\hline Galope & $19,40-23,00=$ & $3,6 * 60 * 15=3240$ & $17463+3240=20703$ \\
\hline Trote & $23,00-23,25=$ & $0,25^{*} 60^{*} 15=225$ & $29704+225=20929$ \\
\hline Passo & $23,25-25,21=$ & $1,96 * 60 * 15=1764$ & $20930+1764=22694$ \\
\hline Parado & $25,21-25,26=$ & $0,05^{*} 60^{*} 15=45$ & $22695+45=22740$ \\
\hline Trote 1 & $25,26-25,50=$ & $0,24^{*} 60^{*} 15=216$ & $22741+216=22957$ \\
\hline Salto & $25,50-25,51=$ & $0,01 * 60 * 15=9$ & $22958+9=22967$ \\
\hline Trote 2 & $25,51-26,14=$ & $0,62^{*} 60^{*} 15=558$ & $22968+558=23526$ \\
\hline Salto 1 & $26,15-26,16=$ & $0,03^{*} 60 * 15=27$ & $23527+27=23554$ \\
\hline Galope 1 & $26,16-26,42=$ & $0,26 * 60 * 15=234$ & $23555+234=23789$ \\
\hline Salto 2 & $26,42-26,43=$ & $0,01 * 60 * 15=9$ & $23790+9=23799$ \\
\hline Galope 2 & $24,43-27,04=$ & $0,61 * 60 * 15=549$ & $23800+549=24349$ \\
\hline Salto 3 & $27,04-27,05=$ & $0,01 * 60 * 15=9$ & $24350+9=24359$ \\
\hline Trote 3 & $27,05-27,46=$ & $0,41 * 60 * 15=369$ & $24360+369=25029$ \\
\hline Salto 4 & $27,46-27,49=$ & $0,03^{*} 60 * 15=27$ & $25030+27=25057$ \\
\hline Galope 3 & $27,49-28,14=$ & $0,65^{*} 60^{*} 15=585$ & $25058+585=25342$ \\
\hline Galope 4 & $28,15-28,23=$ & $0,03^{*} 60^{*} 15=27$ & $25380+27=25407$ \\
\hline Passo 2 & $28,23-28,54=$ & $0,31 * 60 * 15=279$ & $25417+279=25696$ \\
\hline Parado 2 & $28,54-29,11=$ & $0,57^{*} 60^{*} 15=581,40$ & $25697+581,4=26278,4$ \\
\hline
\end{tabular}

Fonte- Própria autoria 
$\mathrm{Na}$ determinação do padrão cinético de movimento em cada andadura calculou-se o tempo em segundos acrescido de 180s pois o smartphone com 0 aplicativo já estava ligado quando foi embarcado no cavalo 1 e levou 180s para começar a filmagem. Nessa tabela pode-se ver que até 730s o cavalo 1 estava ao passo com rédea solta o que pode ser visualizado na (Tabela 5). Os dados dos cavalos 2 e 3 encontram-se no apêndice $B$.

Tabela 5 - Padrão dos movimentos obtidos em uma frequência de amostragem de 15 pontos por segundo

\begin{tabular}{|c|c|c|}
\hline Comportamento & Tempo movimento(min) & Segundos \\
\hline Passo rédea solta & $0-9,18$ & $9,18^{*} 60+180=730$ \\
\hline Passo controlado & $9,18-11,55$ & $11,55^{\star} 60+180=873$ \\
\hline Retidão & $11,55-13,25$ & $13,25^{*} 60+180=975$ \\
\hline Trote curto & $13,25-15,18$ & $15,18^{*} 60+180=1090,8$ \\
\hline Trote alongado & $15,18-19,40$ & $19,40 * 60+180=1344$ \\
\hline Galope & $19,40-23,00$ & $23,00 * 60+180=1560$ \\
\hline Trote & $23,00-23,25$ & $23,25^{*} 60+180=1575$ \\
\hline Passo & $23,25-25,21$ & $25,21^{*} 60+180=1692,6$ \\
\hline Parado & $25,21-25,26$ & $25,26^{*} 60+180=1695,6$ \\
\hline Trote 1 & $25,26-25,50$ & $25,50 * 60+180=1710$ \\
\hline Salto & $25,50-25,51$ & $25,51 * 60+180=1710,6$ \\
\hline Trote 2 & $25,51-26,14$ & $26,14^{*} 60+180=1748$ \\
\hline Salto 1 & $26,14-26,16$ & $26,16^{*} 60+180=1749,6$ \\
\hline Galope 1 & $26,16-26,42$ & $26,42^{*} 60+180=1765,2$ \\
\hline Salto 2 & $26,42-26,43$ & $26,43^{*} 60+180=1765,8$ \\
\hline Galope 2 & $26,43-27,04$ & $27,04^{*} 60+180=1802,4$ \\
\hline Salto 3 & $27,04-27,05$ & $27,05^{\star} 60+180=1803$ \\
\hline Trote 3 & $27,05-27,46$ & $27,46^{*} 60+180=1827,6$ \\
\hline Salto 4 & $27,46-27,49$ & $27,49^{*} 60+180=1829,4$ \\
\hline Galope 3 & $27,49-28,14$ & $28,14^{*} 60+180=1867,8$ \\
\hline Salto 5 & $28,14-28,15$ & $28,15^{*} 60+180=1869$ \\
\hline Galope 4 & $28,15-28,23$ & $20,23^{*} 60+180=1873,8$ \\
\hline Passo 2 & $28,23-28,54$ & $28,54^{*} 60+180=1892,4$ \\
\hline Parado 2 & $28,54-29,11$ & $29,11^{*} 60+180=1926,6$ \\
\hline
\end{tabular}

Fonte: Própria autoria 
Na DMCP pelo acelerômetro do sensor no cavalo 1 no treino com a andadura de galope, que é um movimento assimétrico de três tempos e uma suspensão, pode ser visualizado no eixo $X$ na (Figura 11), eixo $Y$ (Figura 12), eixo $Z$ na (Figura 13), esses eixos são do acelerômetro em todos os gráficos da Amplitude x Tempo.

Figura 11 - Padrão galope eixo- X

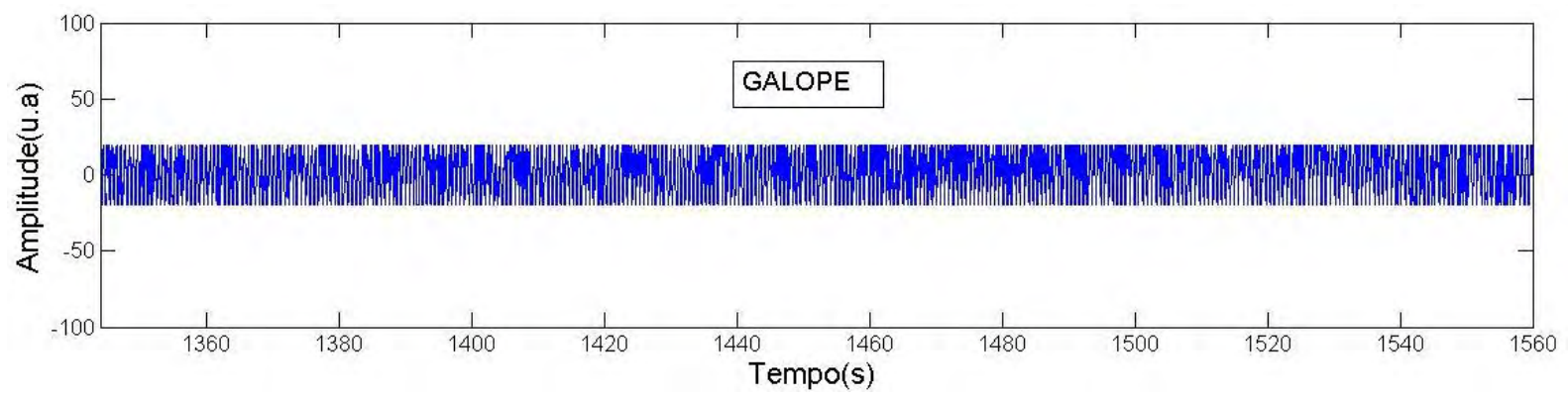

Fonte: Própria autoria

Figura 12 - Padrão galope eixo- Y

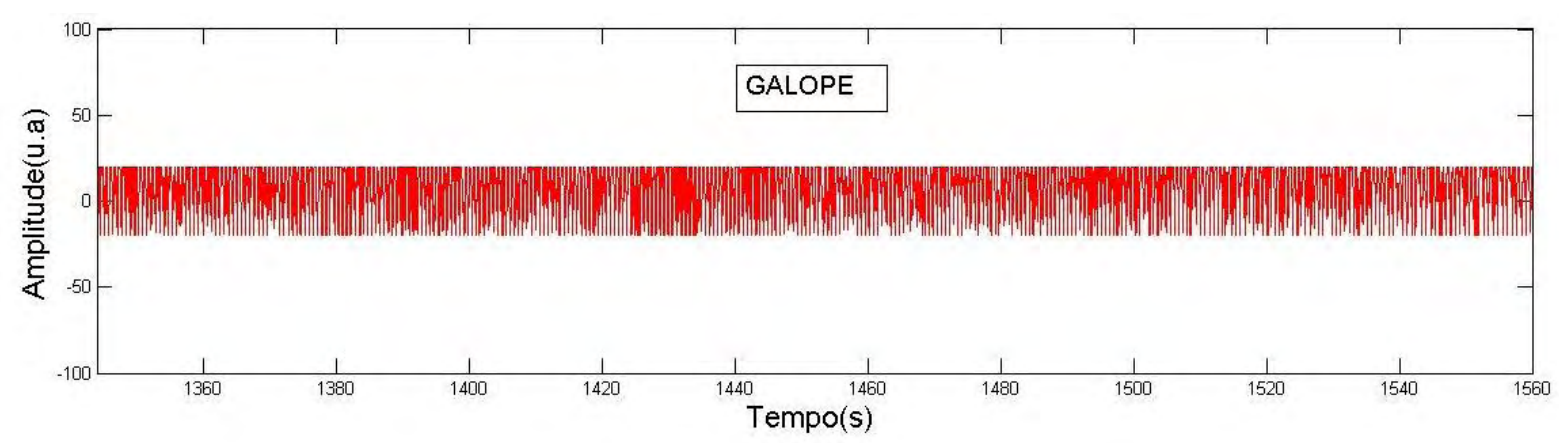

Fonte: Própria autoria

Figura 13 - Padrão galope eixo- Z

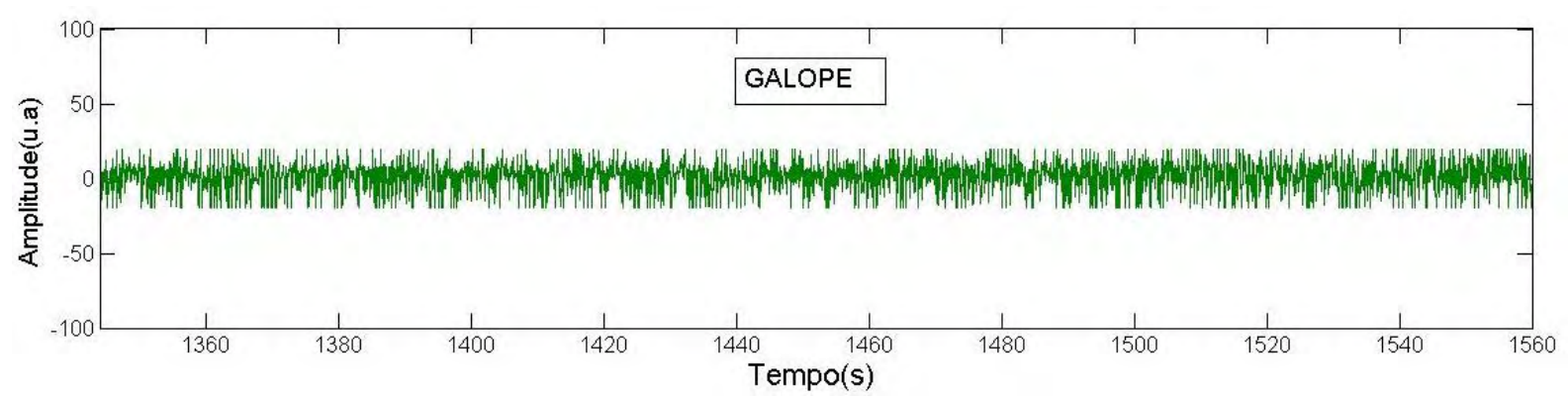

Fonte: Própria autoria 
$\mathrm{Na}$ DMCP pelo acelerômetro do sensor do cavalo 1 no treino, padrão trote curto pode ser visualizada o eixo $X$ na (Figura 14), eixo $Y$ (Figura 15), eixo $Z$ na (Figura 16). O trote é uma andadura de dois tempos em diagonal, quando o MAD está suspenso o MPE (membro posterior esquerdo) também está em suspensão.

Figura 14 - Padrão trote curto eixo- X

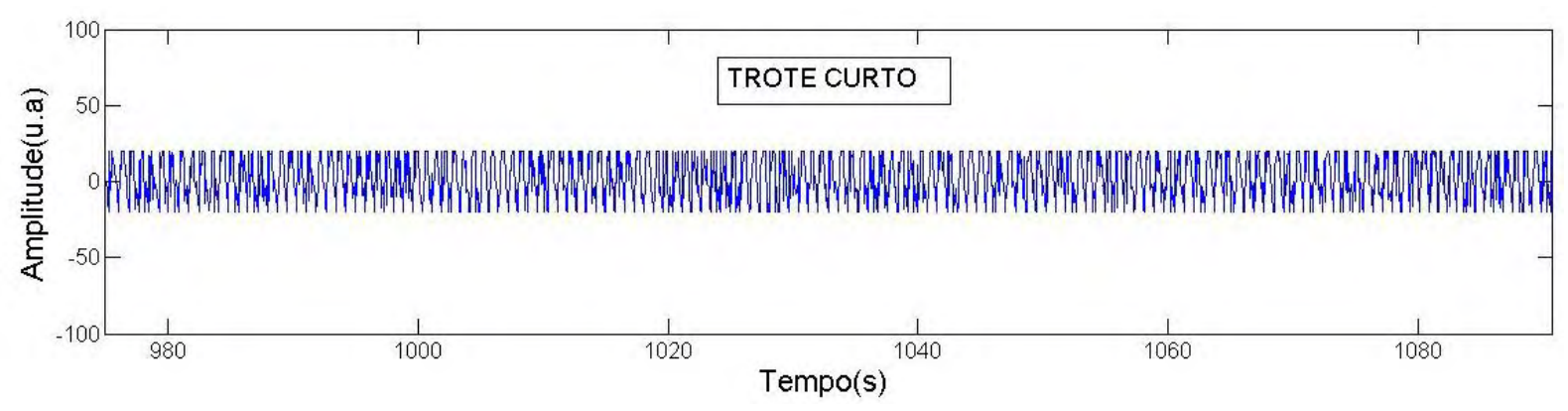

Fonte: Própria autoria

Figura 15 - Padrão trote curto eixo- $Y$

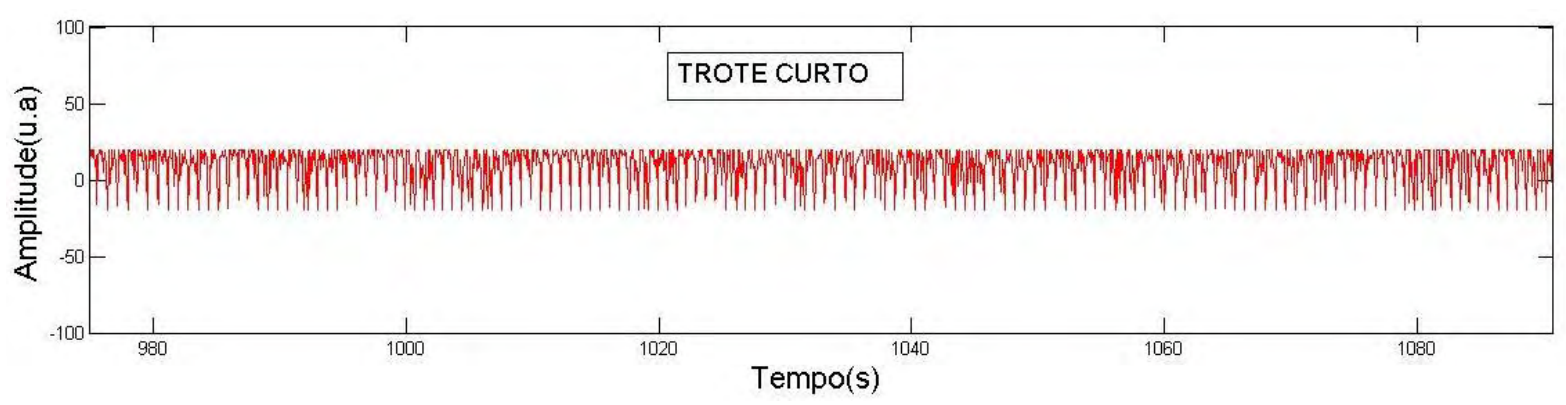

Fonte: Própria autoria

Figura 16 - Padrão trote curto eixo- Z

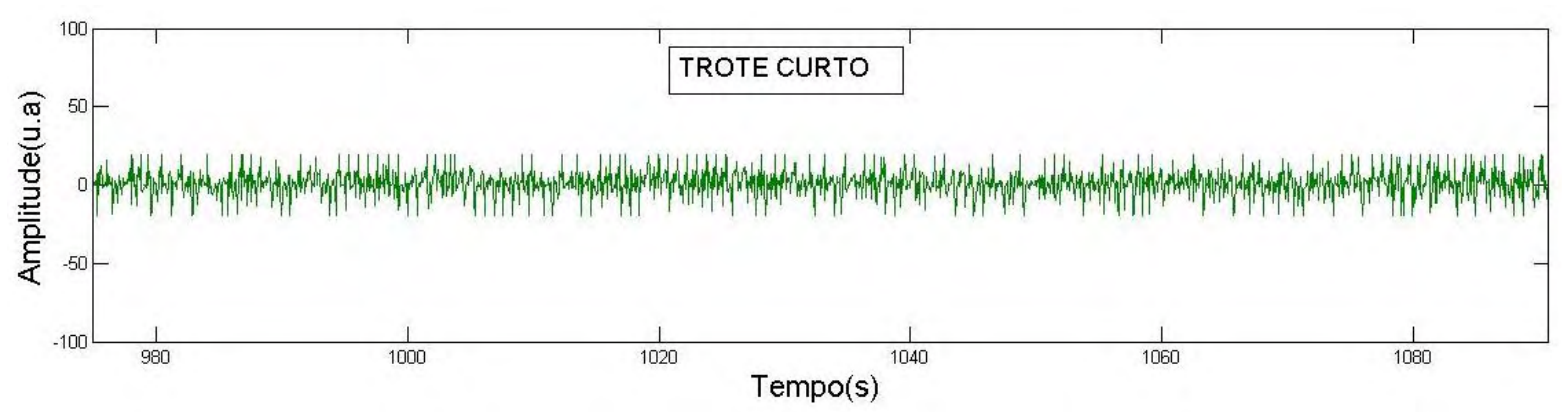

Fonte: Própria autoria 
Na DMCP pelo acelerômetro do sensor do cavalo 1 no treino, padrão trote alongado pode ser visualizada o eixo $X$ na (Figura 17), eixo $Y$ (Figura 18), eixo $Z$ na (Figura 19). $O$ trote alongado é semelhante ao trote curto porém com uma passado do cavalo mais ampla e consequentemente uma maior velocidade.

Figura 17 - Padrão trote alongado eixo- X

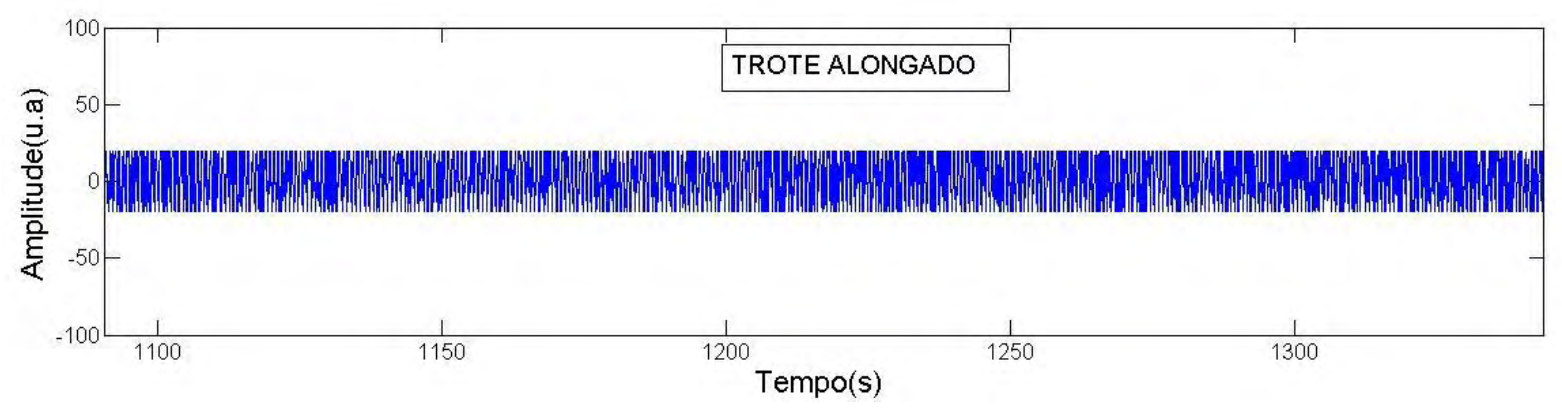

Fonte: Própria autoria

Figura 18 - Padrão trote alongado eixo- Y

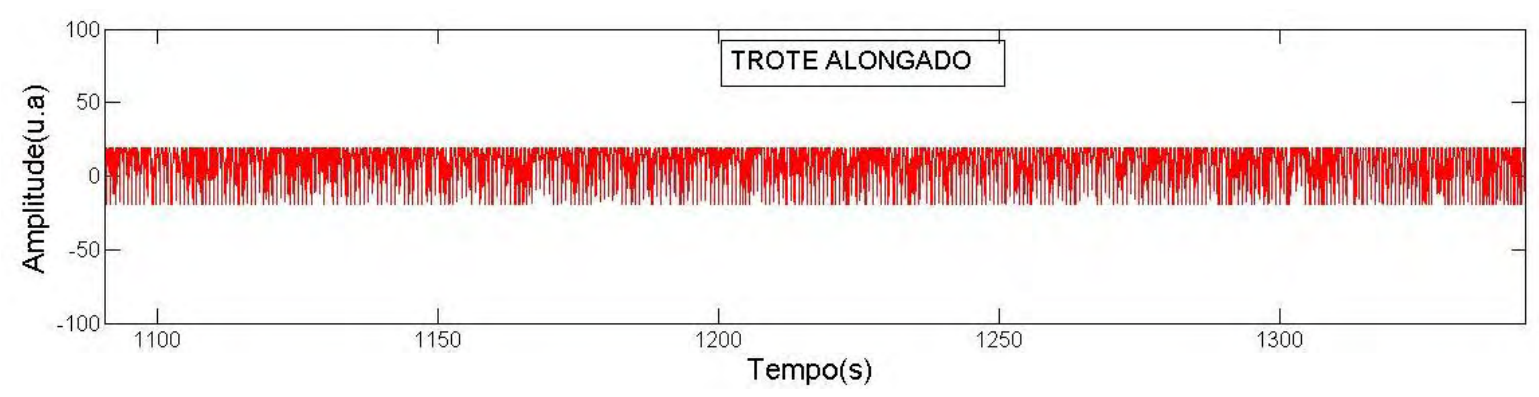

Fonte: Própria autoria

Figura 19 - Padrão trote alongado eixo- Z

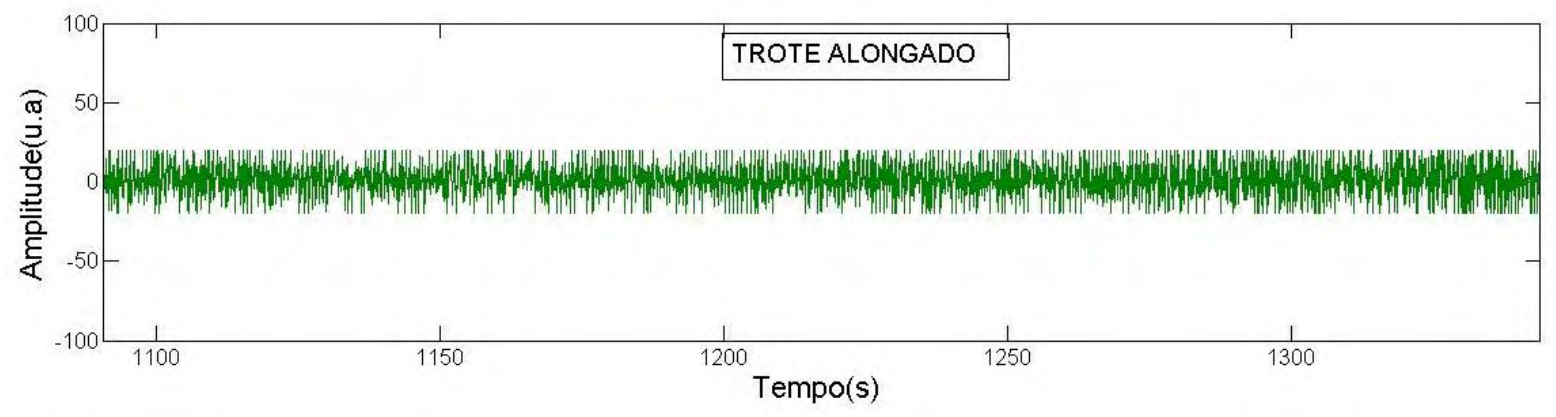

Fonte: Própria autoria 
Na DMCP pelo acelerômetro do sensor do cavalo 1 no treino, o movimento de retidão pode ser visualizada no eixo $X$ na (Figura 20), eixo $Y$ (Figura 21), eixo $Z$ na (Figura 22).

Figura 20 - Padrão retidão eixo- X

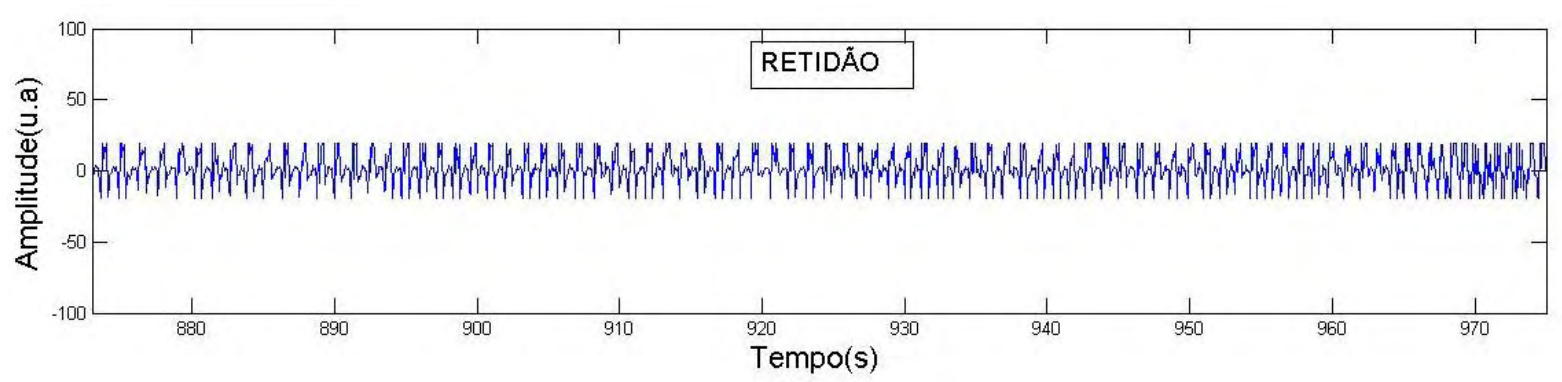

Fonte: Própria autoria

Figura 21 - Padrão retidão eixo- Y

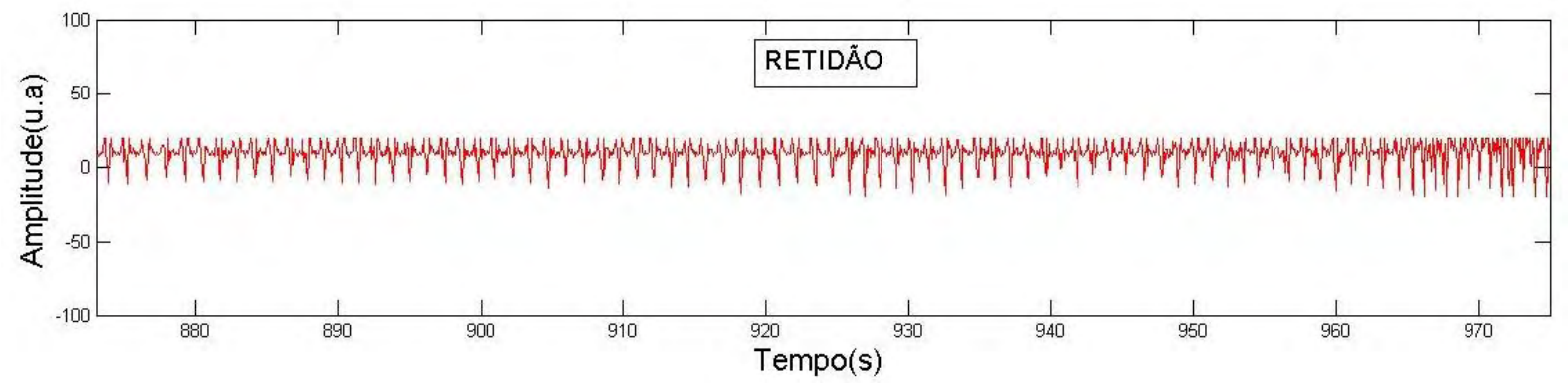

Fonte: Própria autoria

Figura 22 - Padrão retidão eixo- Z

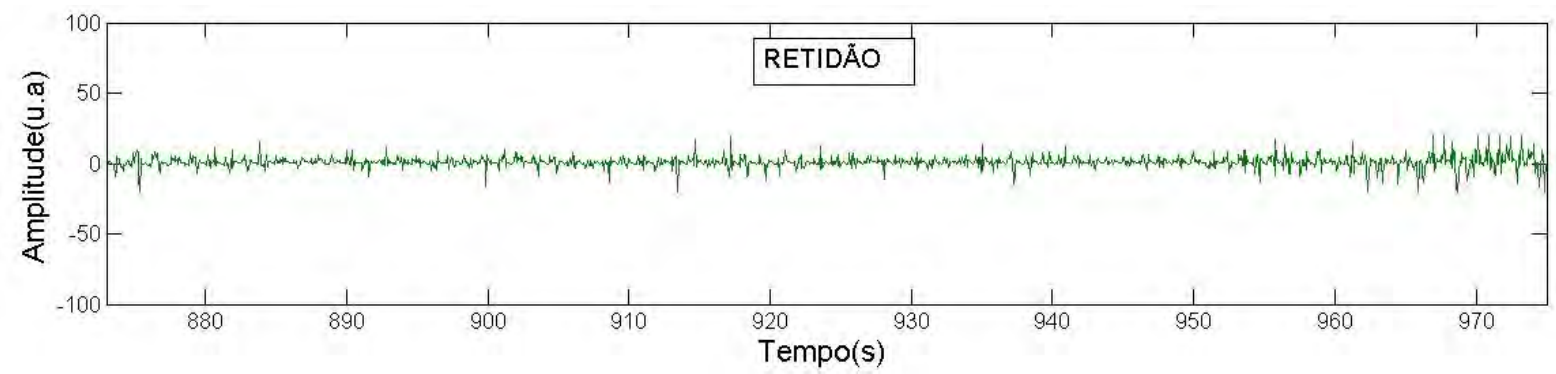

Fonte: Própria autoria 
$\mathrm{Na}$ DMCP pelo acelerômetro do sensor do cavalo 1 no passo controlado obteve-se o eixo X na (Figura 23), eixo Y (Figura 24), eixo Z na (Figura 25).

Figura 23 - Padrão passo controlado eixo- X

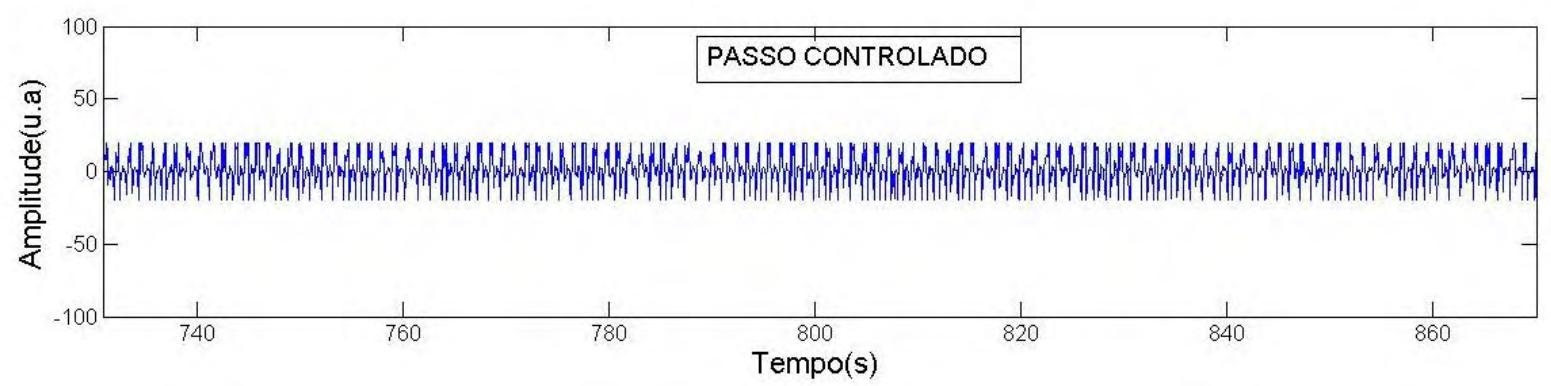

Fonte: Própria autoria

Figura 24 - Padrão passo controlado eixo- $Y$

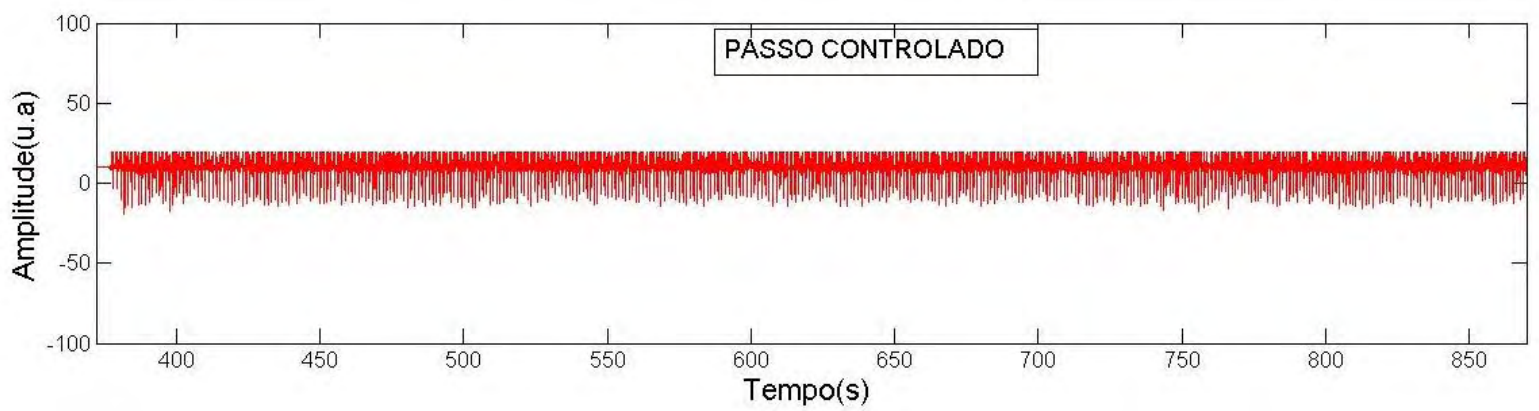

Fonte: Própria autoria

Figura 25 - Padrão passo controlado eixo- Z

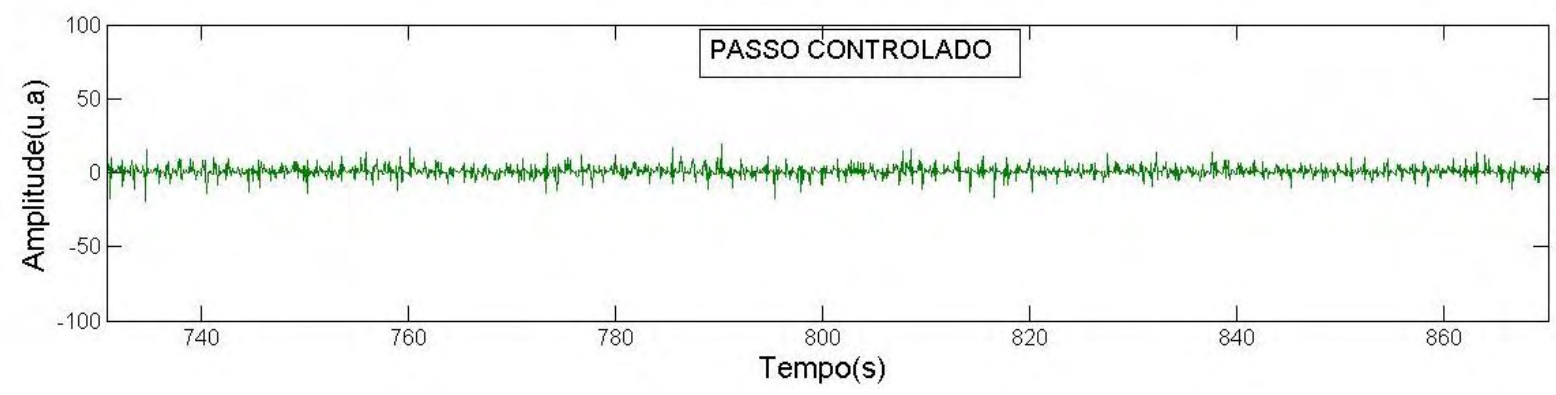

Fonte: Própria autoria 
Na DMCP pelo acelerômetro do sensor no cavalo 1 no passo com rédea solta foram obtido nos 3 eixos as figuras: eixo $X$ na (Figura 26), eixo $Y$ (Figura 27), eixo $Z$ na (Figura 28). Passo com rédea solta é uma andadura sem a interferência da rédea na boca do cavalo.

Figura 26 - Padrão passo rédea solta eixo- X

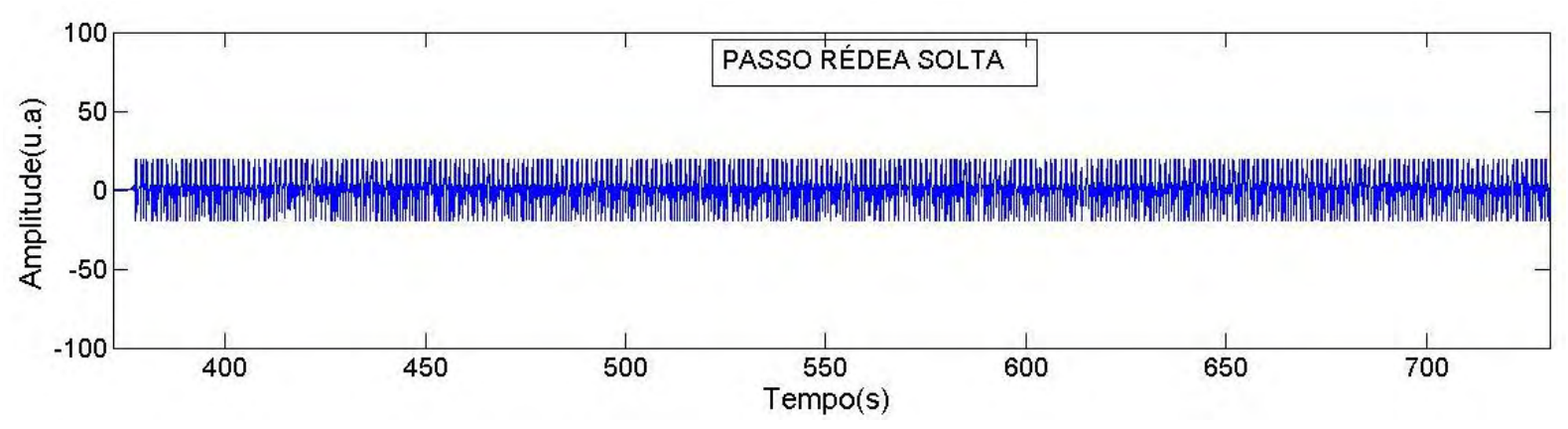

Fonte: Própria autoria

Figura 27 - Padrão passo rédea solta eixo- Y

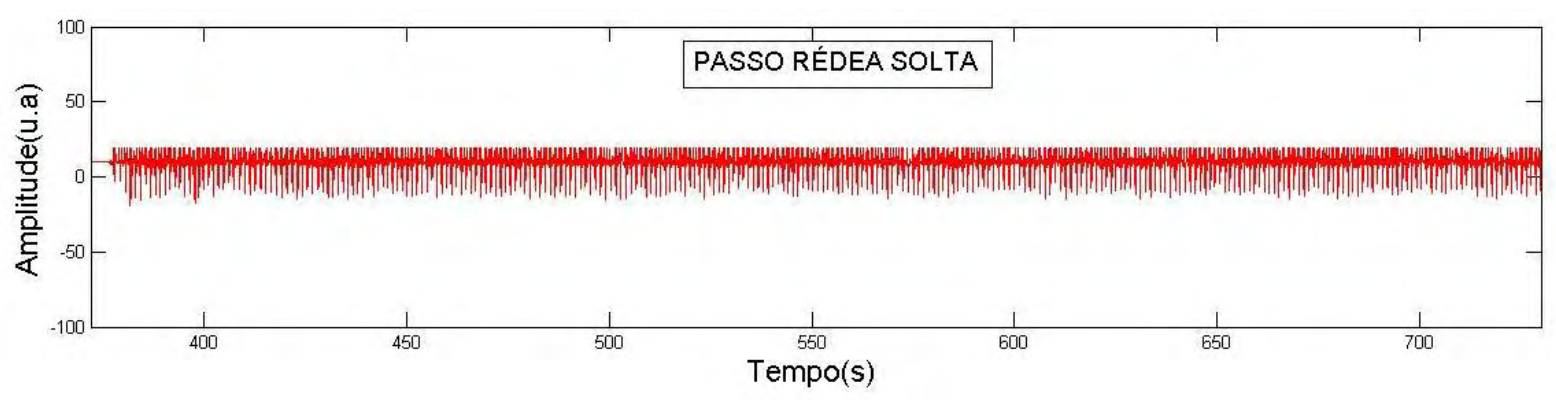

Fonte: Própria autoria

Figura 28 - Padrão passo rédea solta eixo- Z

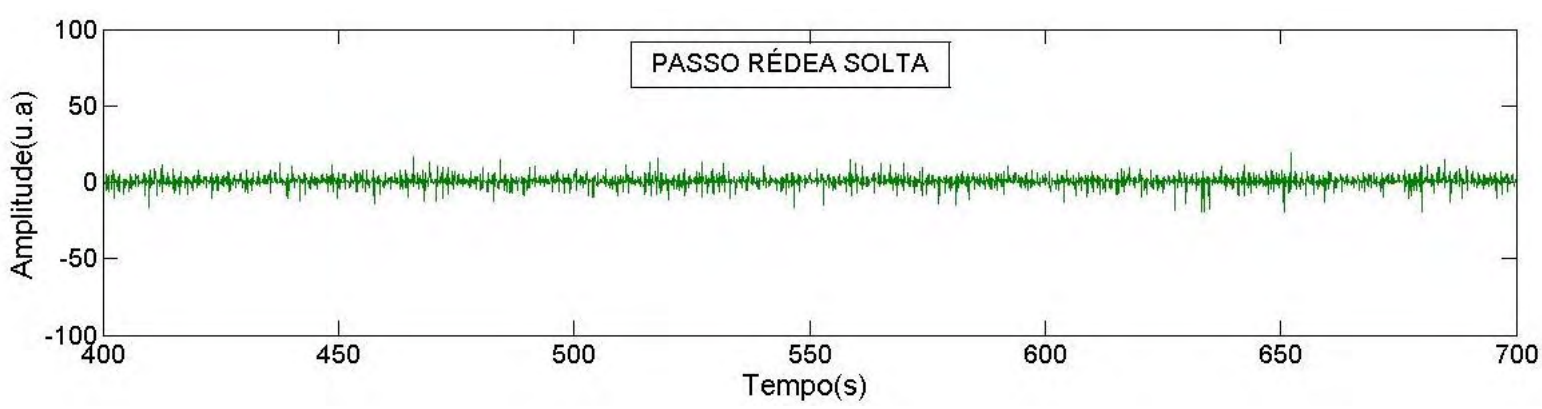

Fonte: Própria autoria 
$\mathrm{Na}$ DMCP do salto do cavalo 1 obtido dos 3 eixos $\mathrm{X}, \mathrm{Y}, \mathrm{Z}$ no treino podem ser visualizados na (Figura 29), (Figura 30), (Figura 31).

Figura 29 - Padrão salto eixo- $X$

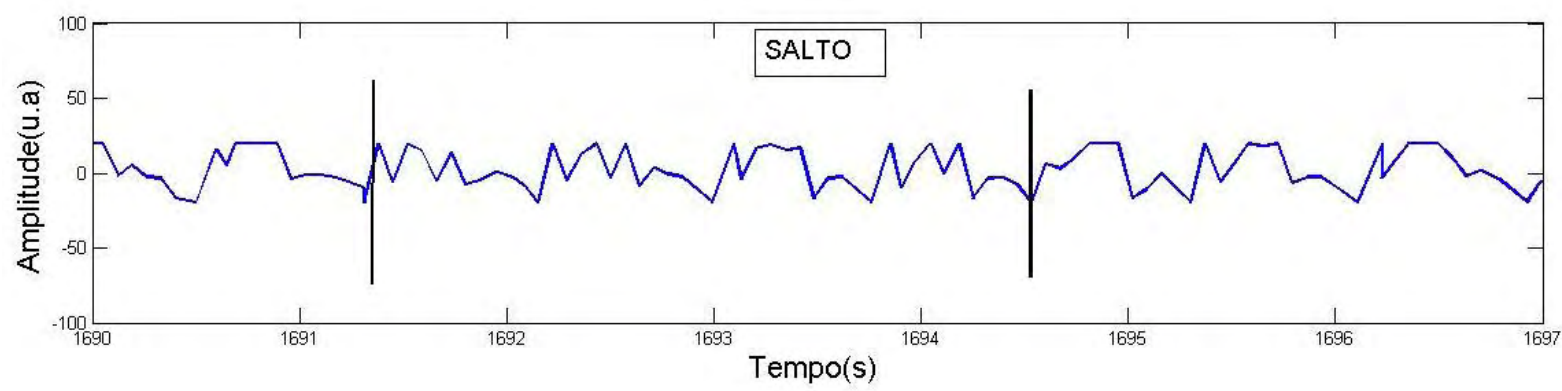

Fonte: Própria autoria

Figura 30 - Padrão salto eixo- $Y$

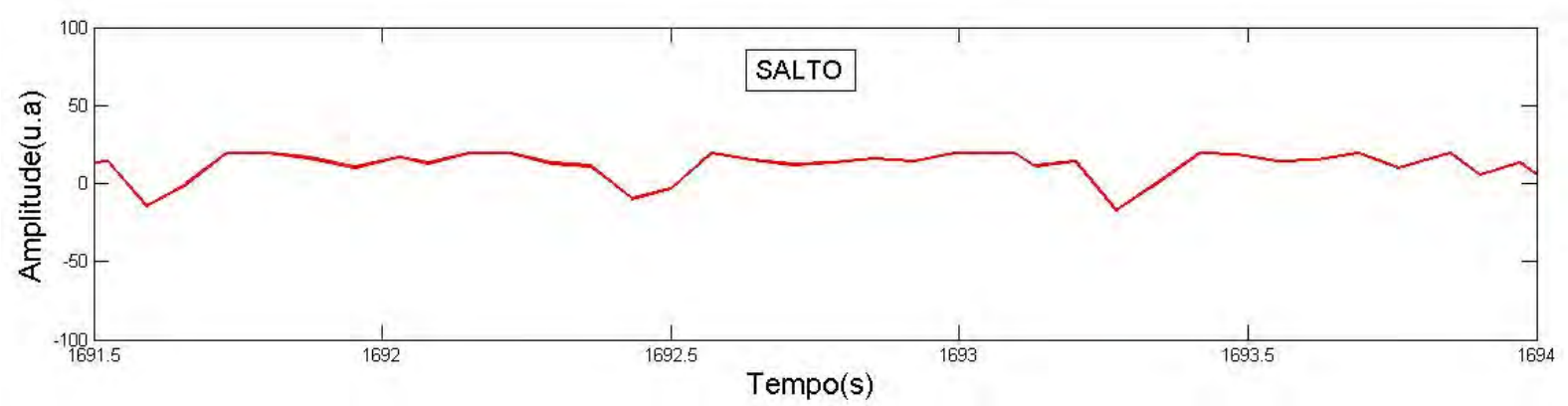

Fonte: Própria autoria

Figura 31 - Padrão salto eixo- Z

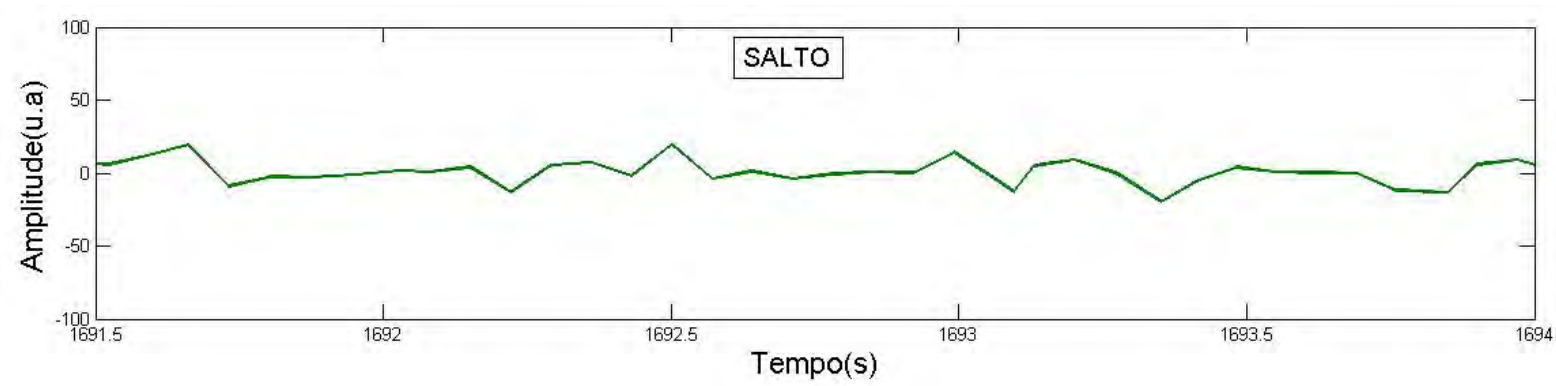

Fonte: Própria autoria 
Na DMCP de rolar obtido dos 3 eixos $X, Y, Z$ do acelerômetro do cavalo 3 no pasto podem ser visualizados na (Figura 32), (Figura 33), (Figura 34).

Figura 32 - Padrão rolando eixo- X

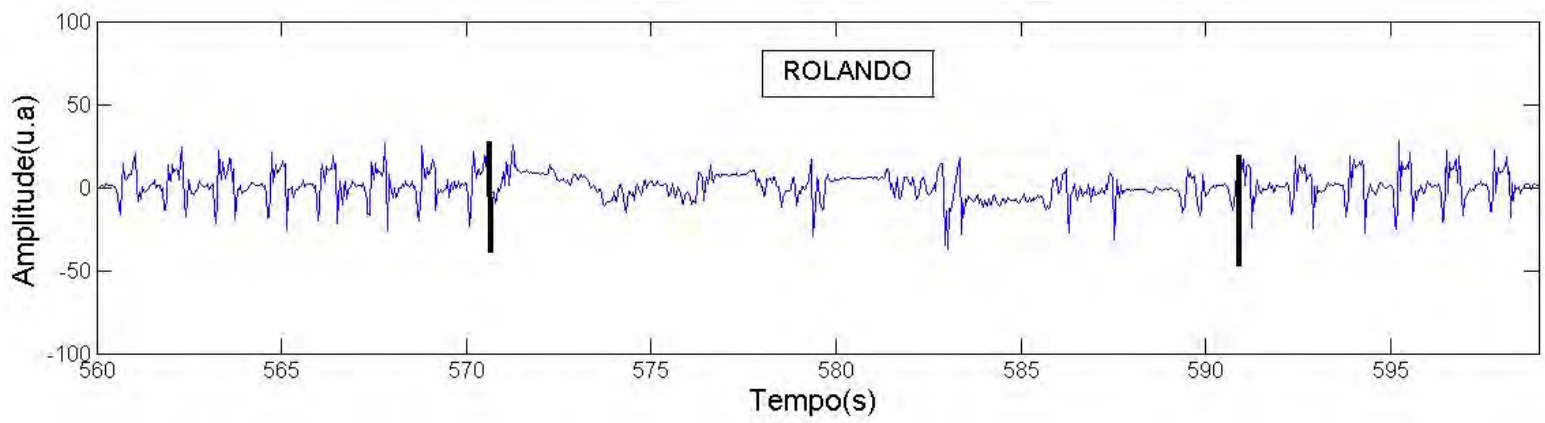

Fonte: Própria autoria

Figura 33 - Padrão rolando eixo- $Y$

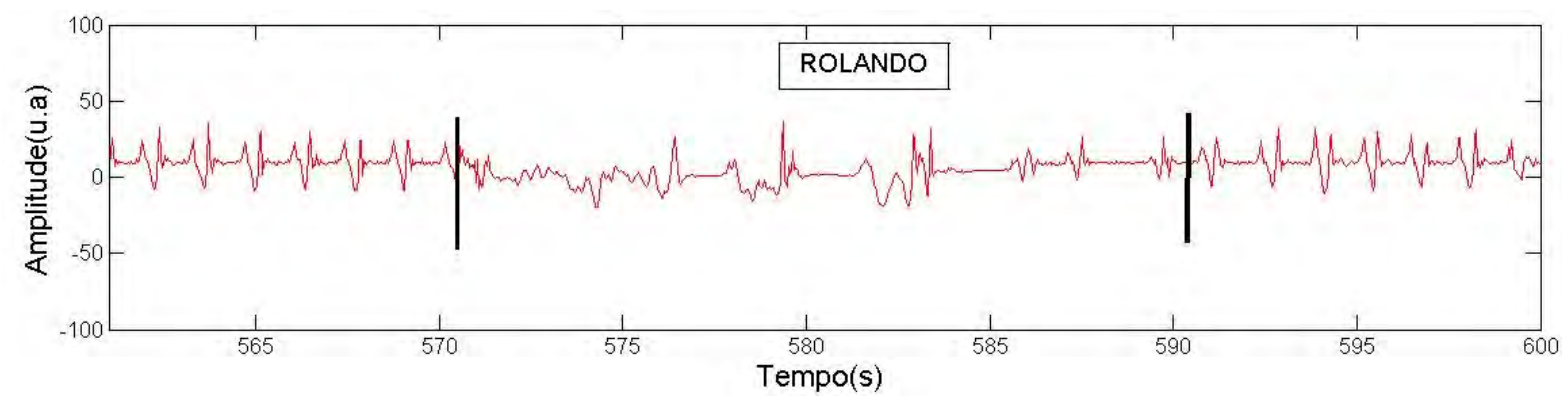

Fonte: Própria autoria

Figura 34 - Padrão rolando eixo- Z

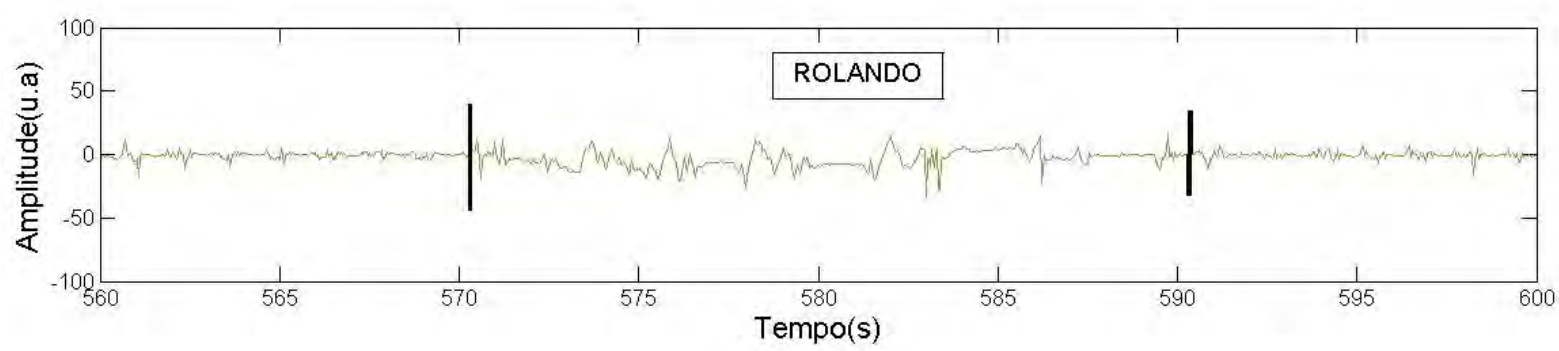

Fonte: Própria autoria 
$\mathrm{Na}$ DMCP de bater o MAD na barriga do acelerômetro nos 3 eixos $\mathrm{X}, \mathrm{Y}, \mathrm{Z}$ do cavalo 2 na baia são visualizadas nas (Figura 35), (Figura 36), (Figura 37).

Figura 35 - Padrão trote eixo- X

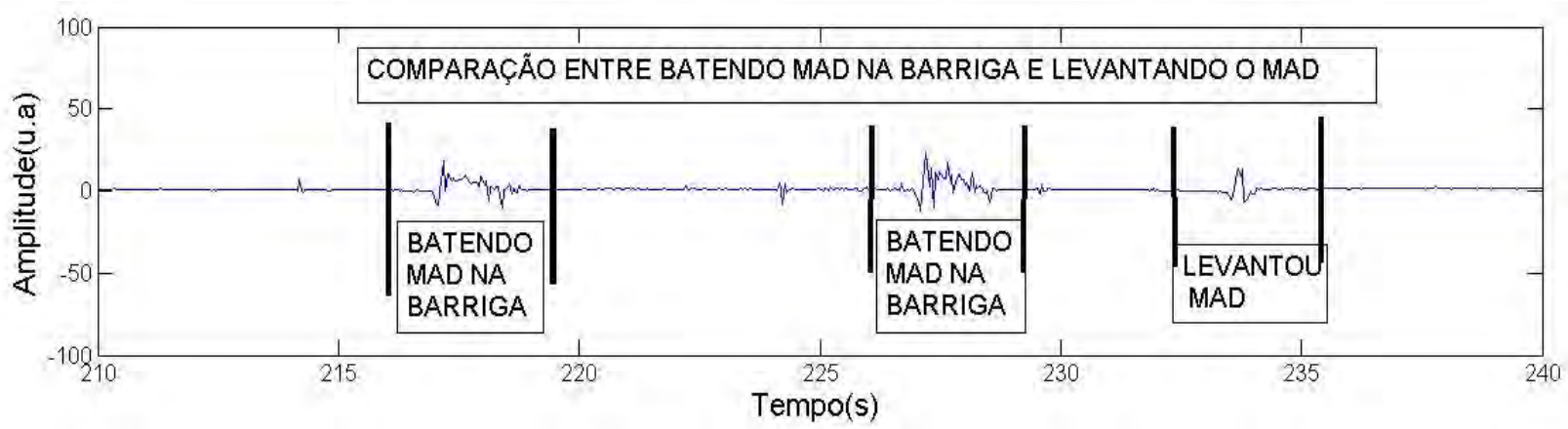

Fonte: Própria autoria

Figura 36 - Padrão trote eixo- $Y$

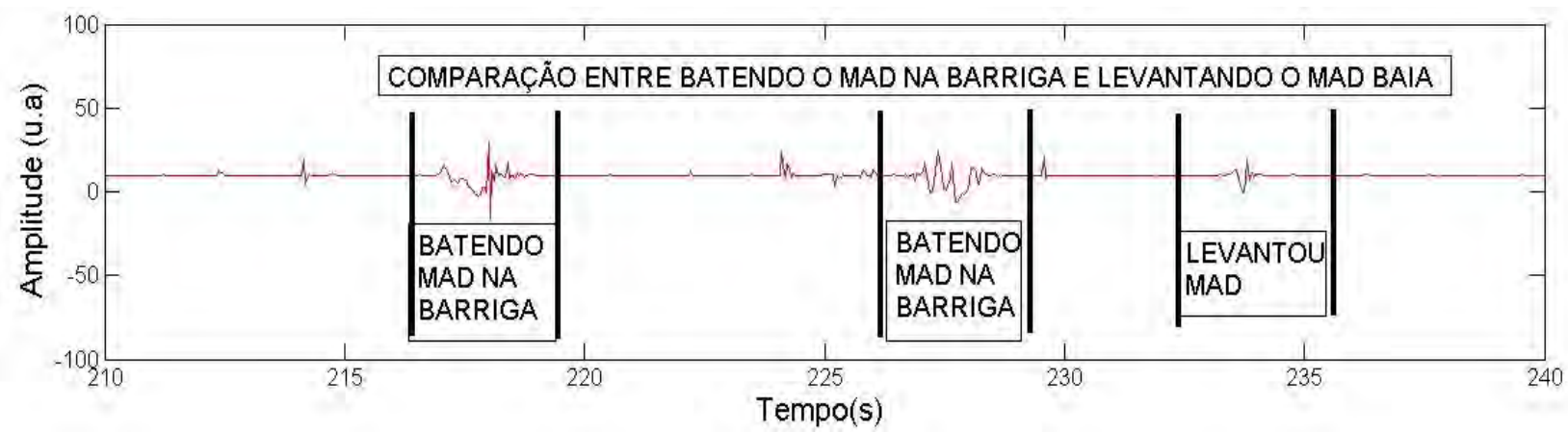

Fonte: Própria autoria

Figura 37 - Padrão trote eixo- Z

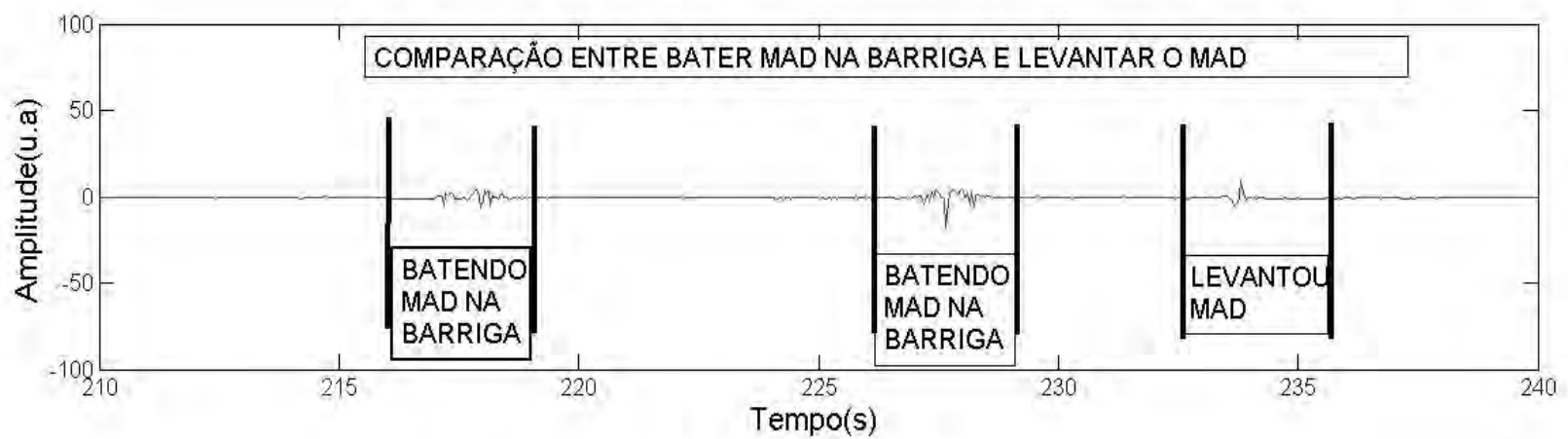

Fonte: Própria autoria 
Os gráficos obtidos na DMCP na filmagem do cavalo 1 no domínio do tempo mostram que o comportamento temporal da saída do sensor tem uma correlação visual com o movimento do cavalo, considerando a evolução da amplitude no tempo. Cada movimento tem um padrão diferente que não dá para ser analisado perfeitamente no domínio do tempo, por conter ruídos e componentes aleatórios, desta maneira os gráficos foram analisados no domínio da frequência

A Figura 38 ilustra a densidade espectral de potência, que é a energia contida em cada faixa de frequência, dos movimentos do cavalo 1: passo rédeas livre, passo controlado, retidão, trote curto, trote alongado e galope respectivamente ao longo do eixo X do acelerômetro.

Figura 38 - Densidade espectral de potência dos sinais no eixo X: A) passo rédeas livres; $B$ ) passo controlado; C) retidão; D) trote curto; E) trote alongado; F) Galope
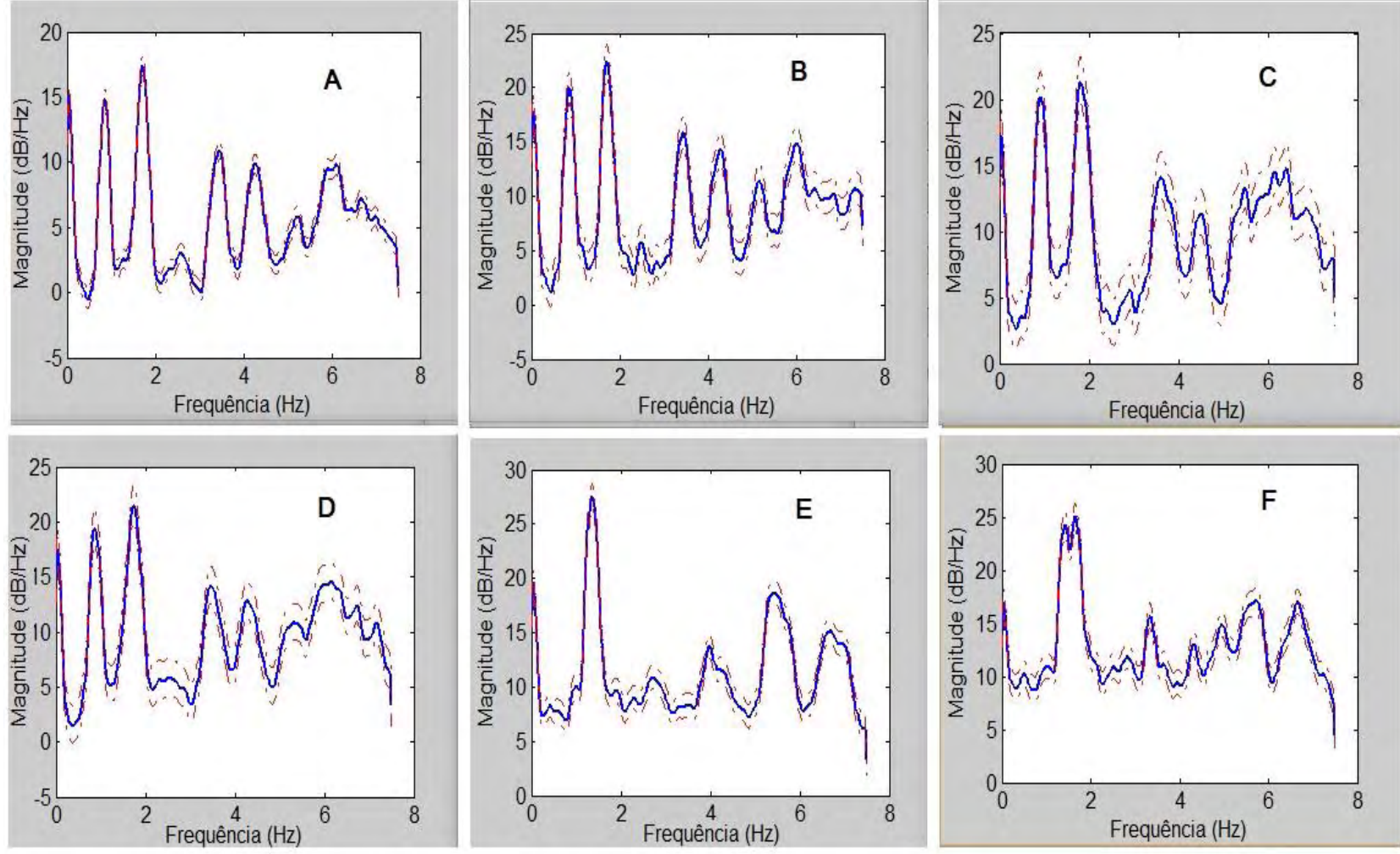

Fonte Própria autoria 
A Figura 39,40 mostram o espectro de potência dos movimentos do cavalo 1: para os eixos $\mathrm{Y}$ e $\mathrm{Z}$ respectivamente.

Figura 39 - Densidade espectral de potência dos sinais no eixo Y: A) passo rédeas livres; B) passo controlado; C) retidão; D) trote curto; E) trote alongado; F) Galope
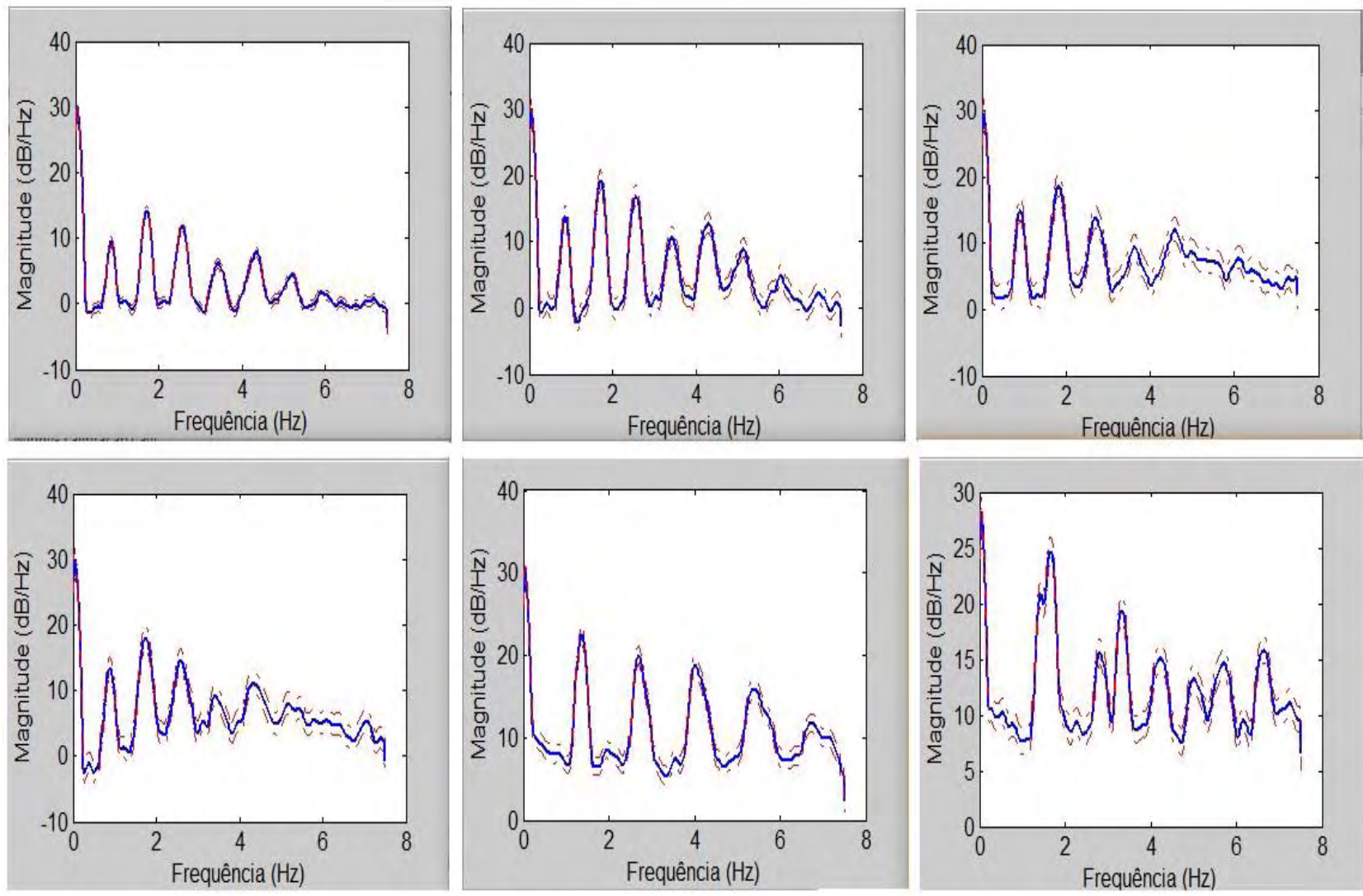

Fonte: Própria autoria 
Figura 40 - Densidade espectral de potência dos sinais no eixo $Z$ dos movimentos do cavalo $1::$ A) passo rédeas livres; B) passo controlado; C) retidão; D) trote curto; E) trote alongado; F) Galope
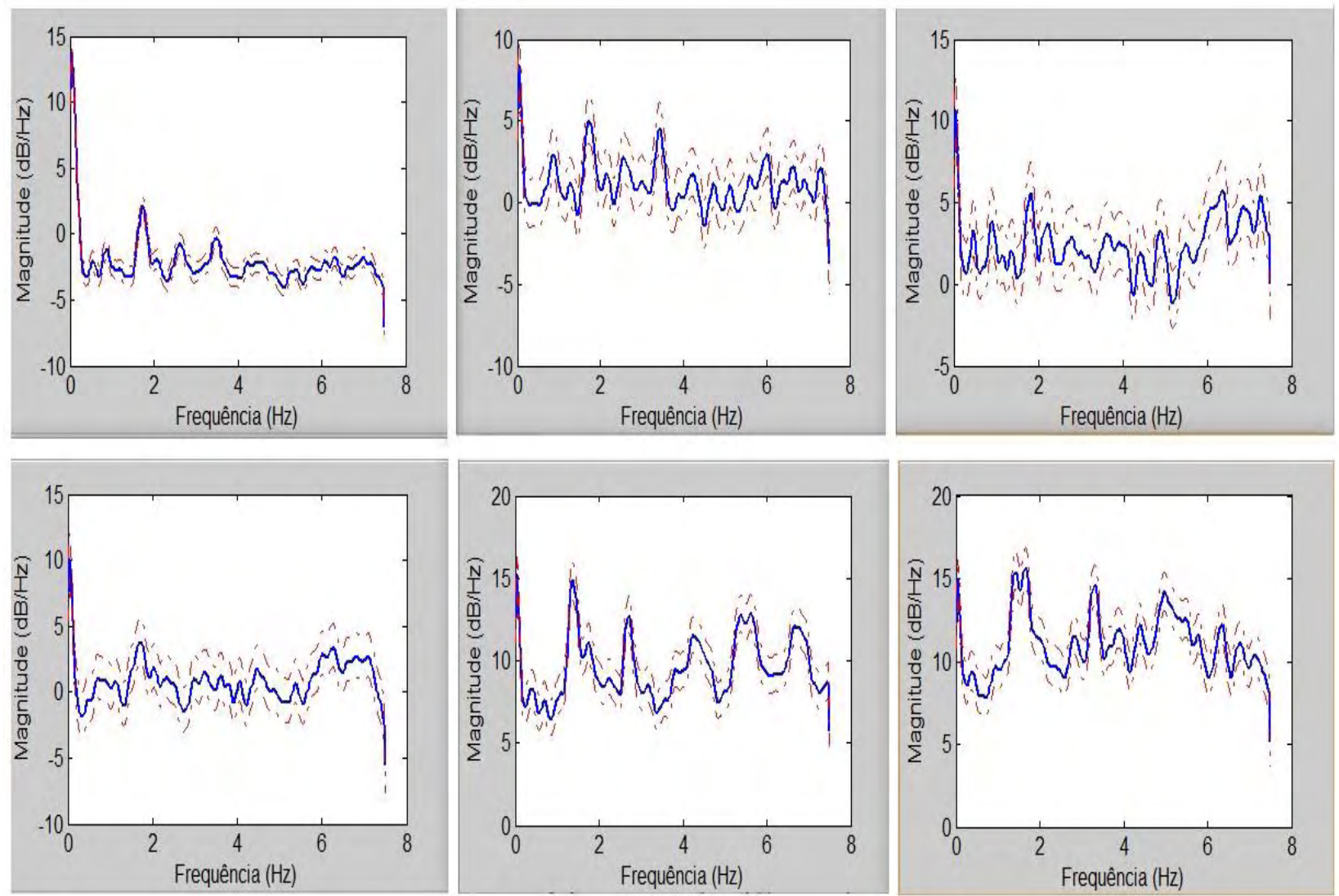

Fonte: Própria autoria 


\subsection{Dados do cavalo 2}

DMCP do $\mathrm{C} 2$ na baia mostrando os 3 eixos $\mathrm{X}, \mathrm{Y}, \mathrm{Z}$ do acelerômetro na (Figura 41), (Figura 42), (Figura 43).

Figura 41 - DMCP cavalo 2 na baia e no pasto eixo- $X$

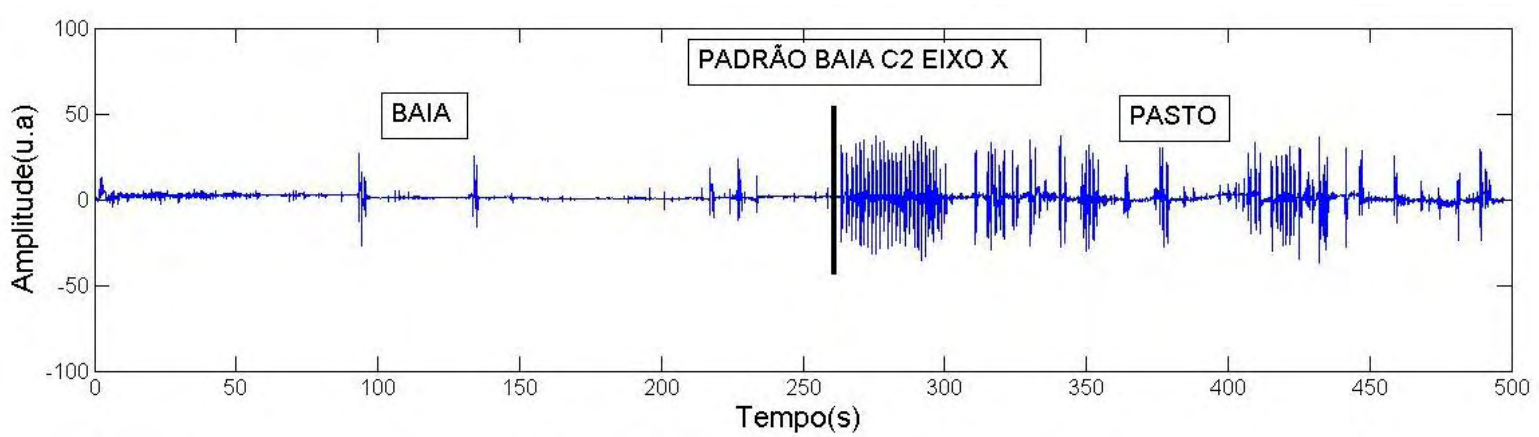

Fonte: Própria autoria

Figura 42 - DMCP cavalo 2 na baia e no pasto eixo- $Y$

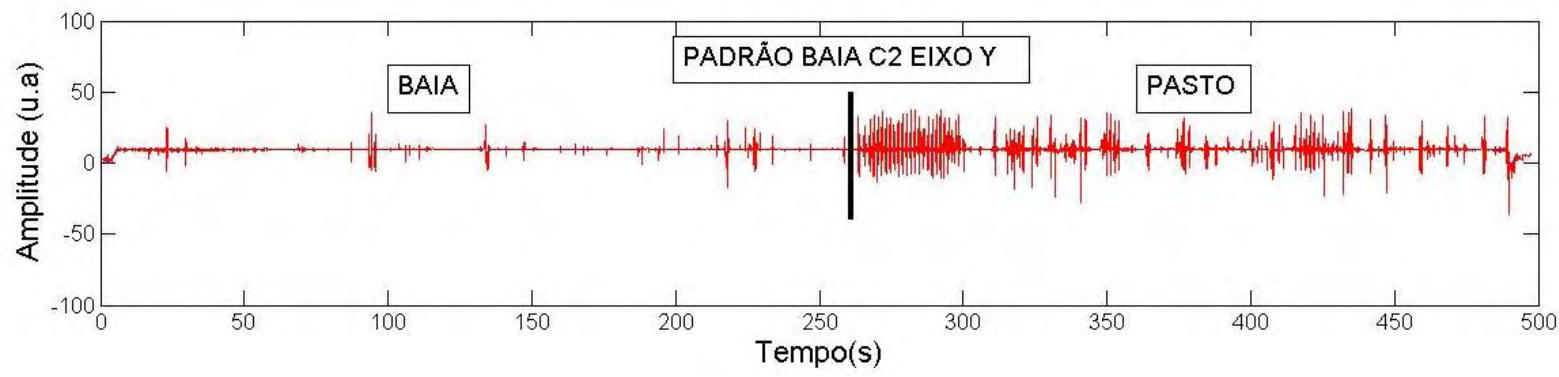

Fonte: Própria autoria

Figura 43 - DMCP cavalo 2 na baia e no pasto eixo- $Z$

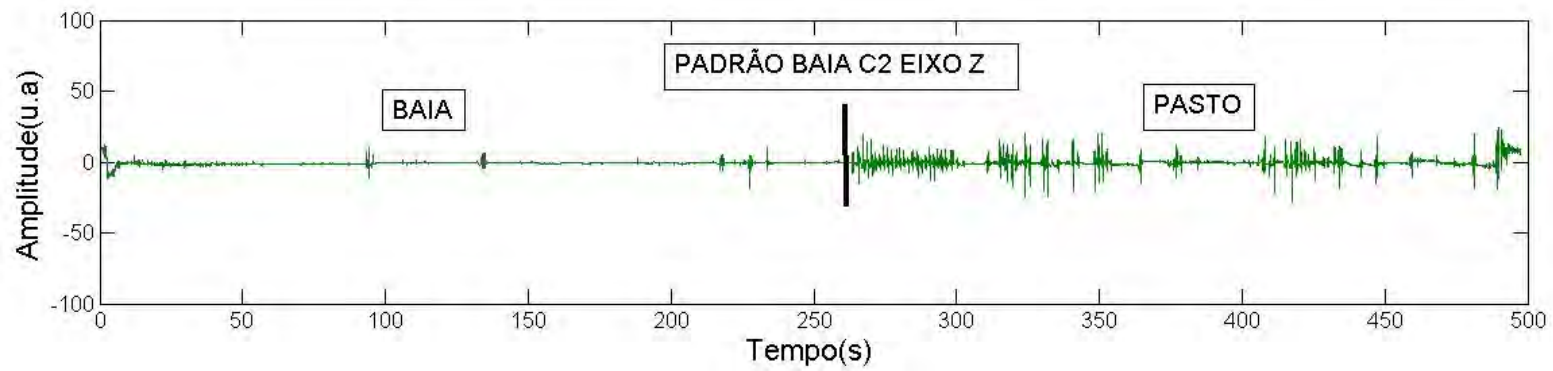

Fonte: Própria autoria 
DMCP do cavalo 2 na baia mostrando os 3 eixos $X, Y, Z$ do acelerômetro ao passo, na (Figura 44), (Figura 45), (Figura 46).

Figura 44 - Padrão passo na baia eixo- $X$

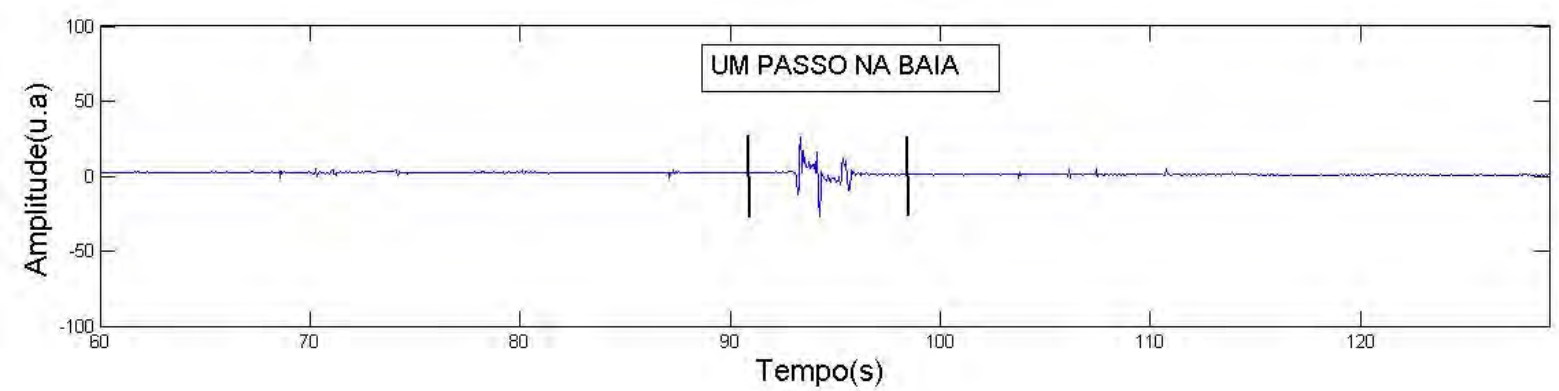

Fonte: Própria autoria

Figura 45 - Padrão passo na baia eixo- $Y$

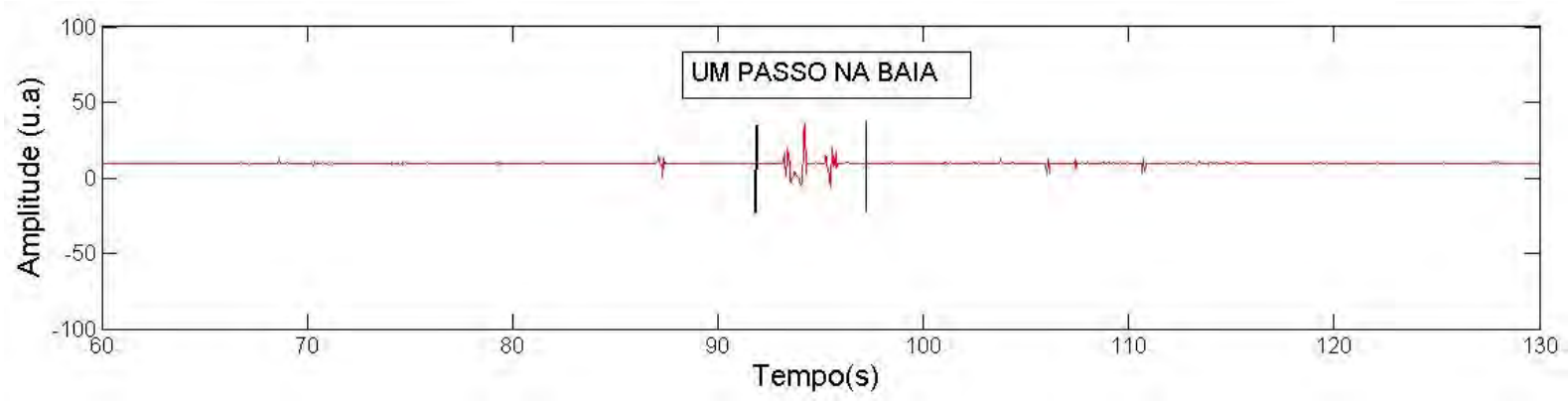

Fonte: Própria autoria

Figura 46 - Padrão passo na baia eixo- Z

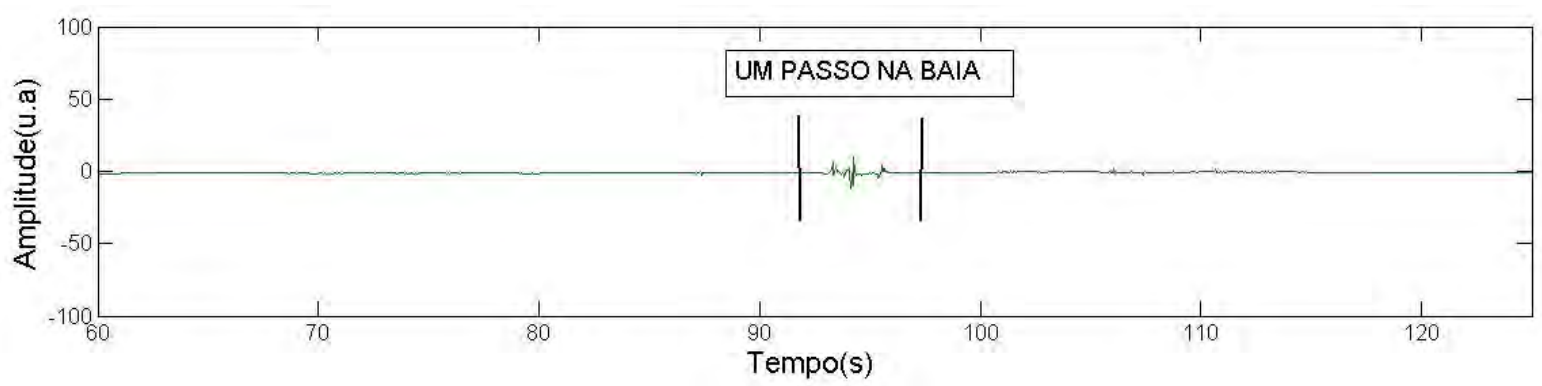

Fonte: Própria autoria 
DMCP do cavalo 2 na baia mostrando os 3 eixos $X, Y, Z$ do acelerômetro batendo o MAD na barriga, na (Figura 47), (Figura 48), (Figura 49).

Figura 47 - Padrão bater MAD na barriga dentro da baia eixo- $X$

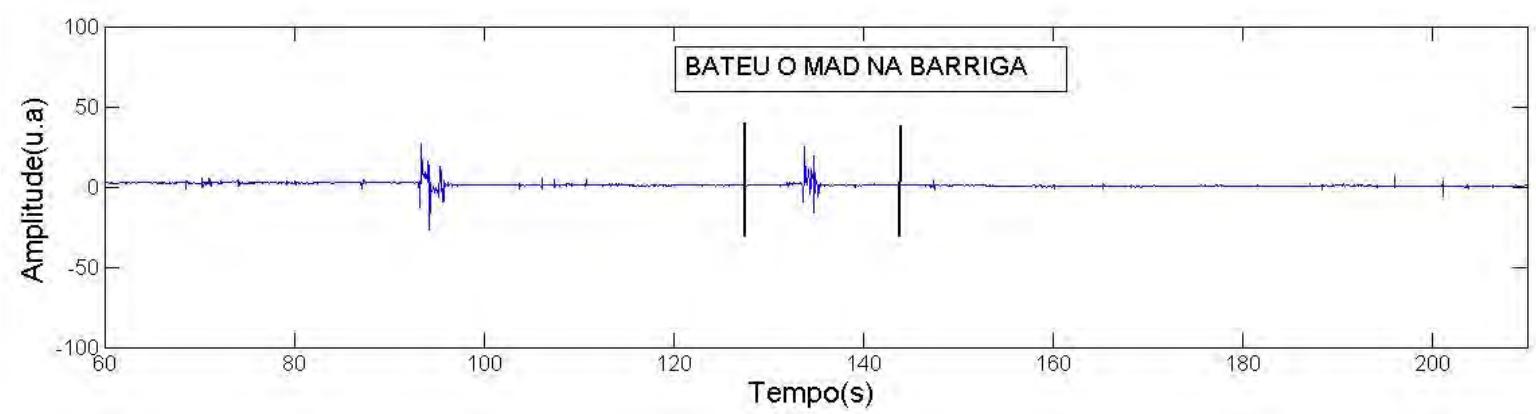

Fonte: Própria autoria

Figura 48 - Padrão bater MAD na barriga dentro da baia eixo- $Y$

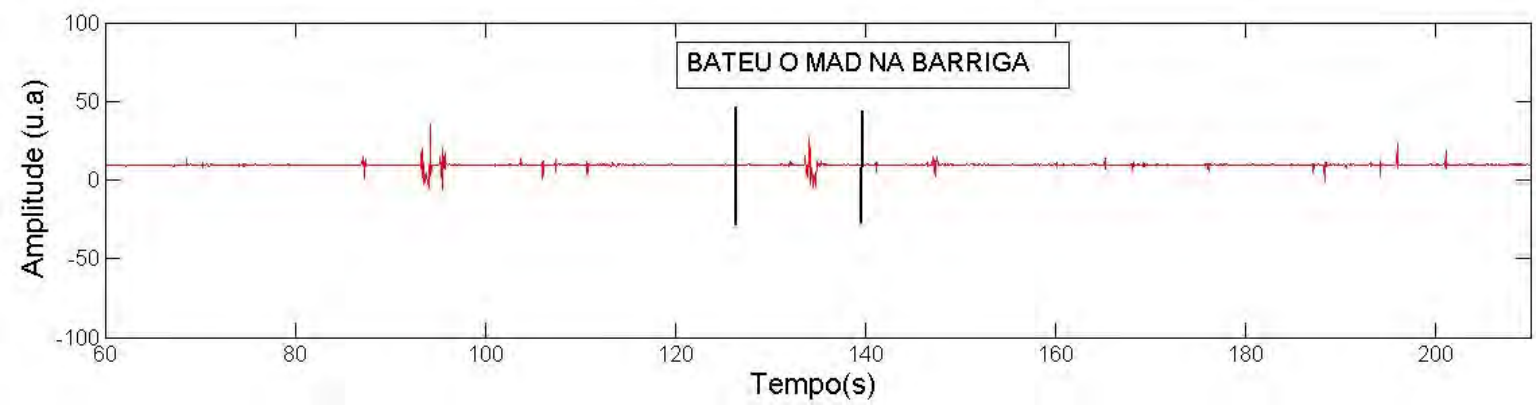

Fonte: Própria autoria

Figura 49 - Padrão bater MAD na barriga dentro da baia eixo- Z

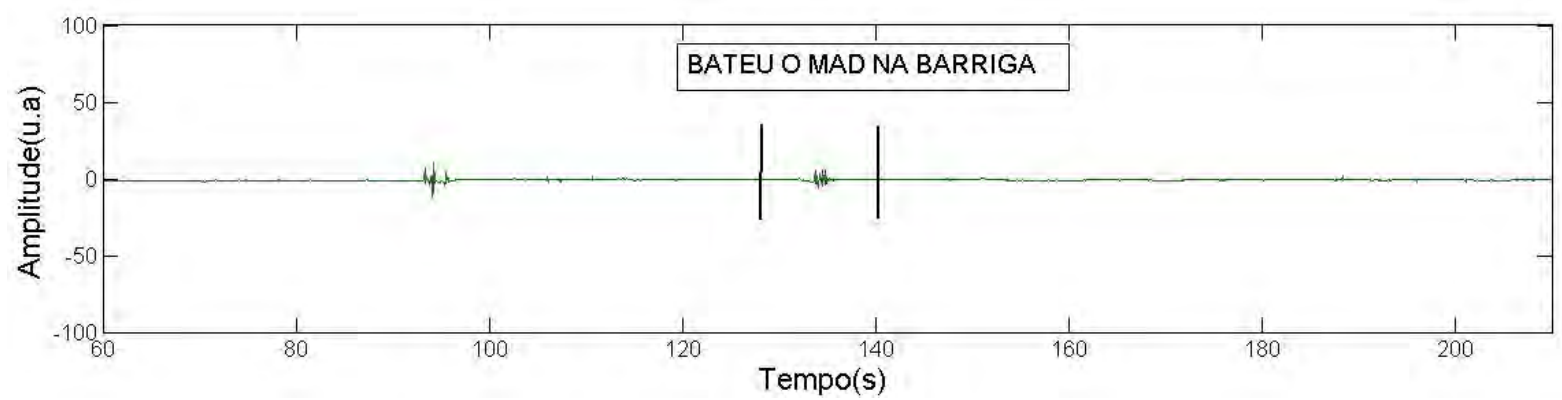

Fonte: Própria autoria 
DMCP do cavalo 2 na baia mostrando os 3 eixos $X, Y, Z$ do acelerômetro batendo o MAD na barriga e levantando o MAD, na (Figura 50), (Figura 51), (Figura $52)$.

Figura 50 - Comparando bater o MAD na barriga e levantar o MAD eixo- X

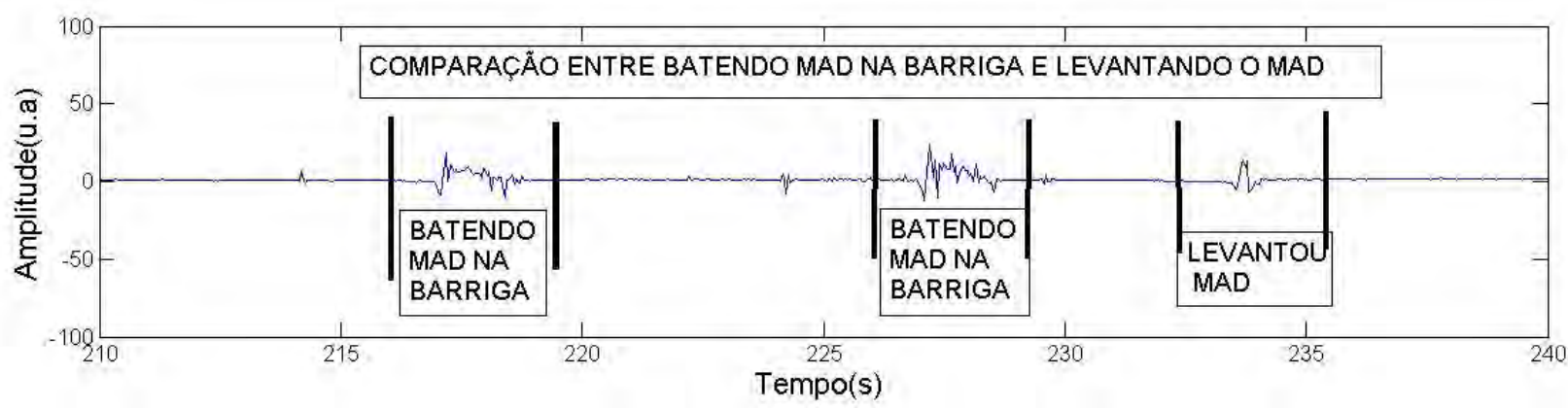

Fonte: Própria autoria

Figura 51 - Comparando bater o MAD na barriga e levantar o MAD eixo- $Y$

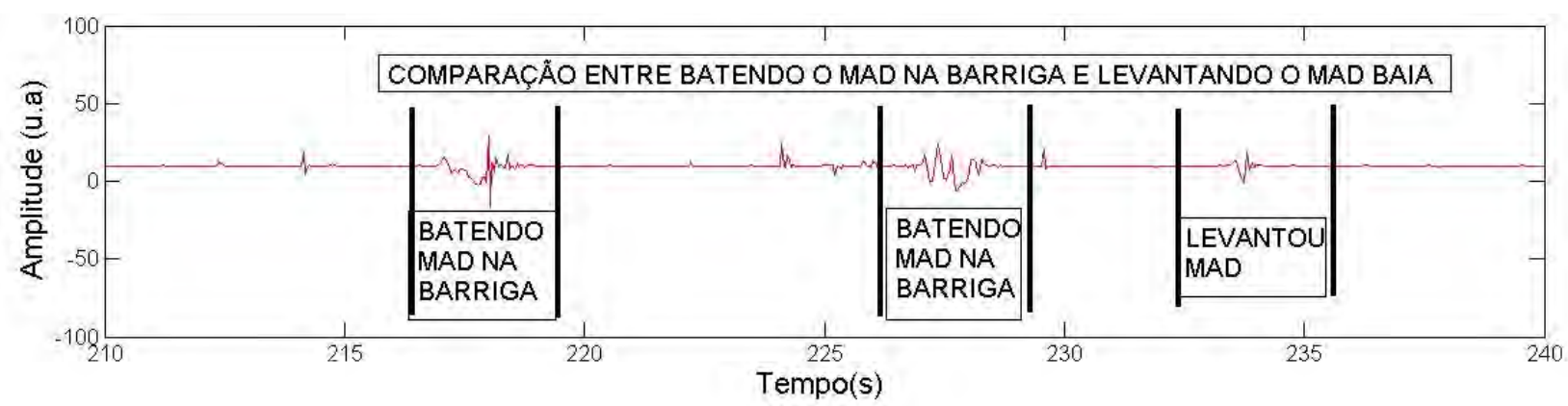

Fonte: Própria autoria

Figura 52 - Comparando bater o MAD na barriga e levantar o MAD eixo- Z

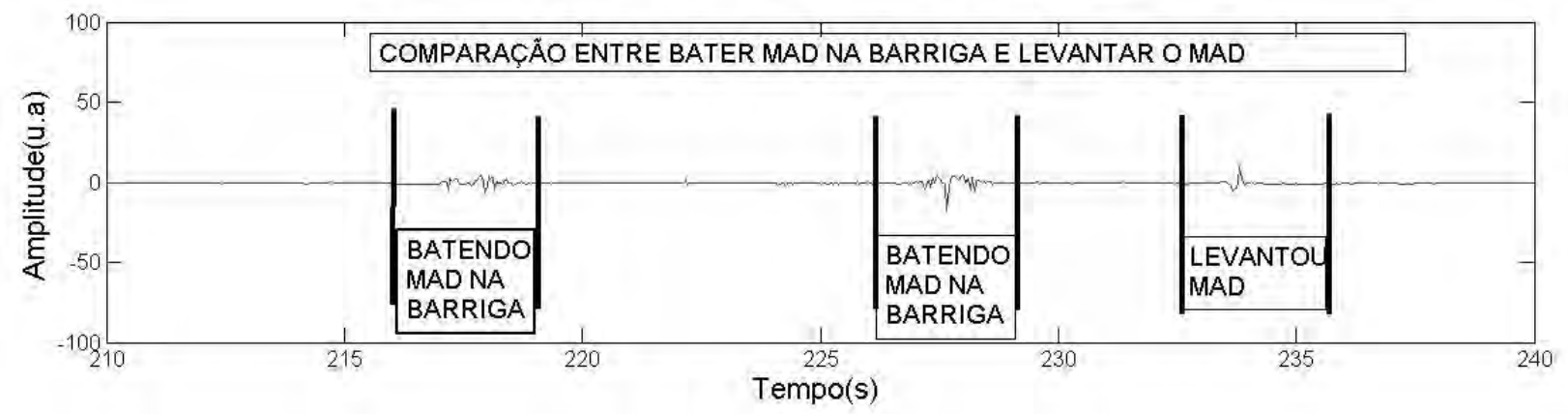

Fonte: Própria autoria 
DMCP do cavalo 2 na baia mostrando os 3 eixos $X, Y, Z$ do acelerômetro no passo com cabresto indo para o pasto, na (Figura 53), (Figura 54), (Figura 55).

Figura 53 - Padrão passo com cabresto indo para o pasto eixo- $X$

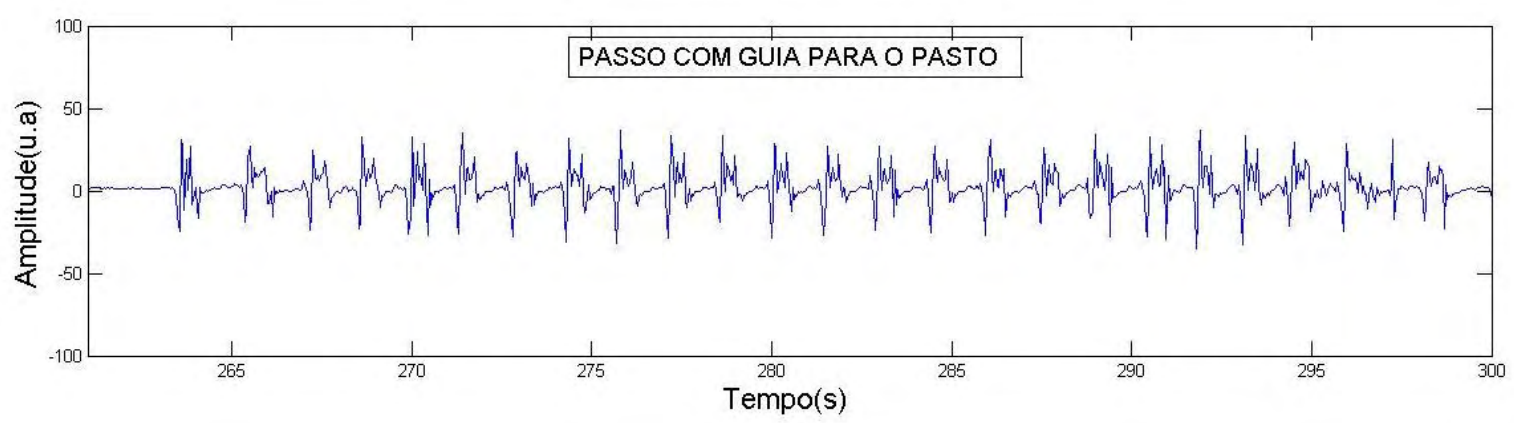

Fonte: Própria autoria

Figura 54 - Padrão passo no cabresto indo para o pasto eixo- $Y$

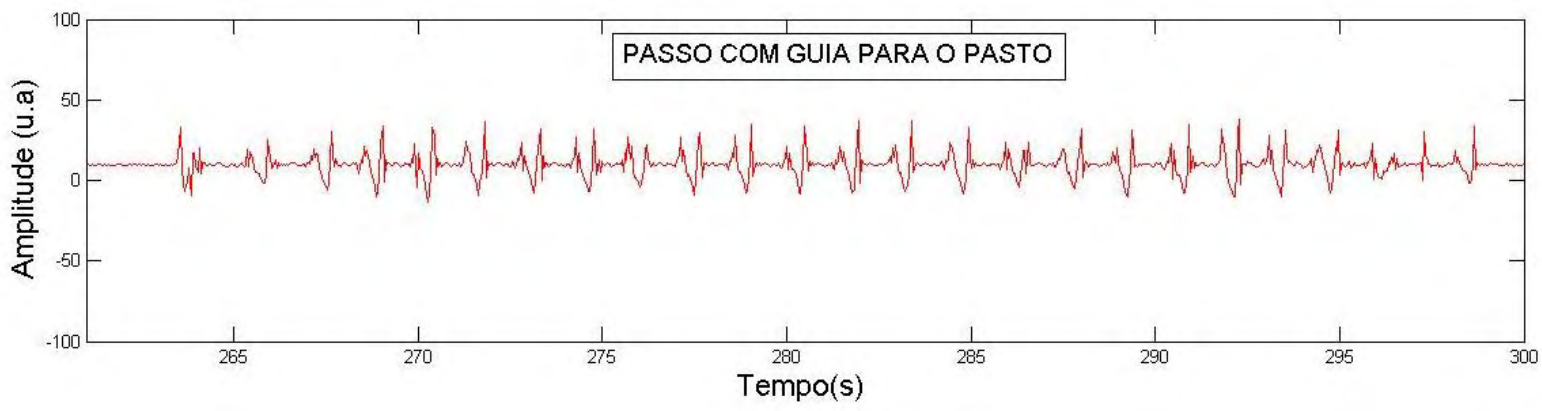

Fonte: Própria autoria

Figura 55 - Padrão passo no cabresto indo para o pasto eixo- Z

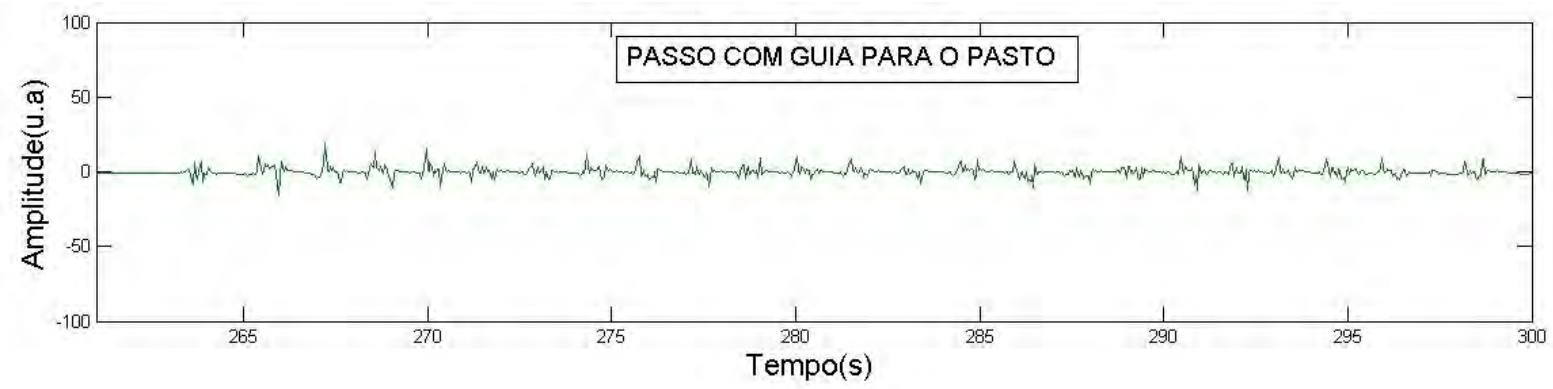

Fonte: Própria autoria 


\subsection{Dados do cavalo 3}

Na DMCP de rolar obtido dos 3 eixos $X, Y, Z$ do cavalo 3 no pasto podem ser visualizados na (Figura 56), (Figura 57), (Figura 58).

Figura 56 - Padrão rolando eixo- X

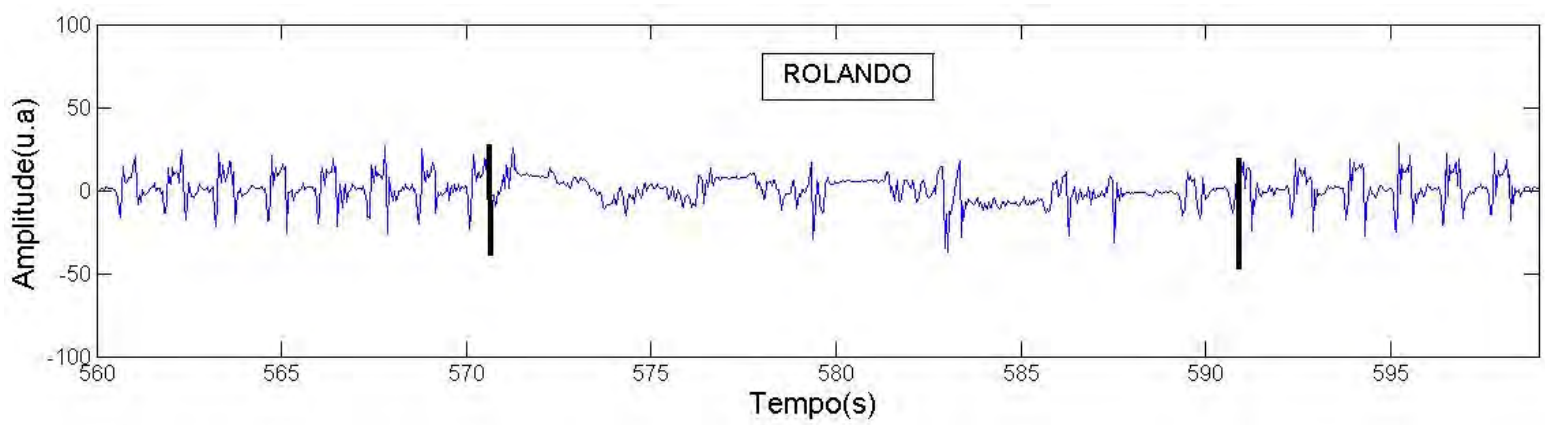

Fonte: Própria autoria

Figura 57 - Padrão rolando eixo- Y

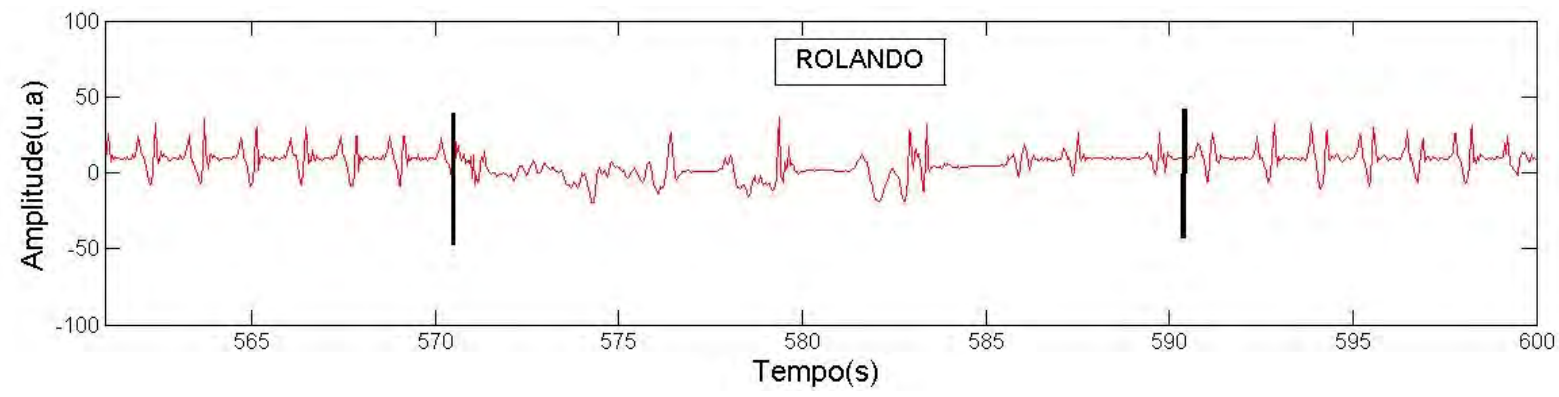

Fonte: Própria autoria

Figura 58 - Padrão rolando eixo- Z

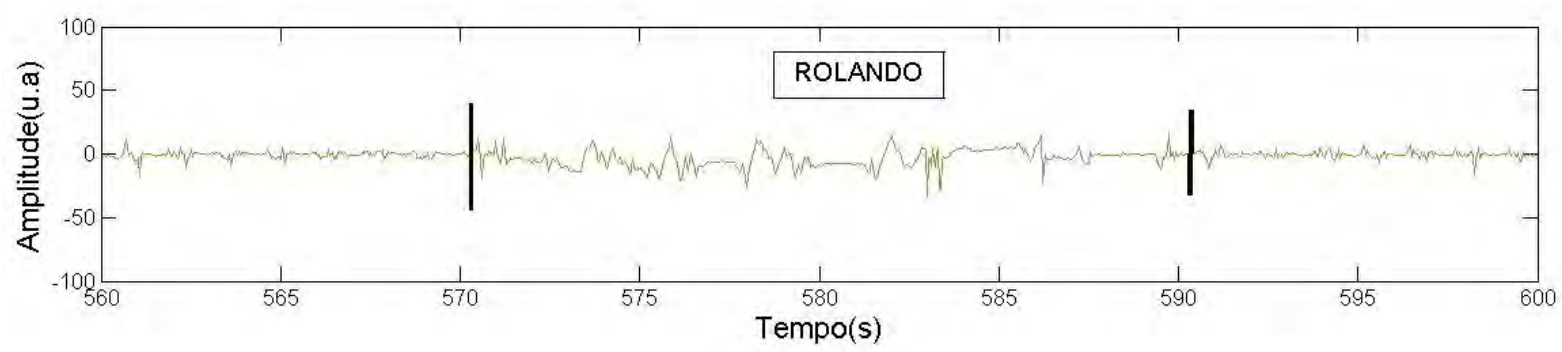

Fonte: Própria autoria 
$\mathrm{Na}$ DMCP de andar ao passo obtido dos 3 eixos $\mathrm{X}, \mathrm{Y}, \mathrm{Z}$ do cavalo 3 no pasto podem ser visualizados na (Figura 59), (Figura 60), (Figura 61).

Figura 59 - Padrão passo no pasto eixo- X

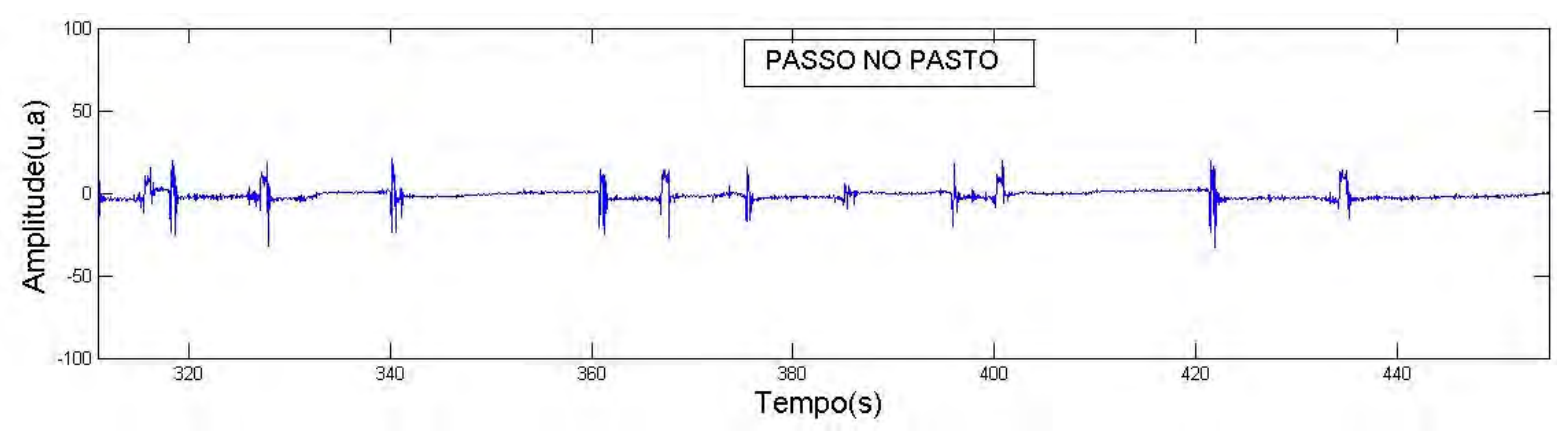

Fonte: Própria autoria

Figura 60 - Padrão passo no pasto eixo- $Y$

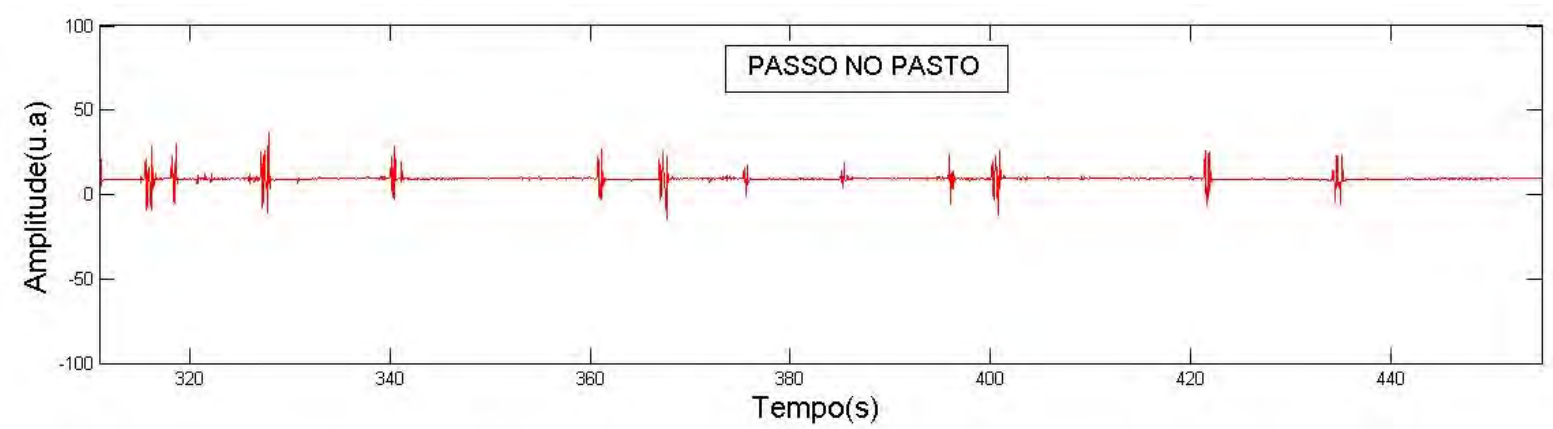

Fonte: Própria autoria

Figura 61 - Padrão passo no pasto eixo- Z

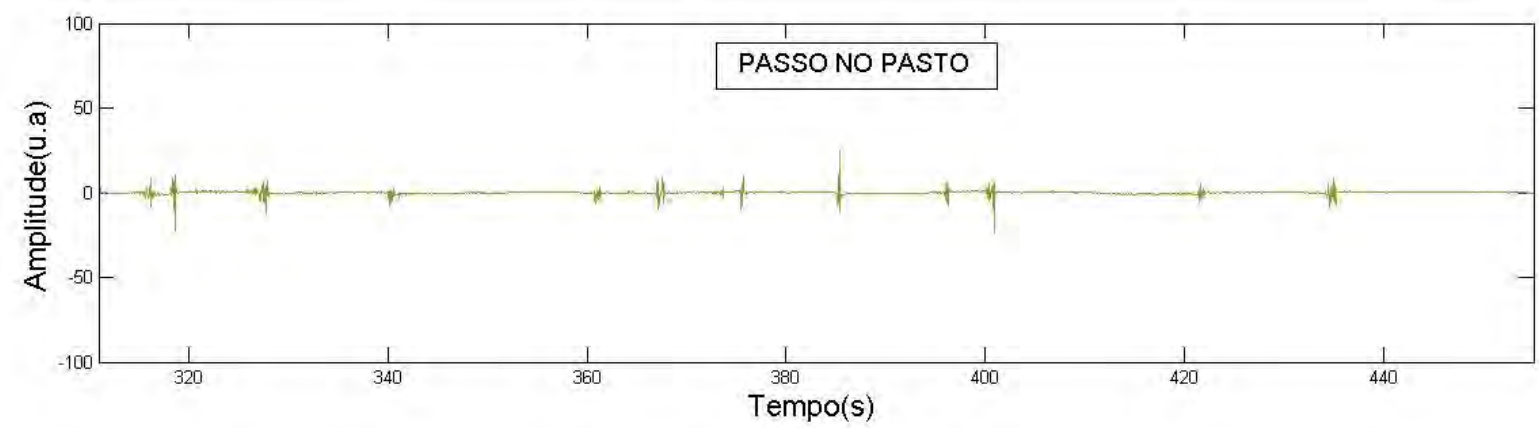

Fonte: Própria autoria

Demais figuras utilizados estão disponíveis no Apêndice B. 


\section{Discussão}

Apesar do aumento do poder de processamento computacional dos dispositivos móveis, é notável a ausência tanto na literatura técnica quanto no setor comercial do uso destes dispositivos, no processamento e análise de sinais cinéticos em equinos, tal qual foi realizada nesta dissertação, principalmente tendo-se em conta a existência de aplicativos para monitorar montarias e fichas de anamnese, ou ainda para acompanhamento da saúde do animal, mas nenhum avaliou os padrões dos movimentos cinéticos.

Foram testados três tipos de equipamentos móveis, porém optou-se pelo que apresentou o menor custo e tamanho (APÊNDICE A), já que o sistema operacional dos aparelhos era o mesmo, ou seja, o sistema Android e o sensor cinético neles instalados possuíam a mesma especificação técnica.

Todos os resultados apresentados (ver também APÊNDICE B) mostraram que o comportamento temporal da saída do sensor apresenta uma correlação visual com o movimento sendo executado pelo animal, considerando a evolução da amplitude no tempo. Nota-se, como exemplo na Figura 46D e 46F, que representa o trote curto e galope respectivamente, uma diferença na amplitude. Já no domínio da frequência, nota-se nitidamente que os movimentos possuem uma distribuição dos picos de frequência distintos para cada tipo de movimento. Sendo assim, tanto no domínio da frequência quanto no domínio do tempo e nos três eixos medidos, existe uma correlação entre o movimento e o sinal do acelerômetro.

Com relação aos eixos ( $\mathrm{X}, \mathrm{Y}$ e $\mathrm{Z}$ ) nota-se que em alguns movimentos a diferença no padrão temporal e espectral se manifestam de forma diferente, por exemplo, o movimento passo livre e retidão apresenta um comportamento temporal e frequência muito similares no eixo $\mathrm{X}$ e $\mathrm{Y}$, porém é completamente distinguíveis no eixo Z. Este fato se deve à complexidade do movimento espacial do animal, corroborando inclusive com resultados da literatura (BUCHNER, OBERMÜLLER e SCHEIDL, 2000) e demonstra que todas as componentes do espaço são importantes no movimento.

Outro aspecto importante é a forma com que os picos de frequência ocorrem. Nota-se que nos espectros de potência dos movimentos principais, o galope 
apresenta um pico duplo, que ocorre em todas as direções do movimento. Isso permite a suposição de que, no galope, o movimento espacial do animal é mais equilibrado nos três eixos. Esta informação é importante pois, poderá ser usada como uma forma de medir a estabilidade espacial do animal quando o mesmo está se deslocando à galope podendo, por exemplo, servir de base para auxiliar em treinamentos ou avaliação de animais.

Os movimentos no espaço dos animais, representados tanto no domínio do tempo com no domínio da frequência, pressupõe um padrão. Desta forma, estes resultados permitem a suposição do uso da tecnologia aqui explorada, como um sistema de monitoramento cinético do comportamento do animal, o que poderá ter aplicações diretas com diagnósticos do estado de saúde do animal, uma vez que seu comportamento cinético está relacionado com seu estado de saúde, conforme mencionado na literatura (ABUTARBUSH, et al., 2005). Os dados da literatura corroboram com os resultados apresentados nesta dissertação com relação ao fato de que o movimento espacial dos animais tem relação direta com seu comportamento dinâmico (OLSEN, 2013). Este fato permite avaliar o pioneirismo desta dissertação, uma vez que tais estudos não mediram o padrão dos movimentos cinéticos, apesar de inferirem sua importância no comportamento do animal (BUCHNER; OBERMÜLLER; SCHEIDL, 2000).

\subsection{Proposição de modelo de análise do movimento cinético padrão}

Os dados obtidos demonstram a existência de um padrão cinético nas componentes $\mathrm{X}, \mathrm{Y}$ e $\mathrm{Z}$ obtidas do sensor e possuem uma relação com o movimento realizado pelo animal. Este fato permite propor uma forma de inferir a relação entre o padrão cinético e outras informações do animal. Desta forma, esta dissertação propõe, baseados nos resultados obtidos, um modelo de análise do padrão cinético para equinos, conforme ilustrado no diagrama de fluxo da (Figura 62).

Este Modelo de análise tem como entrada principal os dados cinéticos vetorizados em forma digital e também informações fisiológicas e ambientais. Estes dados, ao serem processados em uma unidade computacional, irão gerar 
informações no domínio do tempo e no domínio da frequência, contextualizados pelas informações fisiológicas e ambientais.

Esta informação é usada, no modelo proposto, para gerar os padrões identificáveis nos dados e, estes padrões, podem alimentar um sistema de decisão que se procederá, ou baseado em algoritmos inteligentes, ou geridos pelo gestor das informações.

Figura 62 - Diagrama de fluxo ilustrando Modelo de Identificação de padrões cinéticos proposto nesta dissertação.

\section{Modelo de Identificação de padrão} cinético em equinos

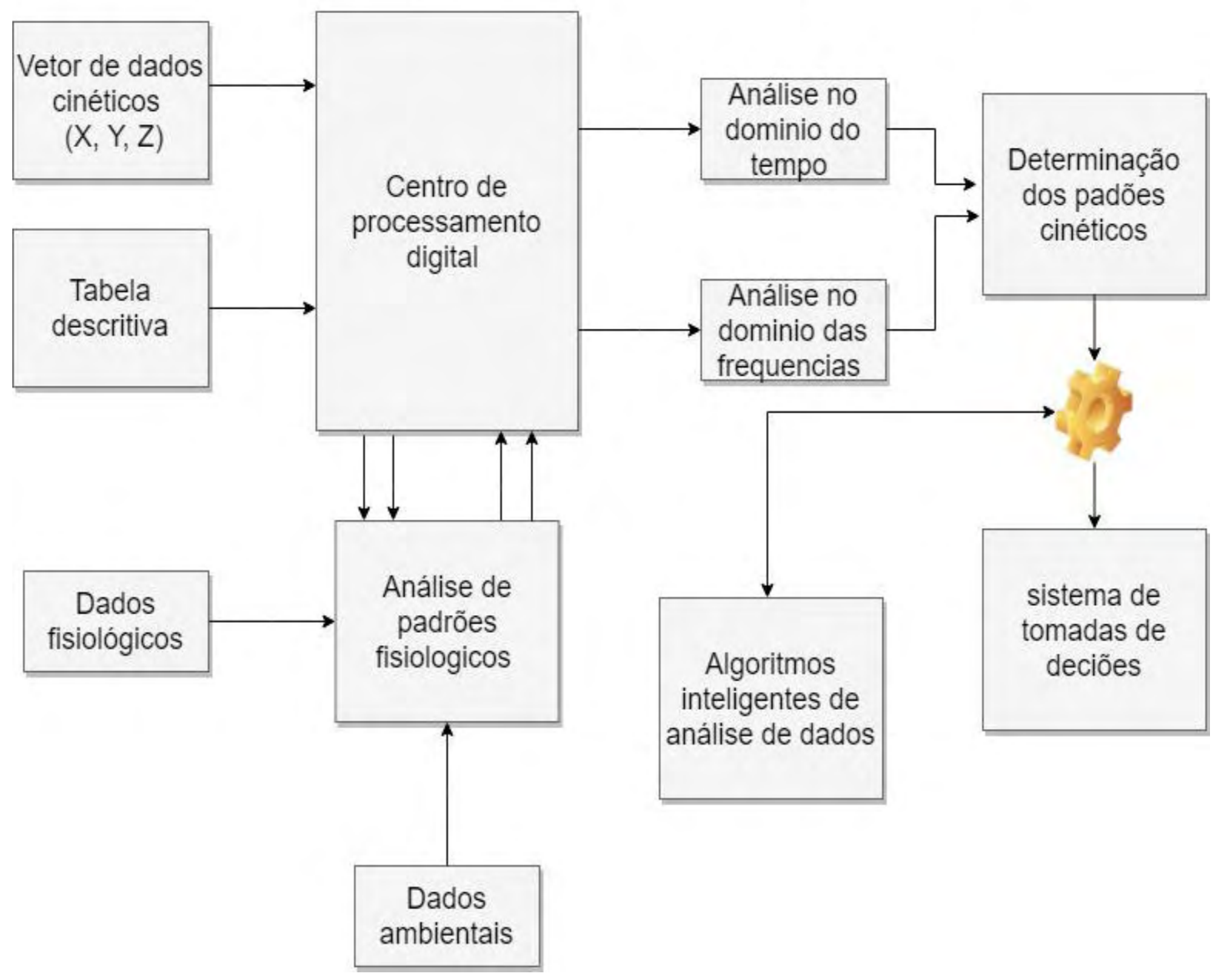

Fonte: Própria autoria 


\section{Conclusão}

Apesar da subjetividade inerente à avaliação de custo, esta dissertação apresenta dados que permitem concluir que é tecnicamente viável o uso de tecnologia móvel para monitorar o comportamento cinético de equinos e inferiu, por meio da comprovação da existência de padrões cinéticos que representam movimentos específicos do equino, sua importância no diagnóstico precoce dos sintomas da síndrome cólica.

Especificamente, mesmo que de forma breve, esta dissertação avaliou três diferentes tipos de dispositivos móveis: Sansung Galaxy S4 Duos GT-19192, LG 10 Novo, Sansung Galaxy S Duo GT-S7582L, para uso em equinos e, neste aspecto, conclui-se que dispositivos de pequeno porte com o sistema Android instalado com aplicativo de acesso ao sensor cinético pode ser usado para a coleta de dados cinéticos.

Foram avaliadas as formas de fixação nos cavalos e concluiu-se que a região da canela é adequada para prender o dispositivo.

Avaliou-se, por fim, a relação dos dados dos sensores com o comportamento cinético do equino, por meio de observação no domínio do tempo e da frequência, e concluiu-se existir padrões específicos para cada tipo de movimento do equino, o que permitiu, inclusive, propor um modelo de avaliação de padrão cinético em equinos. 


\section{REFERÊNCIAS}

ABUTARBUSH, S.M.; CALMART J.L.; SHOEMAKER R.W. Causes of gastrointestinal colic in horses in western Canada: 604 cases (1992 to 2002). Canadian Veterinary Journal, Ottawa, v. 46, n. 9, p. 800-805, 2005.

ASSOCIAÇÃO BRASILEIRA DE ACADEMIAS. ACAD Brasil. Disponível em: <www.acadbrasil.com.br> Acesso em: 20 ago. 2014.

ALBANO, M, M.; ABATTI, P, J.; DECONTO, I. Sistema biotelemétrico adesivo para transmissão sem fio do parâmetro vital eletrocardiograma (ECG). In: CONGRESSO BRASILEIRO DE ENGENHARIA BIOMÉDICA - CBEB, 24, 2014, Uberlândia. Anais... Uberlândia, 2014.

AGÊNCIA NACIONAL DE TELECOMUNICAÇÕES - ANATEL. Disponível em: < http://www.anatel.gov.br/dados/acessos-telefonia-movel> Acesso em: 24 mar. 2019.

ANDRIAMANDROSO, A. L. H. et al. Development of an open-source algorithm based on inertial measurement units (IMU) of a smartphone to detect cattle grass intake and ruminating behaviors. Computers and Electronics in Agriculture, New York, US: Elsevier Science, v. 139, p. 126-137, 2017.

BRADFORD, P. SWITH: Medicina interna de grandes animais: 3. ed. Barueri: Editora Manole, 2006, p 233-237.

BUCHNER, H.H.F.; OBERMÜLLER, S.; SCHEIDL, M. Body Centre of Mass Movement in the Sound Horse. The Veterinary Journal, v. 160, n. 3, p. 225-234, 2000.

CBN.GLOBORADIO. Disponível em: <http://www.globo.com/2015/series/corrida-derua> 21/01/2015 Acesso em: 30 abr. 2017.

CONCEIÇÃO JUNIOR, O. P. et al. Estimação espectral do sinal de vibração para o monitoramento do desgaste do dressador de ponta única. Revista Matéria, Rio de Janeiro, art. 11748, p.827-849, 2016.

DUARTE, F. J. A. Classificação de atividades físicas através do uso do acelerómetro do Smartphone, 2013. 100 p. Dissertação (Mestrado) - Instituto Superior de Engenharia de Lisboa, Portugal, 2013.

FRANCELLINO, O. R. J. et al. Pronto atendimento de síndrome cólica em equinos. MEDVEP: Revista Científica de Medicina Veterinária, Curitiba, ano XIII, n. 25, 2015.

FREITAS, L. O. Uma metodologia para assistir pacientes em ambientes homecare pervasivos. 2011. 90 p. Dissertação (Mestrado) - Santa Maria: UFSM, RS, Brasil, 2011. 
HENSON, M. S; HAYWARD, L. J. The Mathematics of Animal Behavior: An Interdisciplinary Dialogue. Notices of the MAS, Providence, US, v. 57, n. 10, p.12481258, 2010.

GLENN, T.; MONTEITH, S. New Measures of Mental State and Behavior Based on Data Collected from Sensors, Smartphones, and the Internet. Current Psychiatry Reports, Michigan, v. 16, n. 12, 2014.

GONÇALVES, S.; JULLIAND, V.; LEBLOND, A. Risck factors associated with colic in horses. Veterinary Research, Les Ulis, v. 33, n. 6, p. 641-652, 2002

GUIDI, A. et al. Validation of smart textile electrodes for electrocardiogram monitoring in free-moving horses. Journal of Veterinary Behavior: Clinical Applications and Research. Amsterdam, NL: Elsevier North Holland h, v. 17, p. S221-S222, 2017.

HARADA, E. TecMundo ensina: testando o Android Lollipop em seu computador 2014. Disponível em: <http:// www.tecmundo.com.br/androidlollipop/65471-tecmundo-ensina-testando-android-lollipop-computador-tutorial.htm> Acesso em 20 fev. 2018.

INSTITUTO BRASILEIRO DE GEOGRAFIA E ESTATÍSTICA (IBGE). Censo Demográfico e Estatística 2011. Disponível em: <http:// www.brasil.gov.br> Acesso em: 03 out. 2016.

JINGXIA, L; WEIMIN, D. Study and evaluation of plant electrical signal processing method. In: INTERNATIONAL CONGRESS ON IMAGE AND SIGNAL PROCESSING, CISP 2011. 4., 2011, Xangai. Proceedings... Piscataway: IEEE, 2011.

LAHEY JR, R. T. Elements of Boiling Heat Transfer-Modern Development and Advances. System, ed. Elsevier Science Publishers, NY, US. p. 389-445, 1992.

LAU, J. K. et al. IPhone ECG application for community screening to detect silent atrial fibrillation: A novel technology to prevent stroke. International Journal of Cardiology, Amsterdam. v. 165, n. 1, p. 193-194, 2013.

LEMOS, N.D.; GAZZOLA, J.M.; RAMOS, L.R. Caring For The Alzheimer's Patient: the impact of the illness on the caregiver. Saúde e Sociedade, São Paulo, v. 15, n. 3, p. 170-179, 2006.

MALINOSKI, A. Equinocultura merece atenção do agronegócio nacional. 2018. Disponível em: < https://www.expointer.rs.gov.br/equinocultura-merece-atencao-doagronegocio-nacional> Acesso em: 20 out.2018.

MARTINS, E. Como funciona o GPS, 2009. Disponível em: $<$ https://tecmundo.com.br/gps/2562-como-funciona-o-gps-htm> Acesso em: 14 ago. 2017. 
MERSKEY, H., BOGDUK, N. Classification of Chronic Pain. 2. ed. Washington: International Association for the Study of Pain (IASP) Task Force on Taxonomy. IASP Press, Washington. 2. ed., p. 209-214, 1994.

MILLER, T. S. Programmed to Run: Develop elite running/racing biomechanical and mental skills, regardless of age, gender, or body type. US, ed. Create space independent publishing platform (Amazon), p.130, 2013.

MORAES, E. N. DE. Atenção à saúde do idoso. Brasília: Organização PanAmericana da Saúde, v. 1, n. 1, p. 98, 2012.

MORAES, W. Preços de celulares. Disponível em< https://www.tudocelular.com/celulares/fichas-tecnicas.html> Acesso em 15 jun.2018.

MURRAY, M.J.; GUARD, C. Moléstias do Sistema Digestivo. In: SMITH, B.P. Tratado de Medicina Interna de Grandes Animais. Barueri: Manole, 1993. v. 1 p. 627-719.

NATIONAL INSTITUTE OF MENTAL HEALTH, Major Depression Among Adults. Disponível em: <http://www.nimh.nih.gov/health/statistics/prevalence/majordepression-among-adults.shtml> Acesso em: 20 ago. 2015a.

NATIONAL INSTITUTE OF MENTAL HEALTH, Bipolar Disorder Among Adults. Disponível em: <http://www.nimh.nih.gov/health/statistics/prevalence/bipolardisorder-among-adults.shtml> Acesso em: 20 ago. 2015b.

OLSEN, E.; PFAU, T.; RITZ, C. Functional limits of agreement applied as a novel method comparison tool for accuracy and precision of inertial measurement unit derived displacement of the distal limb in horses. Journal of Biomechanics, v.46, n.13, p. 2320-2325, 2013.

ORESKO, J. J. et al. A wearable smartphone-based platform for real-time cardiovascular disease detection via electrocardiogram processing. IEEE Transactions on Information Technology in Biomedicine, Piscataway, NJ, v. 14, n. 3, p. 734-740, 2010.

PAGAN, J. D. et al. Estimating digestible energy requirements of three-day-event horses using KER Clocklt Sport smartphone application: Journal of Equine Veterinary Science, Pittsburgh, v. 52, n. 2017, p. 90, 2017.

PAPPACHAN, K, B.; CAESARENDA, W.; TJAHJOWIDODO, T.; WIJAYA, T. Frequency Domain Analysis of Sensor Data for Event Classification in Real-Time Robot Assisted Deburring: Academic Editor: Xue Wang, Singapura, 2017.

PHILIPE, G. Como funciona o GPS? Disponível em: < https://www.oficinadanet.com.br/post/12406-como-funciona-o-gps> Acesso em: 20 ago. 2017.

PIMENTA, D; WILLIMAR, F; SOUZA, H. Giroscópio: apresentação, Mossoró, Universidade Federal Rural do Semi Árido, 2017. 
POPESKO, P. Atlas de Anatomia Topográfica dos Animais Domésticos. Barueri: Manole, 1998. 616p.

PULEO, J; MILROY, P. Running Anatomy. Barueri: Manole, 2010. p 200.

REED, S.M.; BAYLY, W.M.; SELLON, D.C. Disorders of the Gastrointestinal System. Equine. Internal Medicine, Washington: Elsevier Saunders, p.922- 936. 2004.

ROSS, P. E. Managing through the air: IEEE Spectrum, Piscataway, NJ. Publisher: Institute of Electrical and Electronics Engineers, n. December, p. 26-31, 2004.

SAHA, D.; MUKHERJEE, A. Pervasive computing: A paradigm for the 21st century: Computer, v. 36, n. 3, p. 25-31, 2003.

SCULLY, C. G. et al. Physiological parameter monitoring from optical recordings with a mobile phone. IEEE Transactions on Biomedical Engineering, Piscataway, NJ, v. 59, n. 2, p. 303-306, 2012.

SILVA, A.C.S. Aplicação de técnica de processamento digital de sinais na caracterização de sinais cerebrais de bovinos. Dissertação Mestrado: FZEA/USP, 2005.

SITE BRASILEIRO DE TELEFONIA: Disponível em:

$<$ https://www.tudocelular.com/compare/3668-3805-3636.html>. Acesso em: 01 fev. 2018.

SMITH, W.S. Digital Signal Processing, A Practical Guide forngeneers and Scientists, U.S, 650, p. 2003.

TAMBE, S. B.; THOOL, R. C.; THOOL, V. R. Cluster Based Wireless Mobile Healthcare System for Physiological Data Monitoring. Procedia Computer Science, Amsterdam, v. 78, p. 40-47, 2016.

THOMAZELLI, P. Academia e Escola de equitação Troa. Disponíve em: < https://www.dressagearteequestre.com/news/treinamento-de-equidaderetid\%C3\%A3o/ > Acesso em 08 jan. 2019.

THOMASSIAN, A. et al. Enfermidade dos cavalos. 4. ed. Sao Paulo: Livraria Varela, 2005.

TOROUS, J.; FRIEDMAN, R.; KESHVAN, M. Smartphone ownership and interest in mobile applications to monitor symptoms of mental health conditions: Journal of Medical Internet Research, Toronto, v. 1, n. 1, 2014.

UMEK, A; KOS, A. Validation of smartphone gyroscopes for mobile biofeedback applications. Personal and Ubiquitous Computing. 10.1007/s00779-016-0946-4. 2016.

VELLOS, F. Sinal analógico ou digital? Entenda as tecnologias e suas diferenças. Disponível em: <https://www.techtudo.com.br/noticias/noticia/2014/12/sinal- 
analogico-ou-digital-entenda-tecnologias-e-suas-diferencas.html > Acesso em: 08 jan. 2019.

VIEIRA, L. P. Experimentos com o acelerômetro de Tablets e Smartphones. RJ. 2013. p. 20. Dissertação (Mestrado) - Universidade Federal do Rio de Janeiro, Rio de Janeiro, 2013.

VOULODIMOS, A. et. al. A complete farm management system based on animal identification using RFID technology. Computers and Electronics in Agriculture, Chicago, v. 70, n. 2 , p. 380-388, 2010.

WEISER, M.The computer for the 21st century, Scientific American Special, U.S, Issue on communications, computers and network, v. 265, p. 94-104, 1991.

WERNER, J. et al. Validation of a sensor-based automatic measurement system for monitoring chewing activity in horses: Livestock Science, Amsterdam, v. 186, p. 53-58, 2016.

ZIMMERMANN, M., Ethical guidelines for investigations of experimental pain inconscious animals. Pain, Philadelphia, v. 16, p.109-110, 1983. 


\section{APÊNDICE}




\section{APÊNDICE A}

LEVANTAMENTO DOS CUSTOS DE UM SMARTPHONE COM ACELERÔMETRO, GIROSCÓPIO E GPS.

O critério de escolha do smartphone foi realizado através da seleção dos sensores cinéticos necessários para o monitoramento dos equinos tais como: GPS, acelerômetro e giroscópio, e ainda, que possuiam uma rede de telefonia com CDMA ou GSM.(ou 3G/SMS).

Conforme a tabela comparativa dos smartphones (Figura 63) com os respectivos preços, concluiu-se que o aparelho Moto G5 é o que apresenta o melhor custo benefício, porém como o laboratório LAFAC ganhou dois smartphones Sansung Galaxy sendo: 1. o modelo S Duos 2 GT-S7582L que possui os sensores de proximidade, acelerômetro, giroscópio, magnetômetro, sensor de proximidade e bússola com sistema operacional Android 4.2 Jelly Bean, com peso de 118 gramas e a rede é GSM- Quad Band (850/900/1800/1900).

2. o modelo S4 Mini Duos GT-19192 com acelerômetro, giroscópio, bússola e sensor de proximidade. Possui o sistema operacional Android 4.4.2 Kit Kat, pesa 108 gramas e a rede é GSM- Quad Band (850/900/1800/1900).

Esses aparelhos funcionam em 4 bandas GSM. No Brasil, as frequências usadas são: 850/1900: Vivo. 900/1800: Tim, Claro, Oi, Aeiou ( da Unicel), BrTelecom, Telemig, Amazonia celular, Sercontel. Portanto esses smartphones poderão ser usados por quaisquer operadora.

Figura 63 - Tabela de levantamento de custos de um Smartphone

\begin{tabular}{|c|c|c|c|c|c|c|c|c|c|}
\hline Modelo & 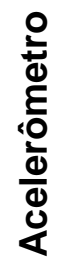 & 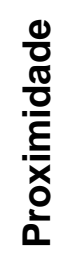 & $\begin{array}{l}\text { 응 } \\
\frac{0}{0} \\
\stackrel{0}{0} \\
\frac{.}{0}\end{array}$ & 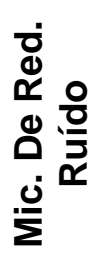 & 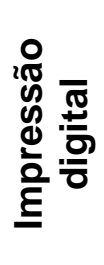 & $\frac{\stackrel{\circ}{d}}{d}$ & 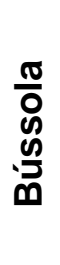 & $\begin{array}{l}\text { Menor } \\
\text { Preço }\end{array}$ & $\begin{array}{l}\text { Maior } \\
\text { Preço }\end{array}$ \\
\hline $\begin{array}{l}\text { Moto } \\
\text { G5 }\end{array}$ & $X$ & $X$ & $X$ & $X$ & $X$ & & & $\begin{array}{c}R \$ \\
719,00\end{array}$ & $\begin{array}{c}R \$ \\
1.100,00\end{array}$ \\
\hline $\begin{array}{l}\text { Moto } \\
\text { G4 Plus }\end{array}$ & $X$ & $X$ & $x$ & $x$ & $X$ & & & $\begin{array}{c}\mathrm{R} \$ \\
776,00\end{array}$ & $\begin{array}{c}R \$ \\
1.379,00\end{array}$ \\
\hline
\end{tabular}




\begin{tabular}{|c|c|c|c|c|c|c|c|c|c|}
\hline $\begin{array}{l}\text { Mod } \\
\text { delo }\end{array}$ & 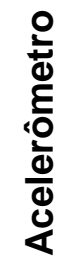 & $\begin{array}{l}\frac{0}{0} \\
\frac{\pi}{0} \\
\frac{0}{E} \\
\frac{1}{x} \\
0 \\
\frac{0}{\alpha}\end{array}$ & $\begin{array}{l}\text { 음 } \\
\text { 응 } \\
\text { 음 } \\
\text { 음 }\end{array}$ & 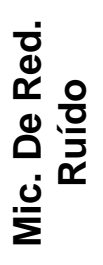 & 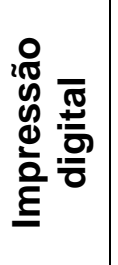 & $\frac{\circ}{d}$ & 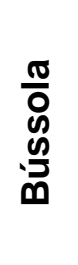 & $\begin{array}{l}\text { Menor } \\
\text { Preço }\end{array}$ & $\begin{array}{l}\text { Maior } \\
\text { Preço }\end{array}$ \\
\hline $\begin{array}{l}\text { Moto } \\
\text { G4 }\end{array}$ & $x$ & $x$ & $X$ & $x$ & & & & $\begin{array}{c}R \$ \\
807,00\end{array}$ & $\begin{array}{c}R \$ \\
2.049,00\end{array}$ \\
\hline $\begin{array}{l}\text { Asus } \\
\text { Zenfone } \\
2\end{array}$ & $x$ & $x$ & $X$ & $x$ & & & & $\begin{array}{c}R \$ \\
826,00\end{array}$ & $\begin{array}{c}R \$ \\
1.673,00\end{array}$ \\
\hline $\begin{array}{l}\text { Asus } \\
\text { Zenfone } \\
3\end{array}$ & $X$ & $x$ & $X$ & & $X$ & $X$ & $X$ & $\begin{array}{c}R \$ \\
967,00\end{array}$ & $\begin{array}{c}R \$ \\
1.699,00\end{array}$ \\
\hline $\begin{array}{l}\text { Asus } \\
\text { Zenfone } \\
4 \text { Max } \\
\end{array}$ & $X$ & $x$ & $X$ & & $X$ & & $X$ & $\begin{array}{c}R \$ \\
978,00\end{array}$ & $\begin{array}{c}R \$ \\
1499,00\end{array}$ \\
\hline $\begin{array}{l}\text { Moto } \\
\text { G5S Plus }\end{array}$ & $x$ & $x$ & $X$ & $X$ & $X$ & & & $\begin{array}{c}\mathrm{R} \$ \\
1.079,00\end{array}$ & $\begin{array}{c}R \$ \\
1.699,00\end{array}$ \\
\hline $\begin{array}{l}\text { Galaxy } \\
\text { A7 }\end{array}$ & $X$ & $x$ & $X$ & $X$ & $X$ & & $X$ & $\begin{array}{c}R \$ \\
1.232,00\end{array}$ & $\begin{array}{c}R \$ \\
2.299,00\end{array}$ \\
\hline $\begin{array}{l}\text { Moto } \\
\text { Z Play }\end{array}$ & $X$ & $x$ & $X$ & $X$ & $X$ & $X$ & $X$ & $\begin{array}{c}\mathrm{R} \$ \\
1.436,00\end{array}$ & $\begin{array}{c}R \$ \\
2899,00\end{array}$ \\
\hline $\begin{array}{l}\text { Moto } \\
\text { Z2 Play }\end{array}$ & $X$ & $x$ & $X$ & $X$ & $X$ & $X$ & $X$ & $\begin{array}{c}R \$ \\
1.466,00\end{array}$ & $\begin{array}{c}R \$ \\
2.699,00\end{array}$ \\
\hline $\begin{array}{l}\text { Galaxy } \\
\text { S7 }\end{array}$ & $x$ & $x$ & $X$ & $X$ & $X$ & $X$ & $x$ & $\begin{array}{c}R \$ \\
1.583,00\end{array}$ & $\begin{array}{c}R \$ \\
2.799,00\end{array}$ \\
\hline $\begin{array}{l}\text { Moto } \\
\text { Maxx }\end{array}$ & $x$ & $X$ & $X$ & $X$ & & & $X$ & $\begin{array}{c}R \$ \\
1.599,00\end{array}$ & $\begin{array}{c}R \$ \\
1.599,00 \\
\end{array}$ \\
\hline $\begin{array}{l}\text { Galaxy } \\
\text { S5 }\end{array}$ & $x$ & $x$ & $X$ & $X$ & $X$ & $X$ & $X$ & $\begin{array}{c}R \$ \\
1.599,00\end{array}$ & $\begin{array}{c}R \$ \\
1.599,00\end{array}$ \\
\hline $\begin{array}{l}\text { Xperia } \\
\text { XA1 Plus }\end{array}$ & $x$ & $x$ & $x$ & $X$ & $X$ & & $x$ & $\begin{array}{c}R \$ \\
1.739,00\end{array}$ & $\begin{array}{c}R \$ \\
2.200,00\end{array}$ \\
\hline $\begin{array}{l}\text { Galaxy } \\
\text { S6 }\end{array}$ & $X$ & $x$ & $X$ & $x$ & $X$ & $X$ & $X$ & $\begin{array}{c}\mathrm{R} \$ \\
1.799,00\end{array}$ & $\begin{array}{c}\mathrm{R} \$ \\
3.144,00\end{array}$ \\
\hline $\begin{array}{l}\text { Galaxy } \\
\text { S7 Edge }\end{array}$ & $X$ & $x$ & $X$ & $X$ & $X$ & $X$ & $x$ & $\begin{array}{c}\mathrm{R} \$ \\
1.847,00\end{array}$ & $\begin{array}{c}R \$ \\
3.999,00\end{array}$ \\
\hline $\begin{array}{l}\text { LG } \\
\text { G6 }\end{array}$ & $X$ & $x$ & $X$ & $X$ & $X$ & & $X$ & $\begin{array}{c}\mathrm{R} \$ \\
1.952,00\end{array}$ & $\begin{array}{c}R \$ \\
3.149,00\end{array}$ \\
\hline $\begin{array}{l}\text { Galaxy } \\
\text { S6 Edge }\end{array}$ & $x$ & $X$ & $X$ & $X$ & $X$ & $X$ & $X$ & $\begin{array}{c}R \$ \\
2.099,00\end{array}$ & $\begin{array}{c}\mathrm{R} \$ \\
3.514,00\end{array}$ \\
\hline $\begin{array}{l}\text { Xperia } \\
\text { XZ1 } \\
\text { Compact } \\
\end{array}$ & $X$ & $X$ & $X$ & $X$ & $X$ & & $X$ & $\begin{array}{c}R \$ \\
2.200,00\end{array}$ & $\begin{array}{c}R \$ \\
3.698,00\end{array}$ \\
\hline
\end{tabular}




\begin{tabular}{|c|c|c|c|c|c|c|c|c|c|}
\hline $\begin{array}{l}\text { Mod } \\
\text { delo }\end{array}$ & 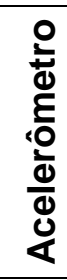 & $\begin{array}{l}\frac{0}{0} \\
\frac{\pi}{\sigma} \\
\frac{0}{\delta} \\
\frac{1}{x} \\
0 \\
0 \\
0\end{array}$ & 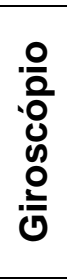 & 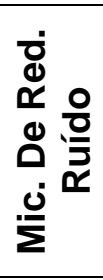 & 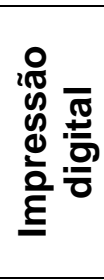 & 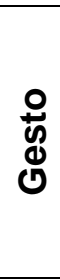 & 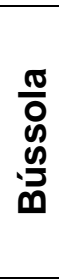 & $\begin{array}{l}\text { Menor } \\
\text { Preço }\end{array}$ & $\begin{array}{l}\text { Maior } \\
\text { Preço }\end{array}$ \\
\hline $\begin{array}{l}\text { Nokia } \\
8\end{array}$ & $X$ & $X$ & $X$ & $X$ & $X$ & & $X$ & $\begin{array}{c}R \$ \\
2.370,00\end{array}$ & $\begin{array}{c}R \$ \\
2449,00\end{array}$ \\
\hline $\begin{array}{l}\text { Galaxy } \\
\text { S8 }\end{array}$ & $x$ & $X$ & $X$ & $X$ & $X$ & $X$ & $X$ & $\begin{array}{c}R \$ \\
2.609,00\end{array}$ & $\begin{array}{c}R \$ \\
3.699,00\end{array}$ \\
\hline $\begin{array}{l}\text { Xperia } \\
\text { XZ1 }\end{array}$ & $X$ & $X$ & $X$ & $X$ & $X$ & & $X$ & $\begin{array}{c}R \$ \\
2.634,00\end{array}$ & $\begin{array}{c}\mathrm{R} \$ \\
3.609,00\end{array}$ \\
\hline
\end{tabular}

Mic. De Red. De Ruído - Microfone de Redução de Ruído.

Fonte: https://www.tudocelular.com/compare/3668-3805-3636.htmll

Dos 43 aplicativos disponíveis para Android, 26 aplicativos se relacionavam com treinamentos, alimentação, ficha clínica podem ser visualizados na (Figura 64) abaixo. Os demais aplicativos eram jogos relacionados com cavalos (no total 17).

Figura 64 - Aplicativos para android

\begin{tabular}{|l|l|}
\hline Horse notes & Registro de alimentação do cavalo, registros médicos \\
\hline EquiTracker & Registro das rotinas médicas \\
\hline EquiTrack & Guia para treinamento \\
\hline Horse Racing Handicapping & $\begin{array}{l}\text { Ferramenta matemática para análise de corrida de } \\
\text { cavalos }\end{array}$ \\
\hline Show horse & Site para registrar eventos e registrar desempenho \\
\hline Horse health tracker & $\begin{array}{l}\text { Guia de saúde através de observação visual e } \\
\text { preenchimento de planilhas }\end{array}$ \\
\hline Horsealot connects & Conectar outros cavaleiros \\
\hline Equine body and health & $\begin{array}{l}\text { Guia de massagem equina, nutrição e recursos gerais } \\
\text { de saúde }\end{array}$ \\
\hline Horse Grimace scale & $\begin{array}{l}\text { Planilha para diagnosticar dor observando as } \\
\text { expressões faciais dos equinos. }\end{array}$ \\
\hline Tutoriel d'exercices & Ensina como fazer exercícios de salto \\
\hline Equitation pour & $\begin{array}{l}\text { Aulas de equitação para melhorar a qualidade dos } \\
\text { cavaleiros }\end{array}$ \\
\hline One stop equine shop & Aplicativo para compras \\
\hline Dressage lite for horse & Aulas em forma de texto sobre dressage \\
\hline
\end{tabular}




\begin{tabular}{|l|l|}
\hline Dressmyhorse & Loja de acessórios para cavalos \\
\hline Matchy matchy & $\begin{array}{l}\text { Aplicativo para escolher a melhor cor dos acessórios } \\
\text { para o cavalo }\end{array}$ \\
\hline Ecuestre, entrena tu & Manual de equitação \\
\hline Equine veterinary & Textos sobre atendimento veterinário \\
\hline Ztable em app för ryttare & Cronograma de treinamento para cavaleiros \\
\hline Equilog & Para gerenciar o treinamento \\
\hline EquineM & Ficha clínica de controle \\
\hline Stable secretary Serenity horses & Ficha clínica e de treinos \\
\hline Serenity horses & Comunidade para cavaleiros \\
\hline Dressur app & Explicação sobre adestramento \\
\hline Equine United & Aplicativo que encontra vendedores de cavalos \\
\hline Horsealot connects rides & Aplicativo para contato entre cavaleiros \\
\hline Horse side vet guide & $\begin{array}{l}\text { Guia de saúde, como aplicar injeções, como tratar } \\
\text { cólicas e outras }\end{array}$ \\
\hline
\end{tabular}

Fonte: https://www.tudocelular.com/asus/noticias/n130953/asus-zenfone-5-outros-quatroatualizacao-novidades.html 


\section{APÊNDICE B}

Figuras do cavalo 1

Na DMCP pelo acelerômetro do sensor do cavalo 1 no treino pode ser visualizado a andadura de galope com zoom no eixo $X$ na (Figura 65), eixo $Y$ (Figura 66), eixo Z na (Figura 67).

Figura 65 - Padrão galope com zoom no eixo- $X$

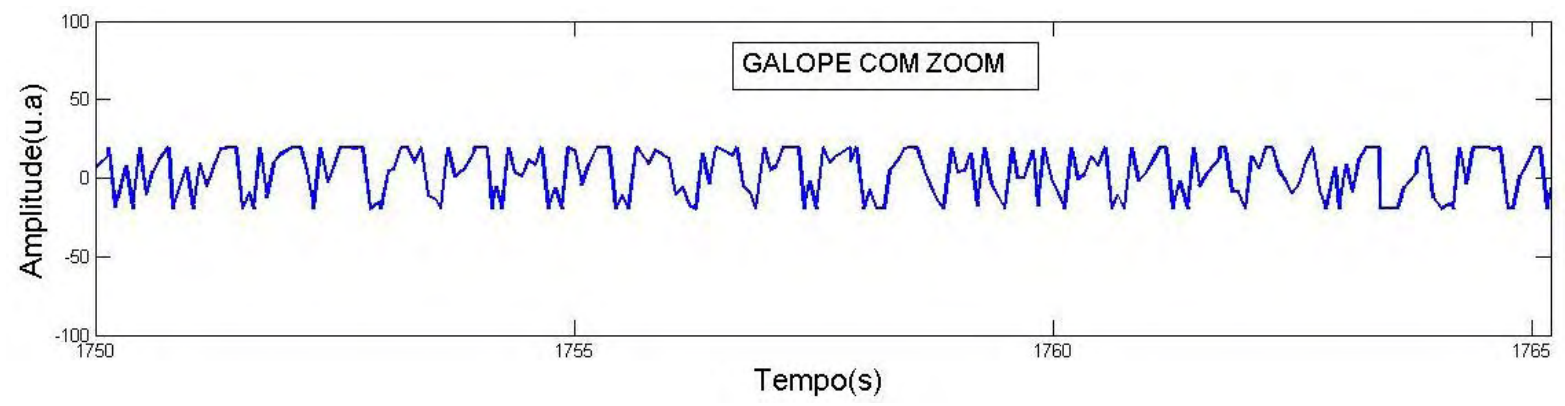

Fonte: Própria autoria

Figura 66 - Padrão galope com zoom no eixo- $Y$

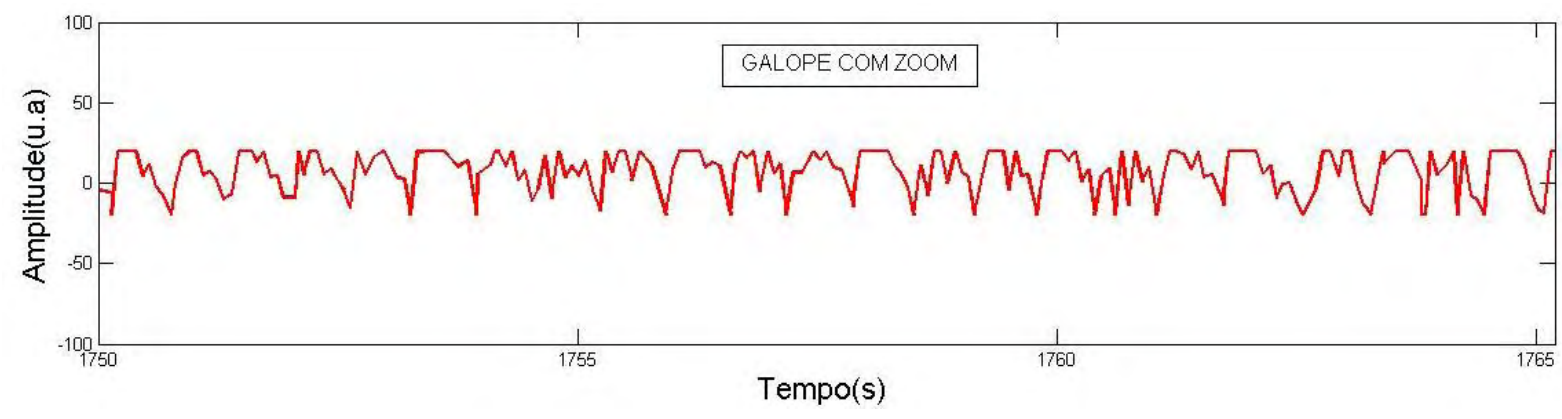

Fonte: Própria autoria

Figura 67 - Padrão galope com zoom no eixo- Z

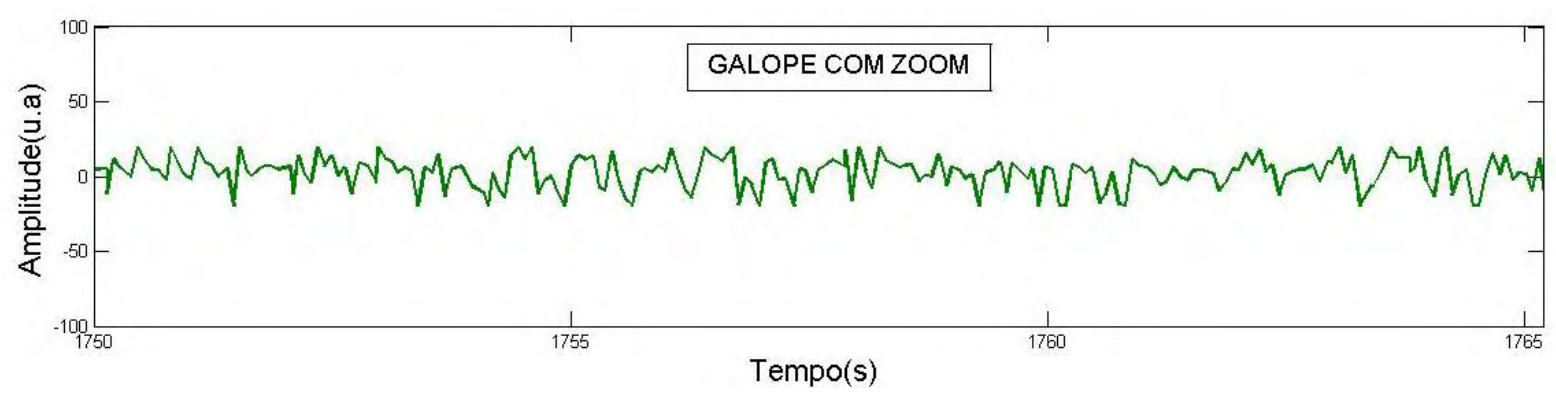

Fonte: Própria autoria 
$\mathrm{Na}$ DMCP pelo acelerômetro do sensor do cavalo 1 no treino pode ser visualizado a andadura de galope com pouco zoom no eixo $X$ na (Figura 68), eixo $Y$ (Figura 69), eixo Z na (Figura 70).

Figura 68 - Padrão galope no eixo- X

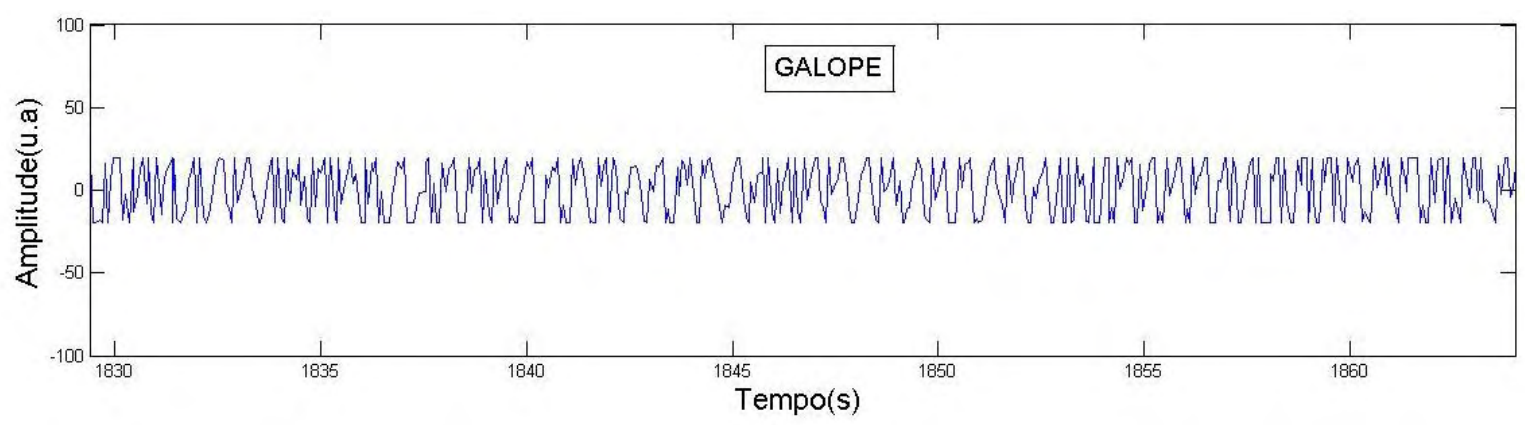

Fonte: Própria autoria

Figura 69 - Padrão galope no eixo- $Y$

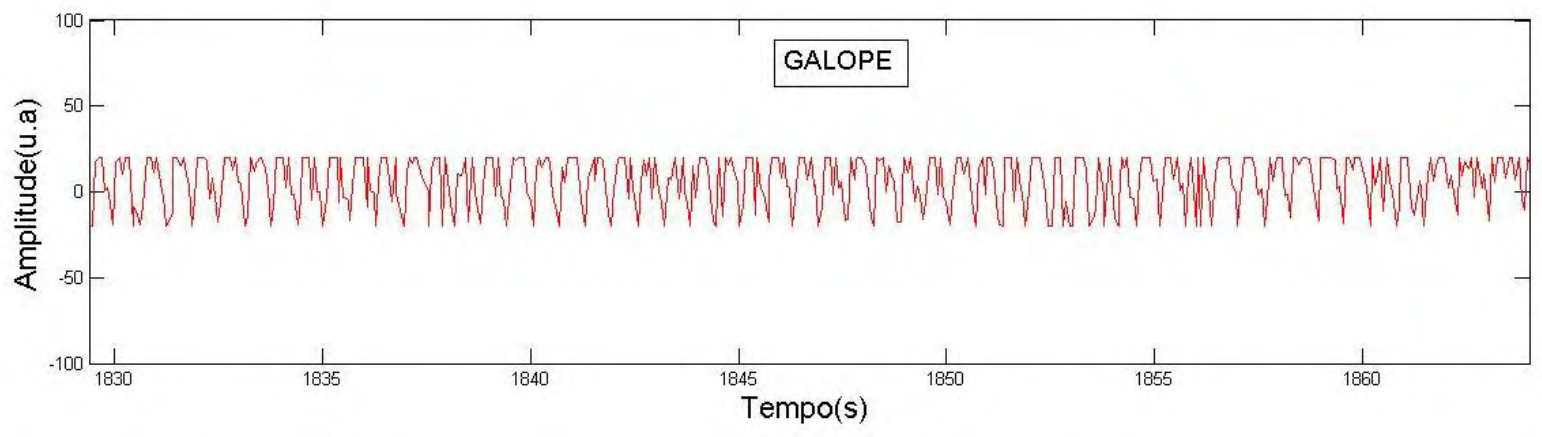

Fonte: Própria autoria

Figura 70 - Padrão galope no eixo- Z

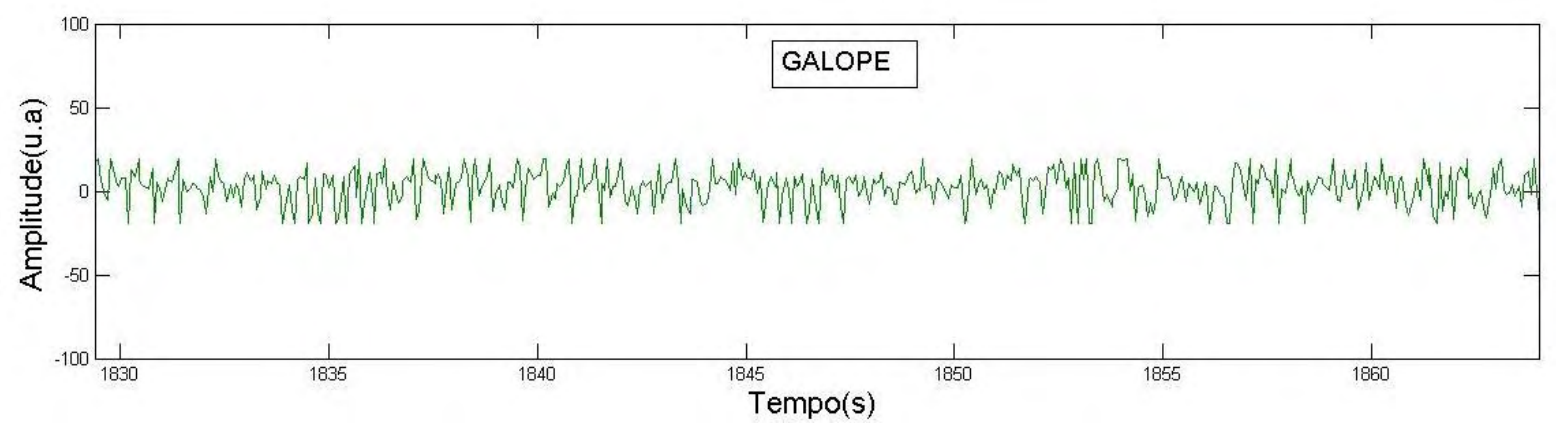

Fonte: Própria autoria 


\subsection{Dados do cavalo 2}

Tabela 6 - Primeira medição com o cavalo2 na baia e no pasto.

\begin{tabular}{lccc}
\hline Comportamento & $\begin{array}{c}\text { Tempo de } \\
\text { movimento }(\mathbf{m i n})\end{array}$ & Cálculo & $\begin{array}{c}\text { Número de } \\
\text { pontos }\end{array}$ \\
\hline $\begin{array}{l}\text { Colocando o } \\
\text { smartphone no }\end{array}$ & $0,00-1,00$ & $1^{*} 60^{*} 30=1800$ & 1800 \\
cavalo & & & \\
Parado & $1,00-1,35$ & $0,35^{*} 60^{*} 30=630$ & $1801+630=2431$ \\
Um passo & $1,35-1,37$ & $0,02^{*} 60^{*} 30=36$ & $2432+36=2468$ \\
Bateu MAD barriga & $1,37-2,16$ & $0,79^{*} 60^{*} 30=1422$ & $2469+1422=3891$ \\
Parado & $2,16-3,38$ & $1,22^{*} 60^{*} 30=2196$ & $3892+2196=6088$ \\
Bateu MAD barriga & $3,38-3,39$ & $0,01^{*} 60^{*} 30=18$ & $6089+18=6107$ \\
Parada & $3,39-3,48$ & $0,09^{*} 60^{*} 30=162$ & $6108+162=6270$ \\
Levantou o MAD & $3,49-3,50$ & $0,01^{*} 60^{*} 30=18$ & $6271+18=6289$ \\
Parada & $3,50-3,55$ & $0,05^{*} 60^{*} 30=90$ & $6290+90=6380$ \\
Levantou o MAD & $3,55-3,56$ & $0,01^{*} 60^{*} 30=18$ & $6381+18=6399$ \\
\hline Andando no pasto & $4,28-5,00$ & $0,72^{*} 60^{*} 30=1296$ & $7697+1296=8993$ \\
Andando & $5,44-5,48$ & $0,04^{*} 60^{*} 30=72$ & $9788+72=9860$ \\
Pastando & $5,48-5,56$ & $0,08^{*} 60^{*} 30=144$ & $9861+144=10005$ \\
Bateu a MAD na & $5,56-5,58$ & $0,02^{*} 60^{*} 30=36$ & $10006+36=10042$ \\
barriga & & & \\
Parado & $5,58-6,07$ & $0,49^{*} 60 * 30=882$ & $10043+882=10925$ \\
\hline
\end{tabular}

Fonte: Própria autoria 
Tabela 7 - Calibração 30 pontos por segundo C2, o início da filmagem coincidiu com o início da medição

\begin{tabular}{|c|c|c|}
\hline Comportamento & $\begin{array}{l}\text { Tempo do movimento } \\
\text { (min) }\end{array}$ & Segundos \\
\hline $\begin{array}{l}\text { Colocando o smartphone } \\
\text { no cavalo }\end{array}$ & $0,00-1,00$ & $1 * 60=60$ \\
\hline Parado & $1,00-1,35$ & $1,35^{\star} 60=81$ \\
\hline Um passo & $1,35-1,37$ & $1,37^{*} 60=82,2$ \\
\hline Bateu MAD barriga & $1,37-2,16$ & $2,16^{*} 60=129,6$ \\
\hline Parado & $2,16-3,38$ & $3,38^{*} 60=202,8$ \\
\hline Bateu MAD barriga & $3,38-3,39$ & $3,39 * 60=203,4$ \\
\hline Parada & $3,39-3,48$ & $3,48^{*} 60=208,8$ \\
\hline Levantou o MAD & $3,49-3,50$ & $3,50 * 60=210$ \\
\hline Parada & $3,50-3,55$ & $3,55^{*} 60=213$ \\
\hline Levantou o MAD & $3,55-3,56$ & $3,56^{*} 60=213,6$ \\
\hline Parado & $3,56-4,28$ & $4,28 * 60=256,8$ \\
\hline Andando para o pasto & $4,28-5,00$ & $5,00 * 60=300$ \\
\hline Parada na porteira & $5,00-5,06$ & $5,06^{*} 60=303,6$ \\
\hline Fechando a porteira & $5,06-5,44$ & $5,44^{*} 60=326,4$ \\
\hline Andando & $5,44-5,48$ & $5,48^{*} 60=328,8$ \\
\hline Pastando & $5,48-5,56$ & $5,56^{*} 60=333,6$ \\
\hline Bateu a MAD na barriga & $5,56-5,58$ & $5,58 * 60=334,8$ \\
\hline Parado & $5,58-6,07$ & $6,07^{*} 60=364,2$ \\
\hline
\end{tabular}

Fonte: Própria autoria 
DMCP do cavalo 2 na baia mostrando os 3 eixos $X, Y, Z$ do acelerômetro ao passo, na (Figura 71), (Figura 72), (Figura 73).

Figura 71 - Padrão passo na baia eixo- $X$

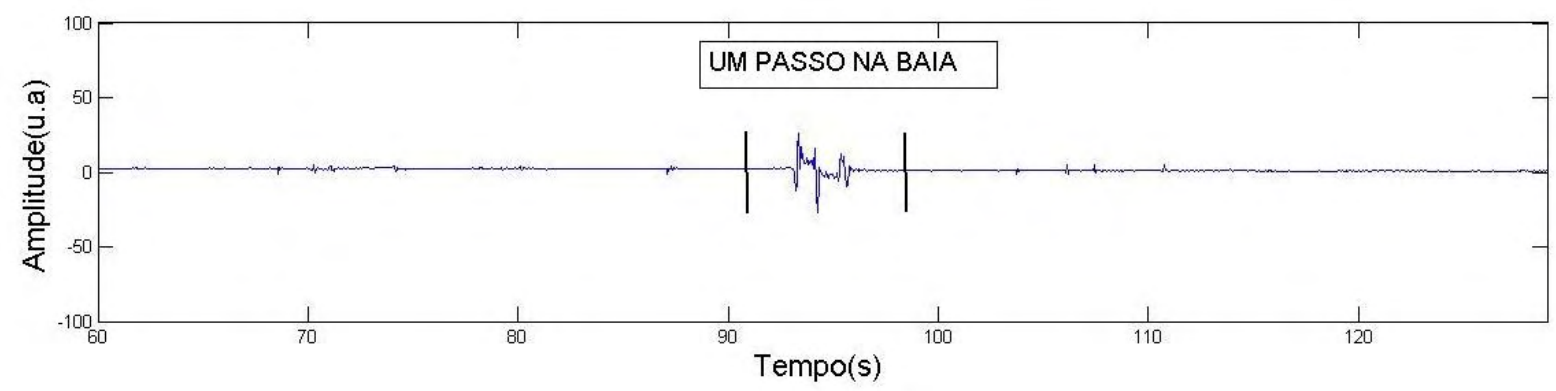

Fonte: Própria autoria

Figura 72 - Padrão passo na baia eixo- $Y$

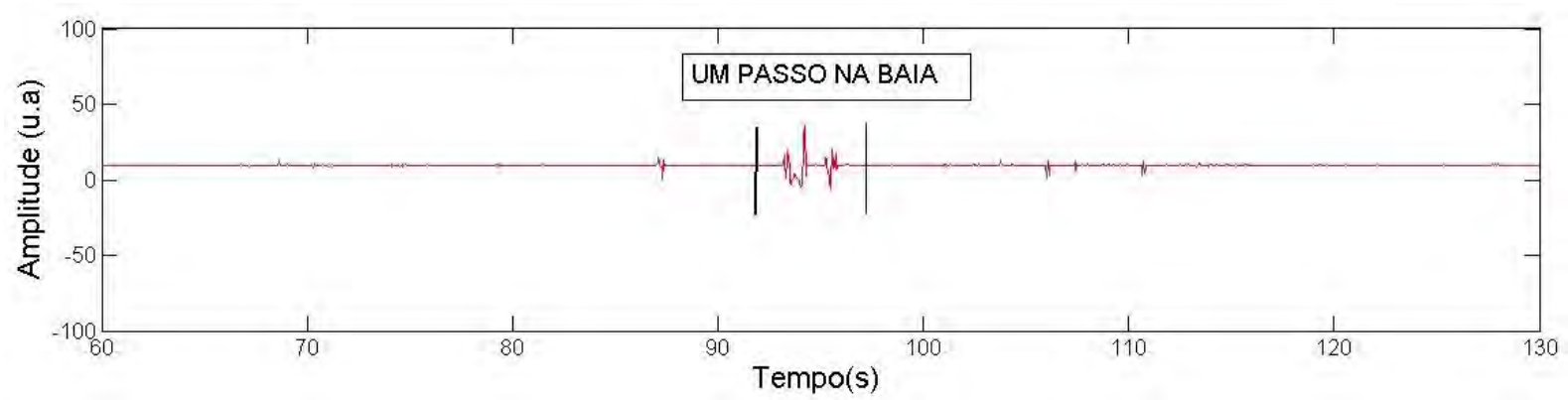

Fonte: Própria autoria

Figura 73 - Padrão passo na baia eixo- Z

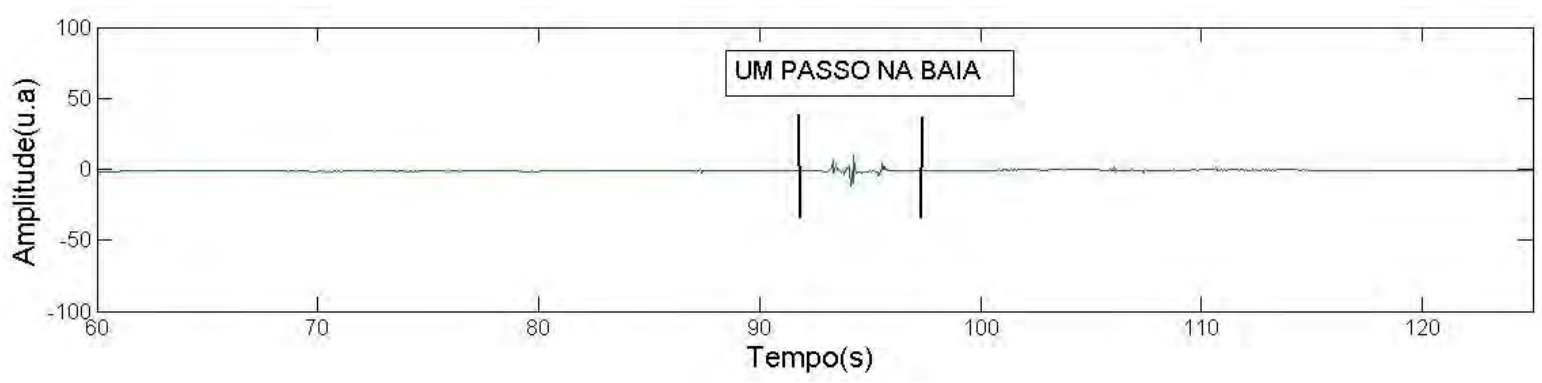

Fonte: Própria autoria 
DMCP do cavalo 2 na baia mostrando nos 3 eixos $X, Y, Z$ do acelerômetro o movimento parado e passo na (Figura 74), (Figura 75), (Figura 76).

Figura 74 - Comparação entre parado e passo no pasto C2 eixo- X

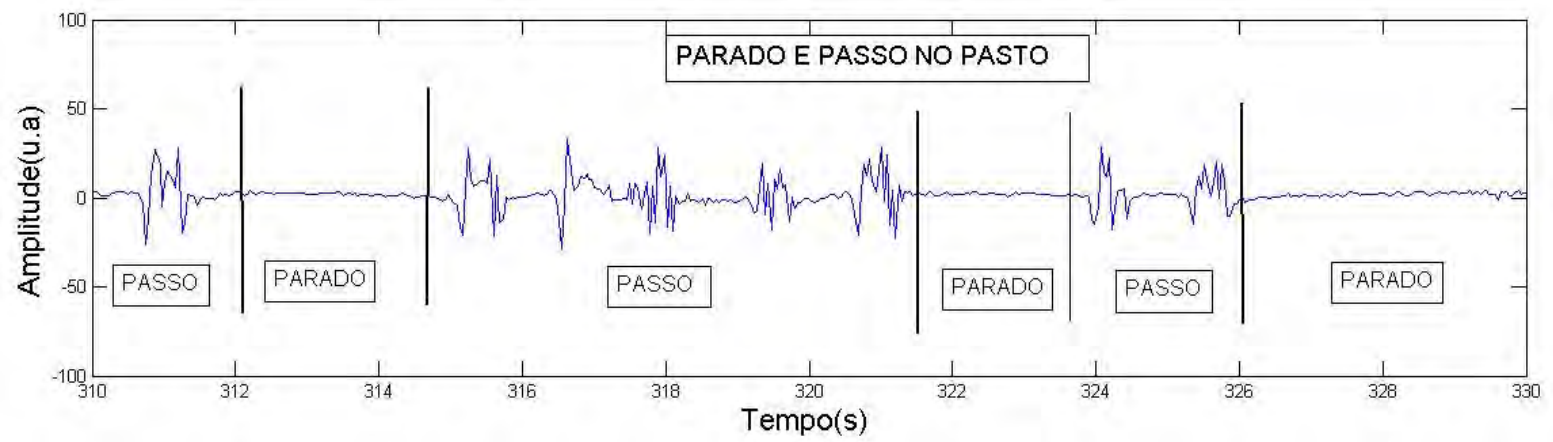

Fonte: Própria autoria

Figura 75 - Comparação entre parado e passo no pasto $C 2$ eixo- $Y$

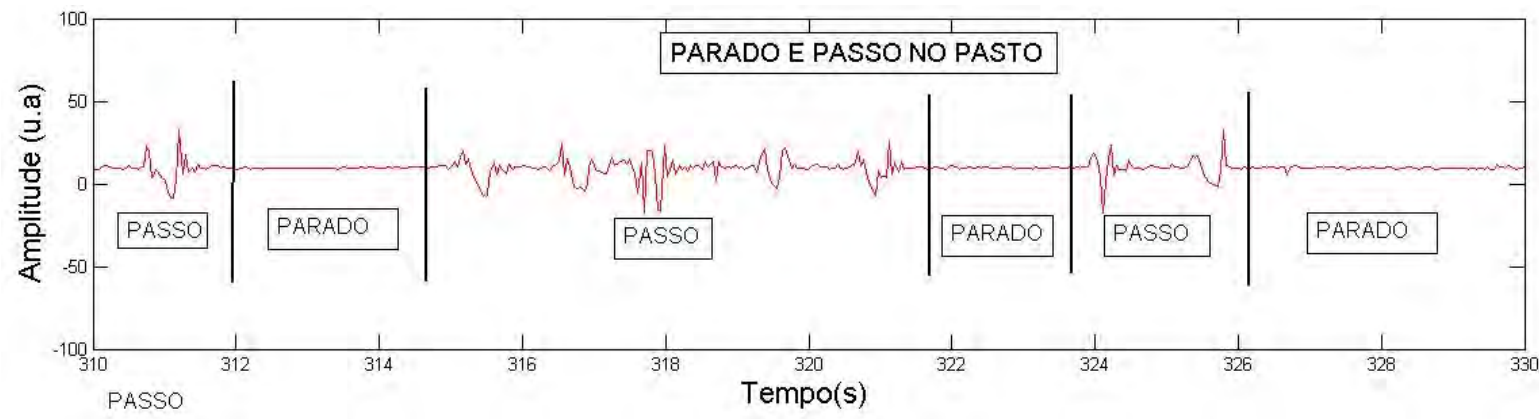

Fonte: Própria autoria

Figura 76 - Comparação entre parado e passo no pasto C2 eixo- Z

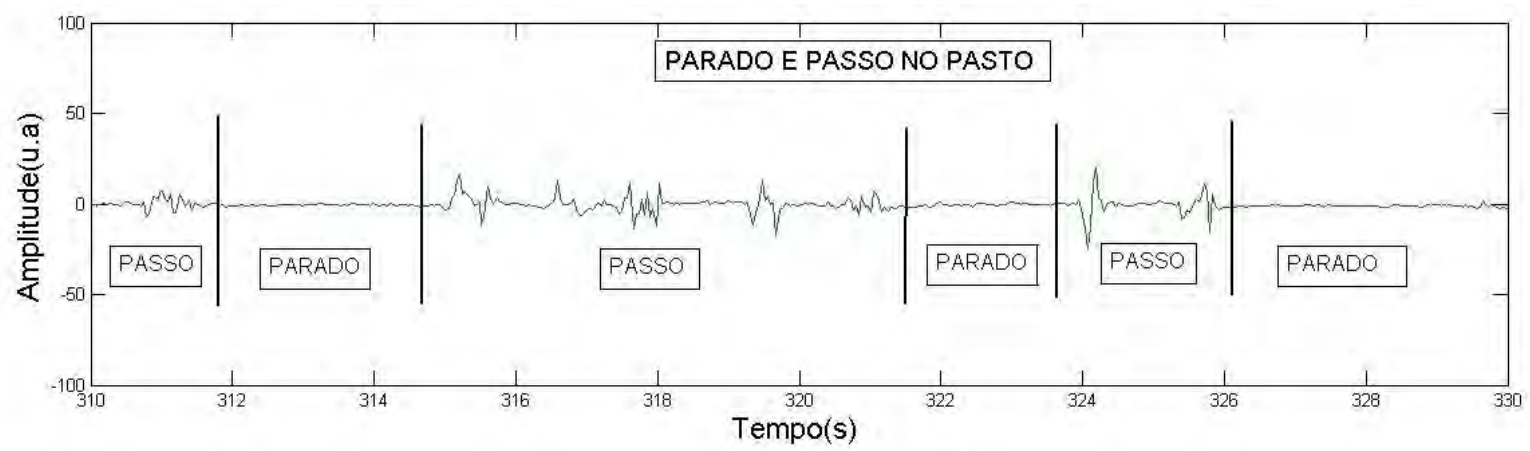

Fonte: Própria autoria 


\subsection{Dados do cavalo 3}

Tabela 8 - Primeira medição com o cavalo3 (C3) no pasto

\begin{tabular}{lccc} 
Comportamento & $\begin{array}{c}\text { Tempo de } \\
\text { movimento(min) }\end{array}$ & Cálculo & $\begin{array}{c}\text { Número de } \\
\text { pontos }\end{array}$ \\
\hline Passo com guia & $0-2,02$ & $2,02^{*} 60^{*} 30=3636$ & $1-3636$ \\
Parado com guia & $2,02-2,05$ & $0,03^{*} 60^{*} 30=54$ & $3637+54=3691$ \\
Passo com guia & $2,05-2,21$ & $0,16^{*} 60^{*} 30=288$ & $3692+288=3980$ \\
Parado & $2,21-2,71$ & $0,5^{*} 60^{*} 30=900$ & $3981+900=4881$ \\
Passo & $2,71-2,83$ & $0,12^{*} 60^{*} 30=216$ & $4882+216=5098$ \\
Parado 1 & $2,83-2,87$ & $0,04^{*} 60^{*} 30=72$ & $5099+72=5171$ \\
Passo & $2,87-2,93$ & $0,06^{*} 60^{*} 30=108$ & $5172+108=5280$ \\
Parado 2 & $2,93-3,02$ & $0,09^{*} 60^{*} 30=162$ & $5281+162=5443$ \\
Um passo & $3,02-3,03$ & $0,01^{*} 60^{*} 30=18$ & $5444+18=5462$ \\
Parado 3 & $3,03-3,11$ & $0,08^{*} 60^{*} 30=144$ & $5463+144=5607$ \\
Passo 2 & $3,11-4,55$ & $1,44^{*} 60^{*} 30=2592$ & $5608+2592=8200$ \\
Parado 4 & $4,55-4,61$ & $0,06^{*} 60^{*} 30=108$ & $8201+108=8309$ \\
Passo 3 & $4,61-5,70$ & $1,09^{*} 60^{*} 30=1962$ & $8310+1962=10272$ \\
Rolando & $5,70-5,90$ & $0,2^{*} 60^{*} 30=360$ & $10273+360=10633$ \\
Passo 4 & $5,90-6,18$ & $0,28^{*} 60^{*} 30=504$ & $10634+504=11138$ \\
Parado 5 & $6,18-6,27$ & $0,09^{*} 60^{*} 30=162$ & $11139+162=11301$ \\
Um passo 2 & $6,27-6,30$ & $0,03^{*} 60^{*} 30=54$ & $11302+54=11256$ \\
Parado 6 & $6,30-6,35$ & $0,05^{*} 60^{*} 30=90$ & $11257+90=11447$ \\
Passo 5 & $6,35-6,42$ & $0,07^{*} 60^{*} 30=126$ & $11448+126=11574$ \\
Parado 7 & $6,42-6,58$ & $0,16^{*} 60^{*} 30=288$ & $11575+288=11863$ \\
Um passo 3 & $6,58-6,59$ & $0,01^{*} 60^{*} 30=18$ & $11864+18=11882$ \\
Parado 8 & $6,59-6,69$ & $0,10^{*} 60^{*} 30=180$ & $11883+180=12063$ \\
Levantou o MAD & $6,69-6,71$ & $0,02^{*} 60^{*} 30=36$ & $12064+36=12100$ \\
Parado 9 & $6,71-6,79$ & $0,08^{*} 60^{*} 30=144$ & $12101+144=12245$ \\
Um passo 4 & $6,79-6,80$ & $0,01^{*} 60^{*} 30=18$ & $12246+18=12264$ \\
Parado 10 & $6,80-6,84$ & $0,04^{*} 60^{*} 30=72$ & $12265+72=12337$ \\
Um passo 5 & $6,84-6,845$ & $0,005^{*} 60^{*} 30=9$ & $12338+9=12347$ \\
Parado 11 & $6,845-6,93$ & $0,085^{*} 60^{*} 30=153$ & $12348+153=12501$
\end{tabular}


Conclusão

\begin{tabular}{|c|c|c|c|}
\hline Comportamento & $\begin{array}{c}\text { Tempo de } \\
\text { movimento(min) }\end{array}$ & Cálculo & $\begin{array}{c}\text { Número de } \\
\text { pontos }\end{array}$ \\
\hline Um passo 6 & $6,93-6,94$ & $0,01 * 60 * 30=18$ & $12502+18=12520$ \\
\hline Parado 12 & $6,94-7,09$ & $0,15^{\star} 60^{\star} 30=270$ & $12521+270=12791$ \\
\hline Levantou o MAD & $7,09-7,10$ & $0,01 * 60 * 30=18$ & $12792+18=12810$ \\
\hline Se sacudiu & $7,15-7,21$ & $0,06^{*} 60 * 30=108$ & $12884+108=12992$ \\
\hline Parado 14 & $7,21-7,26$ & $0,05^{\star} 60^{\star} 30=90$ & $12993+90=13083$ \\
\hline Passo 6 & $7,26-7,30$ & $0,04^{*} 60 * 30=72$ & $13084+72=13156$ \\
\hline Parado 15 & $7,30-7,43$ & $0,13 * 60 * 30=234$ & $13157+234=13391$ \\
\hline Um passo 6 & $7,43-7,45$ & $0,02^{*} 60 * 30=36$ & $13392+36=13428$ \\
\hline Parado 16 & $7,45-7,50$ & $0,05 * 60 * 30=90$ & $13429+90=13519$ \\
\hline
\end{tabular}

Fonte: Própria autoria

Tabela 9 - Calibração 30 pontos por segundo com o início do cálculo do aplicativo acrescido de 180 s do início do filme

\begin{tabular}{|c|c|c|}
\hline Comportamento & $\begin{array}{l}\text { Tempo do movimento } \\
\text { (min) }\end{array}$ & Segundos \\
\hline Passo com guia & $0-2,02$ & $2,02^{*} 60+180=301,2$ \\
\hline Parado com guia & $2,02-2,05$ & $2,05^{\star} 60+180=303$ \\
\hline Passo com guia & $2,05-2,21$ & $2,21^{*} 60+180=312,6$ \\
\hline Parado & $2,21-2,71$ & $2,71^{\star} 60+180=342,6$ \\
\hline Passo & $2,71-2,83$ & $2,83^{*} 60+180=349,8$ \\
\hline Parado 1 & $2,83-2,87$ & $2,87^{*} 60+180=352,2$ \\
\hline Passo & $2,87-2,93$ & $2,93^{\star} 60+180=355,8$ \\
\hline Parado 2 & $2,93-3,02$ & $3,02^{*} 60+180=361,2$ \\
\hline Um passo & $3,02-3,03$ & $3,03^{*} 60+180=361,8$ \\
\hline Parado 3 & $3,03-3,11$ & $3,11^{\star} 60+180=366,6$ \\
\hline Passo 2 & $3,11-4,55$ & $4,55^{\star} 60+180=453$ \\
\hline Parado 4 & $4,55-4,61$ & $4,61^{\star} 60+180=456,6$ \\
\hline \multirow[t]{2}{*}{ Passo 3} & $4,61-5,70$ & $5,70 * 60+180=522$ \\
\hline & & Continua \\
\hline
\end{tabular}




\section{Conclusão}

\begin{tabular}{|c|c|c|}
\hline Comportamento & $\begin{array}{c}\text { Tempo do movimento } \\
\text { (min) }\end{array}$ & Segundos \\
\hline Rolando & $5,70-5,90$ & $5,90 * 60+180=534$ \\
\hline Parado 5 & $6,18-6,27$ & $6,27^{*} 60+180=556,2$ \\
\hline Um passo 2 & $6,27-6,30$ & $6,30 * 60+180=558$ \\
\hline Parado 6 & $6,30-6,35$ & $6,35^{\star} 60+180=561$ \\
\hline Passo 5 & $6,35-6,42$ & $6,42 * 60+180=565,2$ \\
\hline Parado 7 & $6,42-6,58$ & $6,58 * 60+180=574,8$ \\
\hline Um passo 3 & $6,58-6,59$ & $6,59 * 60+180=575,4$ \\
\hline Parado 8 & $6,59-6,69$ & $6,69 * 60+180=581,4$ \\
\hline Levantou o MAD & $6,69-6,71$ & $6,71 * 60+180=582,6$ \\
\hline Parado 9 & $6,71-6,79$ & $6,79^{*} 60+180=587,4$ \\
\hline Um passo 4 & $6,79-6,80$ & $6,80 * 60+180=588$ \\
\hline Parado 10 & $6,80-6,84$ & $6,84^{\star} 60+180=590,4$ \\
\hline Um passo 5 & $6,84-6,845$ & $6,845^{\star} 60+180=590,7$ \\
\hline Parado 11 & $6,845-6,93$ & $6,93^{\star} 60+180=595,8$ \\
\hline Um passo 6 & $6,93-6,94$ & $6,94^{*} 60+180=596,4$ \\
\hline Parado 12 & $6,94-7,09$ & $7,09 * 60+180=605,4$ \\
\hline Levantou o MAD & $7,09-7,10$ & $7,10 * 60+180=606$ \\
\hline Parado 13 & $7,10-7,15$ & $7,15^{*} 60+180=609$ \\
\hline Se sacudiu & $7,15-7,21$ & $7,21^{*} 60+180=612,6$ \\
\hline Parado 14 & $7,21-7,26$ & $7,26^{*} 60+180=615,6$ \\
\hline Passo 6 & $7,26-7,30$ & $7,30 * 60+180=618$ \\
\hline Parado 15 & $7,30-7,43$ & $7,43^{*} 60+180=625,8$ \\
\hline Um passo 6 & $7,43-7,45$ & $7,45^{*} 60+180=627$ \\
\hline Parado 16 & $7,45-7,50$ & $7,50 * 60+180=630$ \\
\hline
\end{tabular}

Fonte: Própria autoria 
Na DMCP pelo acelerômetro do sensor no cavalo 3 mostra, nos eixos $X, Y, Z$ o padrão de movimento no pasto na (Figura 77) eixo X, (Figura 78) eixo Y, na (Figura 79) o eixo Z.

Figura 77 - Padrão pastando eixo- X

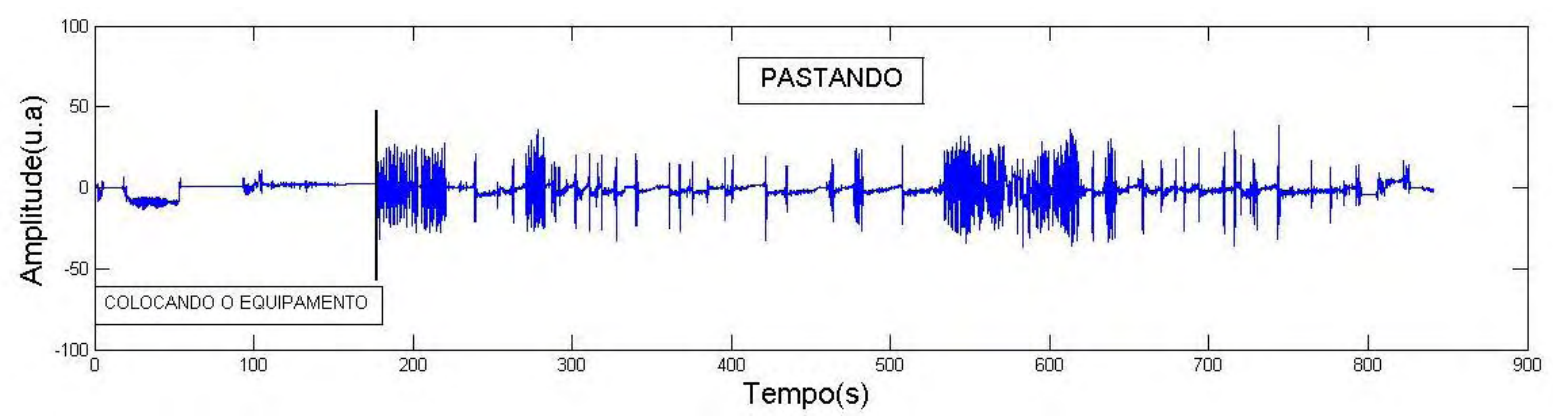

Fonte: Própria autoria

Figura 78 - Padrão pastando eixo- $Y$

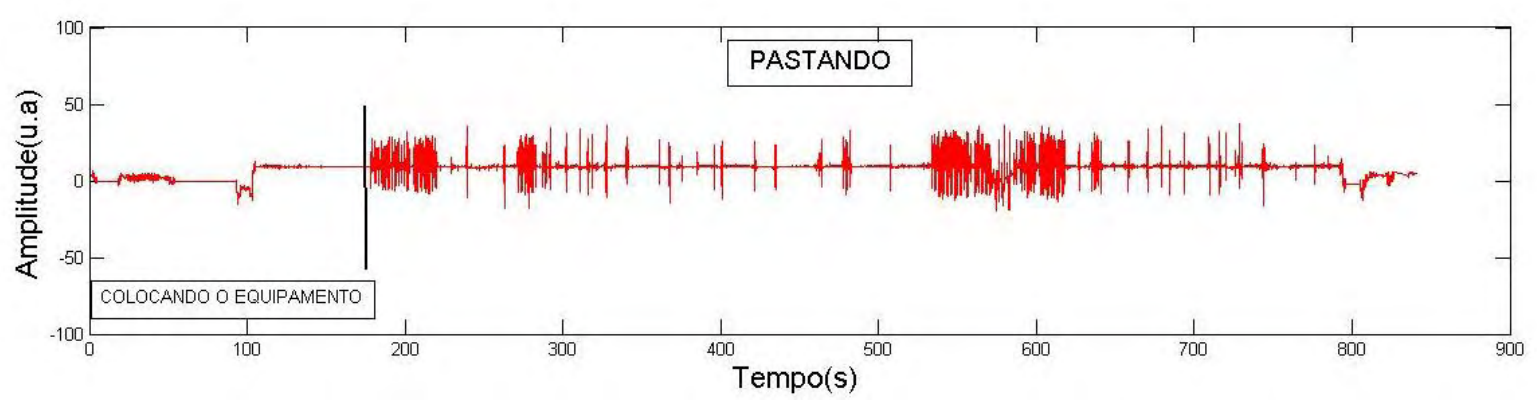

Fonte: Própria autoria

Figura 79 - Padrão pastando eixo- Z

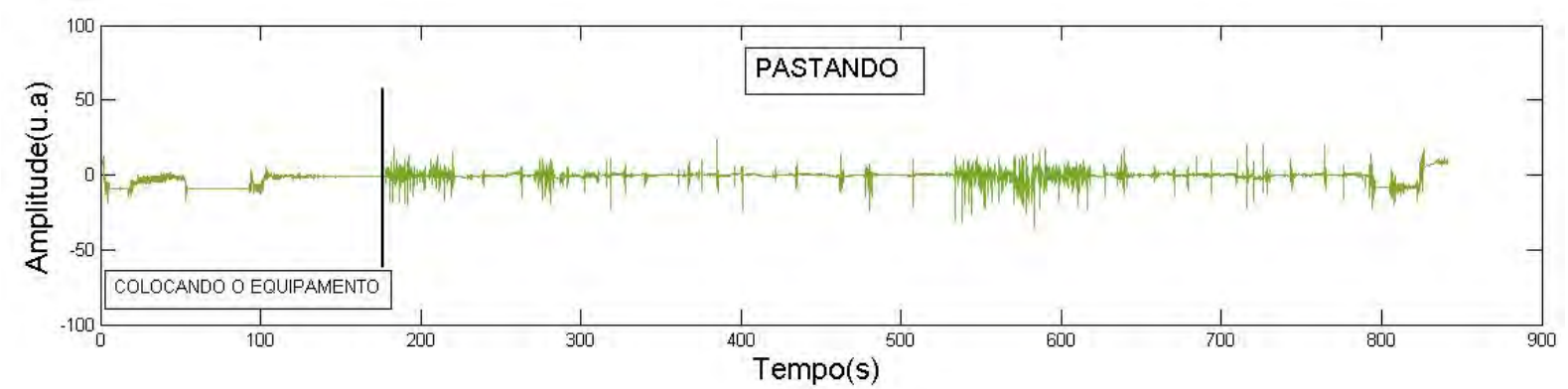

Fonte: Própria autoria 